UNIVERSIDADE DE SÃO PAULO

ESCOLA DE ENFERMAGEM DE RIBEIRÃO PRETO

A UTILIZAÇÃO DA PESQUISA NA PRÁTICA CLÍNICA DE

ENFERMAGEM. LIMITES E POSSIBILIDADES

Maria Helena Larcher Caliri

Tese apresentada a Escola de Enfermagem de Ribeirão Preto da Universidade de São Paulo para concurso de Livre-Docência junto ao Departamento de Enfermagem Geral e Especializada.

RIBEIRÃO PRETO 2002 
UNIVERSIDADE DE SÃO PAULO

ESCOLA DE ENFERMAGEM DE RIBEIRÃO PRETO

\section{A UTILIZAÇÃO DA PESQUISA NA PRÁTICA CLÍNICA DE ENFERMAGEM. LIMITES E POSSIBILIDADES}

Maria Helena Larcher Caliri

RIBEIRÃO PRETO 2002 
Ao Caliri 


\section{AGRADECIMENTOS}

À Luísa, Lucas e Leonardo.

À minha mãe Luíza pelo exemplo de vida, e ao meu pai (in memorian).

À família "Larcher" - "Caliri” pela constante presença, suporte e incentivo (irmãos, cunhados, sobrinhos e agregados). 
Aos mestres do Curso de Graduação em Enfermagem da Universidade Estadual de Londrina.

Aos "mentores" do Programa de Pós-Graduação da Escola de Enfermagem de Ribeirão Preto, em especial, a Profa. Dra. Ana Maria Palermo da Cunha, Dra. Nilza Teresa Rotter Pelá e Dra. Maria Cecília Manzolli.

À Diretora da Escola de Enfermagem de Ribeirão Preto e Chefe do Departamento de Enfermagem Geral e Especializada na gestão atual e pregressas.

À todos os docentes da Escola de Enfermagem de Ribeirão Preto, especialmente os da Área de Fundamentos: Isabel, Maria Lúcia, Silvia, Maria Helena (I), Suely, Denise e Evelin.

Aos funcionários da Escola de Enfermagem de Ribeirão Preto, especialmente os do Departamento de Enfermagem Geral e Especializada, Velmara, Elaine, Eliana G., Eliana B e Edilaine, da Sala de leitura "Glete de Alcântara", Deolinda e Lurdes e da seção de Cooperação Internacional, Carla e Carlos.

Aos enfermeiros da Divisão de Enfermagem do Hospital das Clínicas da Faculdade de Medicina de Ribeirão Preto da Universidade de São Paulo, em especial os da Unidade Ortopedia e do Grupo de Lesões de Pele. 
Aos enfermeiros da Divisão de Enfermagem da Secretaria Municipal da Saúde, em especial os do Grupo de Estudo em Feridas.

Aos alunos de Graduação e Pós-Graduação da Escola de Enfermagem de Ribeirão Preto, em especial os orientandos de Iniciação Científica, Mestrado e Doutorado.

Aos membros da equipe multiprofissional do Grupo do Lesado Medular do Hospital das Clínicas da Faculdade de Medicina de Ribeirão Preto da Universidade de São Paulo, incluindo os "cadeirantes" e seus familiares.

Aos colegas enfermeiros que compõem a "nossa comunidade da prática”, embora mais virtual que presencial: Nádia, Soraia, Luciana, Márcia, Idevânia, Eline, Marilda, Elaine, Paula, Malú, Michele, Margareth, Termutes, Ana Emília, Guta e Bárbara.

A bibliotecária Maria Cristina Manduca Ferreira da Biblioteca Central do Campus da USP - Ribeirão Preto pela parceria na busca e divulgação de informações em Enfermagem e pela revisão das referências bibliográficas e citações.

À Flávia Borges S. Benfati pelo esforço para que esta tese chegasse ao seu final dentro das normas da Universidade de São Paulo.

E a todos que contribuíram direta ou indiretamente para o meu desenvolvimento pessoal e profissional. 


\section{SUMÁRIO}

\section{LISTA DE QUADROS}

\section{LISTA DE FIGURAS}

RESUMO

SUMARY

RESUMÉN

APRESENTAÇÃO

1 - A evolução histórica do conceito de utilização da pesquisa na prática de enfermagem

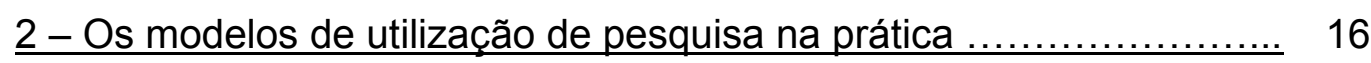

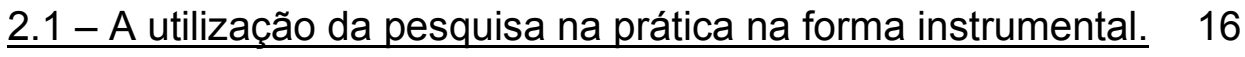

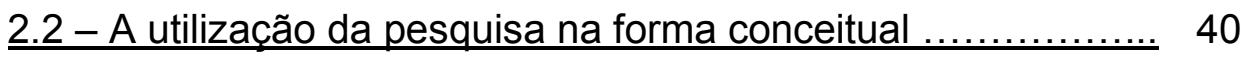

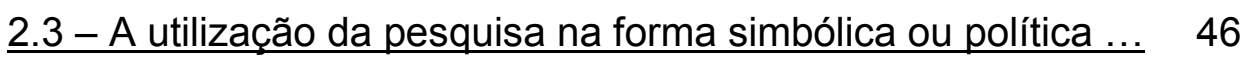

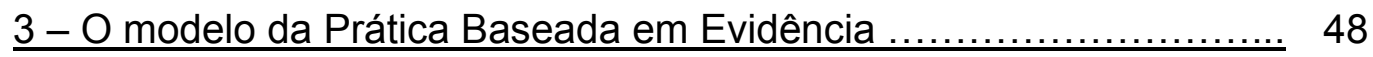

4 - Contexto e consequências da utilização da pesquisa na prática de

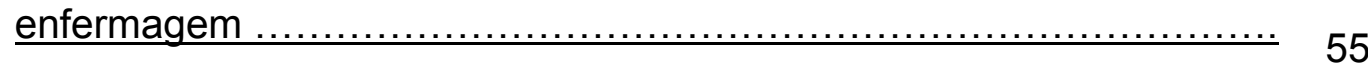

$\underline{5 \text { - A difusão do uso dos resultados da pesquisa na prática de }}$ enfermagem

$\underline{6 \text { - A divulgação do conhecimento sobre úlcera de pressão utilizando }}$

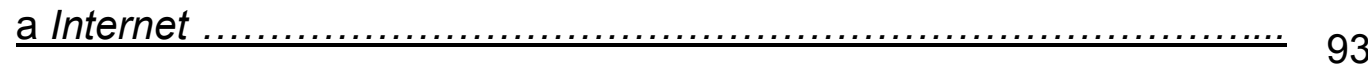

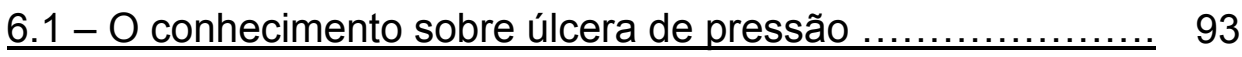

6.2 - A Internet como meio para divulgação de informação ..... 96 


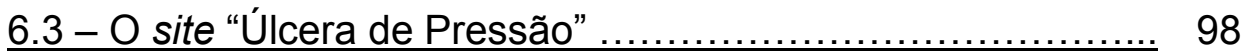

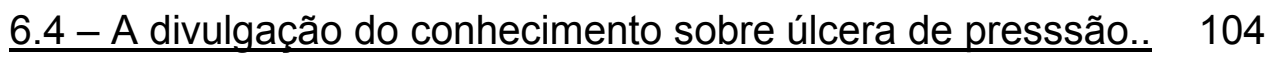

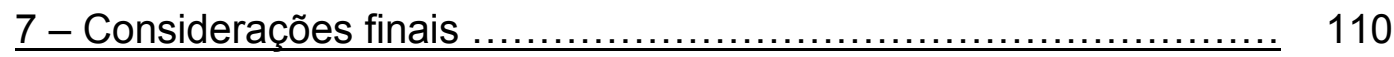

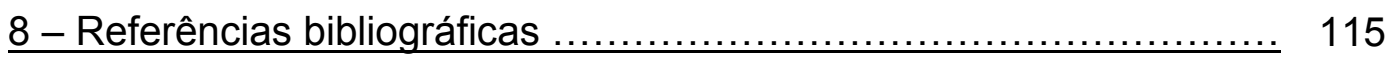

$\underline{9-\text { Apêndice }}$ 


\section{LISTA DE QUADROS}

Quadro 1 - Classificação da barreira para utilização da pesquisa considerando a sua posição (percentagem de enfermeiros que citaram cada item como uma barreira grande ou moderada) segundo vários autores 66

Quadro 2 - Protocolos de intervenção ................................... 90

Quadro 3 - Fontes de evidência online (Diretrizes, revisões integrativas, revisões sistemáticas, protocolos) 


\section{LISTA DE FIGURAS}

Figura 1 - Modelo para o processo de solução de problemas ........ 22

Figura 2 - Modelo para a prática baseada em pesquisa $\ldots \ldots \ldots \ldots \ldots . . \ldots 3$

Figura 3 - Modelo de pesquisa na prática de lowa $\ldots \ldots \ldots \ldots \ldots \ldots \ldots . \ldots$

Figura 4 - Modelo de Stetler para utilização da pesquisa ........... 42

Figura 5 - Adaptação do modelo de Havelock, de ligação entre dois

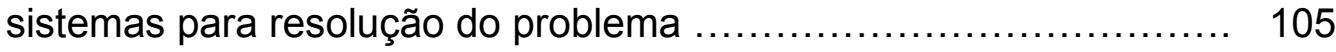




\section{RESUMO}

CALIRI, M.L.H. A utilização da pesquisa na prática clínica de enfermagem.

Limites e possibilidades. 2002, 143p. Tese de Livre-Docência - Escola de

Enfermagem de Ribeirão Preto, Universidade de São Paulo, Ribeirão Preto.

O estudo teve por objetivo analisar o conceito de utilização da pesquisa na prática de enfermagem e apresentar a Internet como veículo para divulgação deste conhecimento. Foram identificados os modelos ou abordagens propostas em diferentes momentos da evolução da prática clínica do enfermeiro, assim como os contextos e eventos que têm facilitado ou dificultado que esta seja baseada em pesquisas ou outras fontes de evidências. As diferenças encontradas no estágio da evolução da utilização da pesquisa nas situações internacional e nacional devem-se à características tanto do sistema social que compreende os enfermeiros e instituições, quanto a própria pesquisa e da forma como é disseminada. Um site na Internet com enfoque na prevenção e tratamento da úlcera de pressão é apresentado como sugestão de estratégia para facilitar o acesso ao conhecimento para os usuários da rede virtual representados por alunos, profissionais e pacientes/familiares. A integração, colaboração e compromisso dos enfermeiros/docentes, enfermeiros/clínicos, universidade e instituições de saúde são condições essenciais para que a prática clínica seja baseada em conhecimento oriundo da pesquisa ou das melhores evidências disponíveis visando a meta comum da obtenção da qualidade do cuidado de enfermagem.

Palavras chaves: Pesquisa em enfermagem, Utilização da pesquisa, Pesquisa em enfermagem clínica, Úlcera de decúbito, Internet 


\section{SUMARY}

CALIRI, M.L.H. Research-based clinical nursing practice: limits and possibilities. 2002, 143p. Tese de Livre-Docência - Escola de Enfermagem de Ribeirão Preto, Universidade de São Paulo, Ribeirão Preto

This study aimed at analyzing the concept of research-based nursing practic as well as to present the Internet as a vehicle for knowledge dissemination. Models and approaches proposed in different phases of evolution of nurses' clinical practice as well as contexts and events that have facilitated it or prevent it from being based on research or other source of evidence were identified. The differences found in the phases of research utilization by nurses at clinical settings in national and international situations are due to characteristics of the social system comprising nurses and institution, to the research itself as well to the way that is disseminated. A website on the Internet with a focus on the prevention and treatment of pressure ulcers is presented as a suggestion of a strategy to facilitate acess to knowledge for users of the virtual network, who are represented by students, professionals and patients/relatives. The integration, collaboration and commitment of nurses from academic and clinical settings as well as universities and health care institutions are essential conditions for clinical practice to be based on knowledge stemming from research or the best evidence available, aiming at achieving the common goal of delivering quality nursing care.

Key words: Research-based nursing practice, evidence-based nursing practice, Decubitus ulcer, Internet 


\section{RESUMÉN}

CALIRI, M.L.H. La utilización de la investigación en la práctica clínica de enfermería: Limitaciones y posibilidades. 2002, 143p. Tese de LivreDocência - Escola de Enfermagem de Ribeirão Preto, Universidade de São Paulo, Ribeirão Preto.

El propósito del estudio fue analizar el concepto de utilización de la investigación en la práctica de enfermería y presentar la Internet como instrumento para divulgación de este conocimiento. Fueron identificados los modelos o abordajes propuestos en diferentes momentos de la evolución de la práctica clínica del enfermeo así como los contextos y eventos que han facilitado o dificultado que esta sea basada en investigaciones o otras fuentes de evidencias. Las diferencias encontradas en el estágio de evolución de la utilización de la investigación en las situaciones internacional y nacional se deben a las características tanto del sistema social que comprende los enfermeros y instituciones, cuanto de la propia investigación y dela forma como es diseminada. Un site en la Internet con enfoque en la prevención y tratamiento de la úlcera por presión es prestado como sugestión de estratégia para facilitar el acesso al conocimiento para los usuários de la red virtual representados por alumnos, profesionales y pacientes/familiares. La integración, colaboración y compromiso de los enfermeros/docentes, enfermeros/clínicos, universidad e instituiciones de salud son condiciones esenciales para que la práctica clínica sea basada en conocimiento oriundo de la investigación o de las mejores evidencias disponibles visando a la meta comun de obtención de la calidad en el cuidado de enfermería.

Términos clave: investigación en enfermería, utilización de la investigación, investigación en enfermería clínica, úlcera de decúbito, Internet 
APRESENTAÇÃO 


\section{Apresentação}

Meu primeiro contato formal com o desenvolvimento da pesquisa em enfermagem ocorreu na década de 80 , ao ingressar no Programa de Mestrado da Escola de Enfermagem de Ribeirão Preto da Universidade de São Paulo.

Embora tivesse dez anos de formada, e exercido atividades de assistência e gerenciamento, além de ensino em nível profissionalizante, iniciar a pós-graduação marcou a minha entrada em outro mundo, o da academia, e exigiu de mim uma reformulação na forma de ver e exercer a enfermagem .

As disciplinas de pós-graduação e a realização da dissertação com enfoque na área de infecção hospitalar permitiram que eu iniciasse a compreensão de como a prática profissional poderia causar impacto na saúde da população quando fundamentada cientificamente . O que antes eu via como um "discurso" passou a tomar forma embora novas questões começassem a me inquietar, dentre elas o debate presente na época sobre o que era pesquisa em enfermagem, qual deveria ser o objeto desta pesquisa e a dualidade entre métodos quantitativos e qualitativos.

Durante o programa de Doutorado, participei do programa sandwich por um ano (1991), na Universidade de Illinois em Chicago e Urbana -Champaign, sob a orientação da Dra. Beverly J. Mc Elmurry, com subvenção da CAPES ( Caliri, 1993). Durante este período, além de cursar disciplina da pós-graduação e participar de grupo de pesquisa, pude desenvolver estágio técnico-científico 
em instituições de saúde. Observei a assistência de enfermagem em diversas situações clínicas, prestado por profissionais de diferentes níveis de formação utilizando o processo de enfermagem operacionalizado em planos de cuidados padronizados e o uso de protocolos de intervenções construído a partir de resultados de pesquisa.

A tese que desenvolvi no Doutorado, referente à experiência de mulheres submetidas a histerectomia em um hospital universitário, identificou que a trajetória destas mulheres foi caracterizada pela incerteza e por estratégias de ação para tentar resolvê-las. Estas estratégias foram direcionadas para buscar informações sobre o procedimento cirúrgico, anestesia e conseqüências advindas da cirurgia principalmente no aspecto da integridade sexual. No entanto, a enfermeira não foi vista pelas mulheres como capaz de auxiliá-las na situação apresentada.

Outra estratégia utilizada foi à busca de suporte / ajuda tanto no aspecto físico da recuperação cirúrgica quanto emocionalmente para falar sobre seus sentimentos quanto à retirada do útero. Novamente, a enfermeira não foi considerada pelas pacientes como elemento de ajuda. $\mathrm{Na}$ época em que realizei a tese, argumentei que várias pesquisas haviam demonstrado que certas intervenções de enfermagem, com pacientes cirúrgicos no período préoperatório, podem promover uma congruência entre as sensações esperadas e as vivenciadas parecendo alterar o estado cognitivo de incerteza (Johnson, 1984 apud Caliri, 1994). 
Discuti esses resultados considerando que o contexto do modelo biomédico de assistência centrado na doença, dominante nas instituições de saúde, é que não favorecia que o cuidado fosse centrado nas necessidades da pessoa.

Hoje, ao refletir sobre esta situação e após a realização de estudos em outras áreas de enfermagem (Dupas, Caliri \& Françoise, 1998; Caliri, Almeida \& Silva, 1998) acredito que existem outras barreiras individuais e organizacionais que dificultam a utilização dos resultados de pesquisa pelas enfermeiras.

Entretanto, esta situação não acontece somente na área assistencial. Estando na atividade de docência nos últimos dez anos, muitas vezes ouço questionamentos de colegas e alunos de graduação e pós-graduação sobre como tal procedimento ou intervenção deveria ser ensinado e realizado pois "cada um faz e ensina de jeito diferente e os livros apresentam o assunto de formas variadas, diferentes da realidade da prática" .

Procurando colaborar para clarear a questão é que me propus como parte da realização desta tese, desenvolver inicialmente uma revisão de literatura referente a análise do conceito "utilização da pesquisa na prática de enfermagem" .

Assim, na parte 1 e 2 apresento a evolução histórica deste conceito na enfermagem e os modelos e formas de utilização da pesquisa surgidos em diferentes épocas. Posteriormente, na parte 3 e 4, introduzo o conceito da "prática baseada em evidências" e apresento a análise do contexto e consequências da utilização da pesquisa na prática de enfermagem. Na parte 5 
analiso a difusão do uso dos resultados da pesquisa na prática e as barreiras e estratégias para sobrepô-las apresentadas pelos autores nacionais e internacionais.

Na parte 6, descrevo a minha experiência na criação e uso de um site na Internet para a divulgação do conhecimento sobre úlcera de pressão assim como os resultados observados da utilização desta inovação.

Encerro o trabalho com as considerações finais na parte 7 . 
1 - A EVOLUÇÃO HISTÓRICA DO CONCEITO DE UTILIZAÇÃO DA PESQUISA NA PRÁTICA DE ENFERMAGEM 


\section{1 - A evolução histórica do conceito de utilização da} pesquisa na prática de enfermagem.

Neste estudo, a revisão de literatura foi realizada, seguindo a proposição de Broome (2000) onde:

$$
\begin{aligned}
& \text { "a construção do conceito requer um trabalho de } \\
& \text { reconhecimento de quais publicações foram feitas na área, } \\
& \text { quais limitações na conceitualização e nos métodos que } \\
& \text { influenciaram o desenvolvimento do conceito, assim como } \\
& \text { sobre quais questões ainda permanecem sem resposta". }
\end{aligned}
$$
(Broome, 2000, p.231).

As publicações foram analisadas utilizando a abordagem evolucionária para análise de conceito conforme a proposta de Rodgers (1993).

Segundo a autora, um conceito é uma aglomeração de atributos e a análise permite que se faça uma quebra ou separação para a identificação dos seus componentes.

A ênfase é na investigação indutiva com enfoque no contexto em que este ocorre tanto sob o ponto de vista da disciplina como no ponto de vista sócio-cultural e temporal.

Tendo o objetivo do estudo como critério norteador, optamos em identificar, na literatura de enfermagem nacional e internacional, publicações 
indexadas sobre o assunto, em base de dados on line.

Para a busca de publicações nacionais, elegemos a Base de Dados LILACS (Literatura Latino-Americana e do Caribe em Ciências da Saúde) e para a busca de publicações internacionais o CINAHL ( Cumulative Index to Nursing \& Allied Health).

O acesso ao LILACS foi feito pela Biblioteca Virtual em Saúde da BIREME (Centro Latino-Americano e do Caribe de Informação em Ciências da Saúde), gratuitamente, enquanto que o ao CINAHL foi feito pelo "direct online service", após o pagamento da anuidade.

Para a busca no LILACS, identificamos inicialmente palavras chaves relacionadas ao conceito estudado: "pesquisa em enfermagem" ; "utilização da pesquisa". Posteriormente incluímos o termo "pesquisa em enfermagem clínica" e para a busca no CINAHL, utilizamos os termos: "nursing practice research based" e "nursing practice evidence based".

No LILACS, a busca inicial com os descritores em saúde “ pesquisa em ENFERMAGEM" identificou 338 publicações. Nova busca incluindo a palavra "utilização" reduziu este número para 27. Optamos em considerar a primeira busca e selecionar as publicações considerando o título e o resumo quando presente. Nesta seleção, identificamos 39 publicações.

No CINAHL, a busca inicialmente resultou em 1760 publicações. Decidimos então excluir artigos referentes a área materno-infantil, pediatria e psiquiatria, concentrando a busca em nossa área de atuação, a saber: assistência de enfermagem ao adulto e idoso. 
Dado ao grande número de publicações indexadas referentes à apresentação em eventos, teses e dissertações que seriam de difícil localização para análise, optamos por incluir nesta amostra somente publicações em periódicos. Considerando estes critérios de seleção, identificamos 169 publicações no CINAHL.

Outros critérios incluídos para seleção da amostra, partindo das publicações identificadas foram: a sua disponibilidade na Biblioteca Central do Campus da USP de Ribeirão Preto ou em bibliotecas virtuais sem ônus; ou a possibilidade de aquisição ou empréstimo pelo serviço de Comutação bibliográfica até 30/08/2002 e o empréstimo de publicações de acervos particulares de pesquisadores.

Identificamos nas publicações analisadas que os antecedentes do surgimento do conceito "utilização da pesquisa na prática de enfermagem" estão relacionados ao início e desenvolvimento da própria Enfermagem como profissão.

Autores argumentam que o uso da pesquisa em enfermagem, surgiu no mesmo momento do nascimento da Enfermagem Moderna quando Florence Nighitingale conseguiu demonstrar por meio da coleta de dados, uma redução no índice de mortalidade dos soldados ingleses, em decorrência de mudanças na prática (Burns \& Grove, 1997; Titler, 1999).

As observações e experiências de Florence compuseram a publicação "Notas sobre a Enfermagem", que por muitas décadas direcionou as 
enfermeiras no desempenho das atividades básicas de cuidado com o ambiente do hospital e o bem estar do paciente (Nightingale, 1989).

Entretanto, este início da Enfermagem onde a produção e utilização do conhecimento eram atividades associadas não persistiu com a concentração da educação de enfermagem nos hospitais. Nesta época, o enfoque do ensino era no preparo da enfermeira para desempenhar funções técnicas como "auxiliar do médico" e a estudante vista como "mão de obra" para hospitais (Almeida \& Rocha, 1986).

Mendes (1989) em uma análise histórica da evolução da pesquisa em enfermagem nos Estados Unidos retrata o impacto positivo ocasionado pela transferência dos programas de graduação para as universidades e o surgimento dos primeiros cursos de pós-graduação específicos para enfermeiros.

Este impacto, segundo a autora, também ocorreu no Brasil pois antes da década de 70 praticamente não havia enfermeiros com formação em pesquisa embora as líderes de enfermagem reconhecessem esta necessidade e tivessem este desejo.

A este respeito, Ferreira-Santos em 1964 argumentou que as situações histórico-sociais da profissão funcionaram como uma motivação externa para empurrar a classe de enfermagem para a necessidade de fazer pesquisa, porém as enfermeiras ainda não haviam sentido esta necessidade - a motivação interna para a pesquisa (Ferreira - Santos apud Mendes, 1989). 
A inserção da enfermagem na Universidade foi acompanhada da obrigatoriedade de produção científica, para que esta pudesse se sustentar como ciência que desse subsídios para a prática profissional.

Tanto nos Estados Unidos da América como no Brasil, a pós-graduação em enfermagem ocasionou o incremento da produção científica por enfermeiros que levou também ao aumento do número de periódicos e de eventos científicos para a sua divulgação.

Este aumento de produção científica, entretanto, não ocasionou as mudanças na prática de enfermagem como era desejado e esperado pelas enfermeiras pesquisadoras, pois a assistência prestada dentro de uma estrutura hospitalar tradicional estava voltada para a realização de tarefas para atendimentos de rotina.

Um estudo seminal sobre esta questão foi desenvolvido por Ketefian em 1975. A pesquisadora selecionou para análise uma intervenção de enfermagem: a verificação da temperatura oral, para a qual havia resultados de pesquisa indicando o tempo ideal de permanência do termômetro de vidro (9 minutos). Investigou entre 87 enfermeiras o conhecimento sobre 0 procedimento. Encontrou que somente uma tinha este conhecimento, advindo da pesquisa (Ketefian apud Polit \& Hungler, 1999). Este estudo levou vários autores a afirmarem que o conhecimento produzido pela pesquisa não estava sendo utilizado na prática e a se preocuparem com formas para modificar a situação no contexto americano. 
No Brasil, a questão da realização do procedimento de verificação de temperatura nos hospitais de forma rotineira, sem a preocupação com o seu resultado ou com a veracidade da informação obtida já havia despertado a atenção de Angerami em 1972.

Em sua tese de Doutorado, a autora identificou que não havia critério uniforme para a mensuração da temperatura e os termômetros usados não eram de boa qualidade portanto, os dados não eram fidedignos (Angerami, 1972).

Em outro estudo (Angerami, 1977), a autora identificou que a mensuração da temperatura na mesma instituição era realizada em horários inadequados, considerando o estudo de biorrítimos de pacientes, o que trazia gasto de recursos humanos e materiais desnecessários, recursos estes que poderiam ser utilizados em outras atividades como assistência individualizada baseada numa decisão efetiva do enfermeiro.

A questão do uso dos resultados da pesquisa na prática, foi enfocada por vários autores na década de 80.

Almeida (1985) investigou o conhecimento e opinião sobre a utilização da pesquisa apresentados por 45 enfermeiros com diferentes níveis de formação e de locais de atuação. Do total entrevistado, $86,7 \%$ não tinham conhecimento sobre aplicação de trabalhos de pesquisa em enfermagem. Destas, 94,6\% opinaram que os resultados das pesquisas não eram claros e $78,4 \%$ achavam que os trabalhos desenvolvidos não tinham repercussão positiva na formação do enfermeiro. Do total da amostra, 57,8\% não tinham segurança para utilizar 
os resultados de pesquisas na prática embora todos acreditassem que isto fosse possível. Quanto ao preparo educacional na graduação para compreender, interpretar e avaliar os resultados de pesquisa, $71 \%$ referiram que as Escolas de Enfermagem não contribuíram para isto.

A autora reconheceu as limitações do seu estudo porém destacou a necessidade de se enfocar a questão da dicotomia existente entre a produção de pesquisa nas instituições de ensino e os profissionais da prática assistencial nas instituições prestadoras de serviços.

Destacou ainda a necessidade de se institucionalizar uma sistemática de trabalho de enfermagem dentro de uma abordagem científica para resolução desta questão nos serviços.

Massarolo et al (1986) desenvolveram seu estudo em um hospital-escola que era campo de ensino e pesquisa de uma universidade pública, visando identificar a utilização dos resultados de 15 intervenções de enfermagem, propostas como resultados de dissertações de mestrado produzidas por docentes. Participaram da pesquisa 55 enfermeiros com cargo de chefia de unidade de internação.

Os resultados identificaram que pouco mais da metade dos integrantes da amostra conhecia pelo menos uma das quinze pesquisas citadas. No entanto, destas, somente $53 \%$ utilizavam os resultados de pelo menos uma pesquisa. A utilização foi citada para atualização do conhecimento (54.9\%) e para mudanças nos procedimentos $(41.9 \%)$. 
Os obstáculos identificados para utilização da pesquisa por este grupo foram: falha na divulgação dos resultados (19\%); falta de acesso às publicações $(18,5 \%)$; falta de tempo para desenvolver pesquisa $(10,7 \%)$; falta de recursos humanos $(10,7 \%)$; falta de recursos materiais $(9,5 \%)$; falta de recursos financeiros para adquirir as publicações (8,9\%); falta de tempo para leitura (71\%); incredibilidade quanto à aplicação dos resultados $(4,8 \%)$, falta de interesse em adquirir publicações (4,2\%); falta de interesse na pesquisa $(4,2 \%)$; dificuldade para ler a pesquisa pela complexidade da redação $(1,8 \%)$.

Observamos que essas barreiras identificadas pelos enfermeiros foram principalmente devido à comunicação dos resultados e a operacionalização da implementação sob o ponto de vista institucional enquanto que os fatores referentes a dificuldades e atitudes pessoais do enfermeiro foram de menor atribuição.

A importância da preocupação com esta questão em nível brasileiro já havia sido destacada no $3^{\circ}$ Seminário Nacional de Pesquisa em Enfermagem (SENPE) em 1984, quando Ribeiro apresentou-a como de responsabilidade coletiva da classe, incluindo aí, os enfermeiros pesquisadores, educadores, administradores e assistenciais:

"Os trabalhos contidos nos Anais dos nossos Congressos constituem o discurso da enfermagem brasileira, mas sem a necessária incorporação à prática, não passam de documentos literários". Assim, "mudanças se fazem necessárias na educação ... se os indivíduos, cada um e todos, 
não mudarem, não haverá mudanças significativas". “Educadores terão que admitir sua maior responsabilidade em encontrar e utilizar recursos que realmente favoreçam e garantam o crescimento individual dos estudantes, de cada um deles e de todos" (Ribeiro, 1984,p. 10-26).

Para clarear a sua posição da exigência do uso da pesquisa para o desempenho profissional, deu um exemplo análogo na área médica:

" Um cirurgião poderá permanecer alguns poucos anos como bom cirurgião mas, com o passar do tempo, se não se envolver com a evolução natural e constante da tecnologia e das ciências médicas, passará a ser um simples curandeiro, com técnicas desatualizadas e chegará até a incapacidade de se utilizar dos novos métodos e recursos da medicina”. (Ribeiro, 1984,p. 10-26).

A autora destacou que a pesquisa dá o apoio para a prática, e esta sem a pesquisa se transforma em rotina. Ressaltou ainda que a utilização da pesquisa daria ao público visibilidade da expansão do papel do enfermeiro e seria uma forma de garantir a qualidade da assistência.

Esta visão da utilização da pesquisa como prioridade profissional e requisito para a transformação da prática melhorando a sua qualidade foi uma das tônicas observadas nas publicações brasileiras da década de 80 . 
Esta mesma situação vivenciada nos Estados Unidos e no Brasil, em relação a dificuldade para utilização da pesquisa, embora em épocas diferentes, também ocorreu no Reino Unido.

Hunt (1981) destacou que antes da década de 70, a questão centralizava-se na necessidade de tornar os enfermeiros capazes de produzir pesquisa e em como promover o financiamento para isto. Ressaltou que a falta de pesquisa colocava a profissão em um posição de desvantagem e que o valor de sua contribuição para o cuidado não era reconhecido nem pelos membros da profissão, nem pelos outros profissionais.

Enfatizou que na década de 70 a atenção foi focalizada nas formas para permitir que os resultados fossem utilizados e assimilados na prática. Apresentou a sua percepção das razões dos enfermeiros não utilizarem os resultados de pesquisa, enfocando aspectos relativos a conhecimentos, habilidades, atitudes e poder do enfermeiro para fazer mudanças na instituição: 1) não conhecem; 2) não compreendem; 3) não acreditam; 4) não sabem como aplicar; 5) não lhes é permitido aplicar. A autora destacou a necessidade de criação de mecanismos internos e externos à profissão para que a expectativa de utilização se tornasse realidade (Hunt, 1981).

Observamos assim que nos diferentes países, o contexto de desenvolvimento da enfermagem como profissão traz a expectativa de uma prática baseada em conhecimento científico próprio que faria diferença nos serviços de saúde implicando em maior qualidade, embora a definição desta qualidade não estivesse ainda muito clara. 
No contexto americano a questão do hiato entre a produção do conhecimento pelos pesquisadores nas universidades e a sua utilização nas instituições passou a ser cada vez mais importante. Já na década de 70 , esforços eram feitos para o desenvolvimento de modelos de integração, hoje considerados as primeiras manifestações de modelos de utilização.

O conceito de utilização da pesquisa é visto nas publicações deste período como tendo diferentes vertentes: o uso "instrumental" da pesquisa para produzir resultados visíveis e mudanças na prática institucional através de intervenções na organização, o "uso conceitual ou cognitivo" e o uso "simbólico ou político" para persuasão. Estas publicações marcaram a evolução do conceito para uma nova era quando o "desejo" e a "expectativa" de utilização começaram a ser vistos como possibilidades (Horsley, Crane, Bingle, 1978; Stetler, 1985).

A operacionalização do conceito na forma instrumental foi marco nesta evolução e os seus atributos são reconhecidos como necessários e importantes até hoje para os novos modelos que se apresentam como inovadores como a Prática Baseada em Evidências (Donaldson,2001;Hunt,2001). 
2 - OS MODELOS DE UTILIZAÇÃO DE PESQUISA NA PRÁTICA 


\section{2 - Os modelos de utilização de pesquisa na prática}

\section{1 - A utilização da Pesquisa na prática na forma instrumental}

Identificamos na literatura analisada que o Governo Federal Americano, na década de 70 , financiou projetos institucionais que visavam aumentar a utilização da pesquisa existente assim como testar a sua operacionalização.

O Projeto WICHE ( Western Council on Higher Education for Nursing) foi o primeiro grande projeto a tratar da utilização da pesquisa em enfermagem. Foi desenvolvido no período de seis anos e envolveu enfermeiras de treze estados americanos com o objetivo de incrementar as atividades de pesquisa em enfermagem.

O modelo foi composto de cinco fases e focalizava na ligação de instituições que tinham os recursos de enfermagem (docentes/pesquisadores) com as instituições que tinham os usuários dos resultados da pesquisa - os enfermeiros da prática. Cada fase foi operacionalizada conforme a proposta das autoras (Polit \& Hungler, 1991; Burns\& Grove, 1997).

As atividades da fase 1 do projeto visaram recrutar participantes e desenvolver os recursos que compreendiam material baseados em pesquisa.

A fase 2 foi planejada para identificação dos problema da prática que precisavam de soluções. Utilizou estratégias de workshop onde os participantes 
eram organizados em duplas educadoras/enfermeiras clínicas. O objetivo era que os participantes desenvolvessem habilidades para criticar a pesquisa e aplicar a teoria da utilização da pesquisa. Cada dupla selecionou uma intervenção de enfermagem baseada em pesquisa para implementar em uma instituição.

Na fase 3 a díade deveria funcionar como agentes de mudança quando os projetos fossem implementados nas instituições dos participantes por 05 meses.

Na fase 4 um novo workshop foi realizado para os participantes relatarem e avaliarem os projetos.

A fase 5 constituiu-se de atividades para o seguimento da continuação do projeto com avaliações 3 e 6 meses após a implantação.

As principais atividades encontradas foram a identificação de pesquisas clínicas com resultados apropriados para serem implementados na prática.

O objetivo do projeto foi parcialmente alcançado com publicações referentes a Programa de ensino para pacientes no pré-operatório; Plano de Cuidado para esposos em luto e avaliação da sua eficácia; Programa para Prevenção e Tratamento de Constipação de residentes em "nursing home" pelo aumento da quantidade de fibra na dieta ( Burns \& Grove, 1997, Polit \& Hungler , 1991)

Esta primeira experiência de utilização da pesquisa exemplificou um dos atributos principais do conceito: a colaboração entre pessoas com experiências diferentes e instituições com missões diferentes porém com 
metas comum: possibilitar a transformação da prática e do status da profissão.

O Projeto CURN ( Conduct and Utilization of Research in Nursing) é considerado o projeto de utilização da pesquisa mais conhecido e cujas contribuições perduraram e foram incorporadas pelos modelos criados posteriormente.

Foi o primeiro projeto desenvolvido nos Estados Unidos de forma colaborativa entre a área de enfermagem e sociologia, e entre enfermeiras pesquisadoras e enfermeiras da prática clínica.

A proposta do projeto e a obtenção dos recursos para realização foi da Associação de Enfermeiras do Estado de Michigan com a meta de preencher o hiato existente entre a pesquisa e a prática e garantir a qualidade da assistência (Horsley, 1983).

A autora principal foi Joanne Horsley, doutora em enfermagem, pesquisadora e docente da Universidade de Michigan que dividiu a coordenação com Donald Pelz, do Instituto de Pesquisa Social da mesma Universidade.

A natureza colaborativa do Projeto é evidenciada pela distribuição de suas atividades (Horsley, 1983):

- A ligação entre as atividades de planejamento e coordenação do projeto foram centralizadas na Universidade e aquelas referente a sua 
implementação, realizadas em mais de 30 hospitais, foi coordenada pela representante da Associação de Enfermeiras.

- O planejamento e coordenação do projeto teve assessoria de Ronald G. Havelock do Instituto de Pesquisa Social da Universidade de Michigan, para que o embasamento conceitual fosse operacionalizado.

- As atividades de educação dos enfermeiros para utilização da pesquisa e o desenvolvimento dos protocolos para a prática foram feitas por duas equipes que incluíram seis enfermeiras docentes da Universidade.

- A coleta e análise dos dados foram realizadas por outras duas equipes de enfermeiras preparada para as atividades de pesquisa.

- Contou ainda com o apoio administrativo dos dois departamentos da Universidade de Michigan e da Associação de Enfermagem, e de uma Especialista em Editoração.

O projeto integrou os processos específicos envolvidos em transformar o conhecimento advindo da pesquisa em atividades da prática, criar o clima para as mudanças e estabeleceu as atividades necessárias para planejar, implementar e avaliar os seus efeitos na prática.

A sua realização teve ainda a assessoria externa de pesquisadores que haviam produzido os estudos originais, utilizados para basear as intervenções de enfermagem testadas na prática, além de outros profissionais que tinham experiência anterior de participação no Programa WICHE. 
O pressuposto que guiou o grupo de Michigan para a construção do projeto foi o de que a transferência de pesquisa para a prática é um processo que envolve diferentes atividades que culminam com a criação de um protocolo de inovação baseado em pesquisa. O projeto foi visto como um novo modelo para integração de docentes e enfermeiras assistenciais. Loomis \& Krone (1980) e Loomis (1985) destacaram que os princípios de colaboração entre o pesquisador e os profissionais da prática clínica para o desenvolvimento do projeto CURN vieram da ciências sociais, com uma abordagem que focaliza nas interações sociais entre os membros dos dois sistemas separados que são então conectados com troca de informação entre os dois. O referencial de Havelock utilizado para estruturar o projeto de acordo com as idéias principais do autor citado foi apresentado:

"De acordo com este modelo, aqueles que estão emitindo as mensagens e os que as estão recebendo só podem obter sucesso na "ligação" se a troca de mensagens ocorre em interação de duas vias e com esforço contínuo de ambos para simular o comportamento de resolução de problemas utilizados pelo outro. Assim o sistema que contém os recursos precisa reconhecer as necessidades internas do sistema que vai utilizar as informações e os seus padrões de solucionar os problemas. O usuário por usa vez precisa ser capaz de valorizar a invenção, a formulação da solução e os processos de avaliação 
do sistema que contém os recursos. Este tipo de interação colaborativa não somente irá tornar as soluções mais relevantes e efetivas mas também irá construir relacionamentos de confiança e percepções mútuas pelas pessoas dos dois sistemas de que a outra está realmente preocupada... e com o tempo serão construídos os canais para uma transferência rápida, efetiva e eficiente das informações." (Loomis, 1985, p. 137)

Partindo da fundamentação desta teoria, a implantação dos resultados de pesquisa foi vista como " um processo consciente, racional e deliberado de produzir inovação e mudança na instituição e na prática de enfermagem de forma aceitável e benéfica para todos os envolvidos" (Horsley \& Crane, 1978; Horsley, 1983).

Os componentes do processo foram discriminados:

- As mudanças, suas características e requerimentos,

- Os agentes de mudança, suas capacidades e recursos,

- O alvo ou recipiente das mudanças,

- O local das mudanças, suas características e recursos,

- A justificativa para as mudanças

- As estratégias para obter as mudanças,

- Os momentos da mudança dentro do contexto da instituição 
O projeto CURN previu que o Processo de Utilização da Pesquisa deveria ser desenvolvido conforme o método de solução de problemas, em seis fases distintas, cada uma com uma função diferente conforme apresentado na figura abaixo:

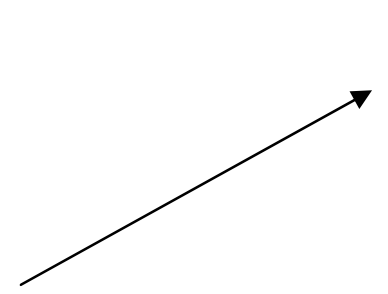

Preocupação com as mudanças na prática de
enfermagem

Satisfação com a solução e implementação ou insatisfação e repetição do círculo
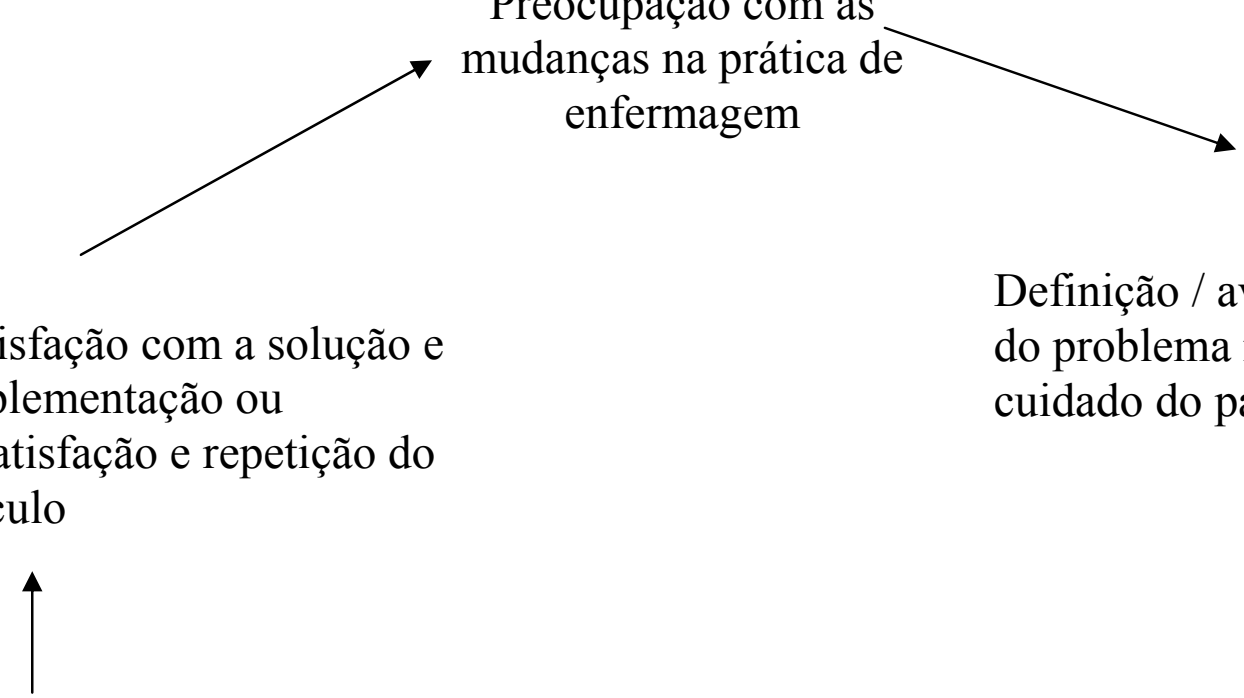

Experimento / teste da

Definição / avaliação do problema no cuidado do paciente

Solução Proposta

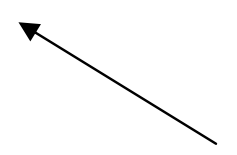

Seleção da Solução em

Busca de Soluções potencial

Figura 1 - Modelo para o processo de solução de problemas (Horsley, 1983, p.4) 
$1^{\text {a }}$ Fase - compreende duas atividades interrelacionadas: identificar os problemas da prática que exigem solução e acessar as bases válidas de pesquisa.

A identificação dos problemas foi vista como ocorrendo de duas formas: por pessoas que identificam os problemas e então procuram soluções ou um novo conhecimento que surge e pode alterar a percepção que alguém tem sobre o evento de forma que uma prática específica, previamente julgada como satisfatória, tornara-se agora problemática ou questionável.

Assim as autoras justificaram que os Departamentos de Enfermagem nos hospitais precisavam estruturar mecanismos para identificar e avaliar os problemas atuais existentes na prática e fornecer acesso à pessoas, organizações e materiais escritos como fontes de bases válidas de pesquisa.

Destacaram entretanto que não estavam sugerindo que cada Departamento de Enfermagem fosse o responsável por avaliar a validade de uma base de pesquisa e justificaram que, naquele momento (1978) esta função deveria ficar com as universidades, consultores em pesquisa ou associações profissionais.

$2^{\mathrm{a}}$ Fase - Esta fase foi planejada para avaliar a relevância da base de conhecimento advindo da pesquisa e como isto se relacionava com o problema identificado na prática clínica, os valores da organização, as políticas e os potenciais custos e benefícios que poderiam advir do uso. 
Enfatizaram que um conjunto de probabilidades deve ser estabelecido relacionado ao potencial para adoção organizacional de uma inovação na prática, derivada da base de pesquisa sob consideração.

$3^{\text {a }}$. Fase - Nesta fase a principal atividade seria desenvolver o projeto da inovação (nova intervenção) que atendesse as necessidades do problema clínico e não excedesse as limitações científicas da base de pesquisa existente. Esta inovação deveria descrever como a intervenção deveria ser feita e prescrever as limitações clínicas à serem impostas. Destacaram que o projeto também deveria conter um plano para implementação contendo:

$>$ O tempo em que o projeto seria desenvolvido.

> Identificação de uma unidade única onde o experimento com a inovação seria desenvolvido.

$>$ Identificação das pessoas chaves relacionadas a implementação.

$>$ Estabelecimento dos meios para identificar e adquirir os recursos adequados ( pessoal / equipamento / tempo e financiamento).

Fazer provisão para treinamento do pessoal se necessário, e

$>$ Provisão de avaliação adequada dos efeitos da inovação.

4a. Fase - A proposta visava a realização do experimento clínico e a avaliação da inovação em uma unidade individual de enfermagem. Entendiam que o experimento deveria incluir medidas padrão dos atuais resultados esperados da intervenção. Ressaltaram que o monitoramento adequado deveria ser feito para 
certificar-se da ocorrência de efeitos não previstos e que a avaliação deveria ser estruturada de forma a fazer parte natural da inovação e não uma atividade adicional para as enfermeiras, feita de forma artificial e sem relevância. Deveria incluir tantas variáveis dependentes (da base de pesquisa utilizada) quanto fossem clinicamente justificáveis. As autoras enfatizaram que divergências entre a base de pesquisa e os dados do experimento referentes a estas variáveis deveriam ser tratados como um problema sério que precisava ser resolvido antes que o significado da avaliação pudesse ser determinado.

5a. Fase - Foi planejada para ocorrer após o experimento e a sua avaliação terem terminado. Seu objetivo seria para auxiliar a decidir se a inovação seria adotada na forma proposta, alterada ou rejeitada. Horsley \& Crane destacaram que a qualidade da decisão seria totalmente dependente da adequação e exatidão das medidas de avaliação que foram feitas durante o experimento clínico. Explicaram que a decisão de rejeitar a inovação fechava o ciclo do processo que poderia começar novamente na fase 1 com uma nova base de pesquisa. A decisão de alterar a inovação retornaria o processo na fase 2,3 ou 4 dependendo do que tivesse sido indicado pelos dados de avaliação, assim como da causa encontrada para a falha do experimento ( Horsley \& Crane, 1978; Horsley, 1983).

Para as autoras, a decisão de adotar a inovação, encaminhava o processo para a $6^{\text {a }}$ fase com desenvolvimento de meios para expandir ou difundir a inovação para outras unidades dentro do hospital e a sua 
manutenção. Enfatizaram que o projeto de utilização de pesquisa era apropriado para questionar a razão custo / benefício das intervenções de enfermagem. Argumentaram que na questão de custo, considerável gasto de tempo é requerido para manter acesso ao novo conhecimento gerado por pesquisa, para desenvolver, implementar e avaliar a nova inovação na prática e para fornecer o necessário desenvolvimento do pessoal. Destacaram que este processo pode também requerer gasto com equipamentos e aparelhos de mensuração normalmente não disponíveis na maior parte dos serviços.

$\mathrm{Na}$ questão de benefícios as autoras destacaram que as funções envolvidas no processo de utilização da pesquisa complementavam os programas de garantia de qualidade e que os benefícios para o paciente resultantes da nova prática deveriam servir para equilibrar parte do custo do seu desenvolvimento.

Demonstraram que desta forma, o processo tanto consumia dados como os produzia, características que julgavam tanto benéficas para a instituição como para a profissão, pois permitia fornecer uma justificativa para as atividades da prática cujo significado podia ser compreendido dentro e fora da profissão e movia a prática clínica para um papel vital na atividade de pesquisa em enfermagem.

Horsley \& Crane explicaram que o processo permitia avaliar o conhecimento gerado sob condições relativamente controladas produzindo dados clínicos de forma sistemática que poderiam ser usados para validar os 
achados atuais e futuros, e que os dados clínicos produzidos por este sistema forneceriam direcionamento para futuras pesquisa em enfermagem.

O projeto CURN produziu protocolos de intervenções baseadas em pesquisa em dez áreas e iniciou o conceito da avaliação da qualidade da assistência de enfermagem à partir dos resultados das intervenções.

Os temas dos projetos de utilização foram:

1. Ensino pré-operatório estruturado.

2. Redução de diarréia em pacientes com sonda gástrica.

3. Preparo pré-operatório envolvendo informações sensoriais.

4. Prevenção de úlcera de pressão.

5. Troca de cateter intra-venoso.

6. Sistema fechado de drenagem vesical.

7. Intervenção de enfermagem para redução / alívio da dor.

8. Redução de estresse pelo preparo sensorial.

9. Estabelecimento de metas mútuas no cuidado do paciente.

10. Cateterismo intermitente utilizando a técnica limpa.

As características destes protocolos foram descritas pelas autoras nas suas publicações ( Haller; Reynolds \& Horsley, 1979; Horsley, Crane e Bingle, 1978): 
- O protocolo começa com a identificação da necessidade de mudança na prática, documentação da extensão do problema clínico e sua relevância para a prática de enfermagem.

- Na segunda seção é feita uma descrição da inovação incluindo os tipos de pacientes que podem, mais provavelmente, serem beneficiados com a inovação.

- É apresentado um resumo da base científica utilizada e identificado os aspectos que são baseados em pesquisa e que nortearão a implementação da inovação.

- O protocolo detalha ainda como a implementação deve ser feita assim como a avaliação sistemática e seus efeitos e descreve os materiais que são requeridos na educação do pessoal que podem ser necessários assim como os custos esperados.

- Finaliza com discussão dos benefícios esperados de resultados positivos do teste da inovação.

- Apresenta, como anexo, as fontes primárias de pesquisa, bibliografia, os formulário para avaliação do protocolo e outros instrumentos da pesquisa original .

Vários autores destacaram que a contribuição do projeto CURN não foi somente os protocolos de pesquisa, mas também os métodos científicos 
utilizados e a tecnologia usada para conduzir os estudos ( Loomis, 1985; Titler, 1997; White,Leske \& Pearcy, 1995).

Uma contribuição importante do projeto CURN foi o estabelecimento de diretrizes para definir os parâmetros de utilização dos resultados de pesquisa quais sejam:

1) Um único estudo não pode fornecer evidência de pesquisa suficiente e válida para justificar eticamente o seu uso com os clientes. Um projeto de utilização deveria ser baseado em uma série de estudos replicados.

2) Quando a replicação direta é mínima, ou seja existem poucos estudos conduzidos com o mesmo design sobre um mesmo assunto, a replicação indireta pode ser usada para validar e expandir uma área definida de pesquisa em enfermagem.

3) A inovação na prática de enfermagem que é desenvolvida a partir de um resultado de pesquisa precisa ser avaliada incluindo pelo menos uma variável dependente usada pelo pesquisador original e tantas quantas forem clinicamente razoáveis.

Para as autoras, as duas primeiras diretrizes visam eliminar a tentativa de implementar resultados de pesquisas inconsistentes ou insuficientes; já a terceira diretriz trata do fato que ao utilizarmos um resultado de pesquisa que atendeu os dois critérios anteriores, os resultados encontrados na prática clínica devem ser aqueles previstos na condição do estudo original. A falha na obtenção deste resultados deve levar a questionamentos quanto ao design 
utilizado e quanto à indicação da implementação da inovação na prática, pois pode trazer riscos para os pacientes ( Horsely, Crane \& Bingle, 1978).

Estas recomendações foram posteriormente incorporadas em outros modelos de utilização de pesquisa e de prática baseada em evidências, compondo a hierarquia das bases de conhecimento para decisões sobre a prática clínica ( Stetler, 1994; Titler et al, 1994; Stetler et al, 1998 (a); Stetler, 2001).

Um aspecto importante na análise de um conceito é a identificação do seu uso de forma equivocada (Rodgers, 1993). Um dos pressupostos básicos defendido pelas autoras do Projeto CURN para utilização da pesquisa e confirmado por outros autores que o utilizaram na prática, é a necessidade de diferenciar o processo de utilização da pesquisa do processo de produção da pesquisa ( Horsley, Crane, 1978; Horsley; Crane \& Bingle, 1978; Goode et al 1987; Stetler, 1994). A confusão entre os dois processos ocorreria porque um conjunto de atividades não acontece de forma isolada do outro. As diferenças precisam então ser clarificadas: "A condução de uma pesquisa direciona-se para a produção de um conhecimento que é generalizável para além da população que foi diretamente estudada" enquanto que o processo de utilização “É direcionado para transferir um conhecimento, específico baseado em pesquisa para a prática, utilizando técnicas desenvolvidas e testadas no contexto da prática" (Horsley; Crane \& Bingle, 1978).

Goode et al. (1987) contribuíram para a evolução do conceito de utilização de pesquisa iniciado com o Projeto CURN ao testá-lo em um pequeno 
hospital não universitário. Ao invés de contar com especialistas da universidade para as atividades colaborativas de assessoria na transferência dos conhecimentos existentes, as autoras relataram que foi formado uma comissão de enfermeiras com mestrado em enfermagem, que agiram como agentes de mudança para implementar o projeto na instituição, conforme recomendado pelos autores originais. Um dos participantes do projeto também era responsável pelo programa de garantia de qualidade e pela realização de auditorias para avaliar a prática institucional. Os outros membros da comissão tinham experiência em identificar problemas clínicos, coletar e interpretar dados assim como em relatá-los, mas todos tinham dificuldades em fazer revisão crítica e avaliação da pesquisa apresentada nas publicações visando a sua utilização. As autoras relataram que foi necessário um período de seis meses para que as enfermeiras adquirissem esta habilidade, porém as suas experiências no desenvolvimento das atividades levou-as a propor uma nova forma de utilização que chamaram de modelo HORN, através do qual os métodos para utilização da pesquisa eram ensinados passo a passo e foram disseminado no formato de manual e vídeo ( Goode et al, 1991).

Com este trabalho, as autoras reforçaram o atributo de cooperação [do conceito] para a utilização da pesquisa e introduziram dois novos atributos: a necessidade de competência das enfermeiras para utilização da pesquisa e a possibilidade do desenvolvimento da competência através da experiência e estudo. 
$\mathrm{Na}$ década de 90, encontramos novas propostas para operacionalizar a utilização da pesquisa na prática institucional, o Modelo de Garantia de Qualidade com Utilização da Pesquisa (QAMUR) e o Modelo de Pesquisa na Prática de lowa. Estas propostas tornaram mais clara a relação das atividades de avaliação, presentes nos Programas de Garantia de Qualidade nas instituições Hospitalares Americanas na década de 70 e 80, com os modelos de Utilização de Pesquisa no seu enfoque instrumental.

Watson, Buleck \& Mc Closkey, 1987 (apud Goode et al, 1991), construíram o QAMUR - "Quality Assurance Model Using Research" integrando estas duas atividades e fornecendo uma ligação entre a educação e a prática de enfermagem. Incluíram também no esquema, a forma com que a produção de pesquisa podia ser transferida para a prática para provocar mudanças.

O QAMUR foi desenvolvido como programa colaborativo de um hospital universitário e uma Escola de Enfermagem, os quais já tinham ligações formais anteriores de ensino, prática e pesquisa.

Leske et al. (1994) apresentaram a representação esquemática deste modelo. 

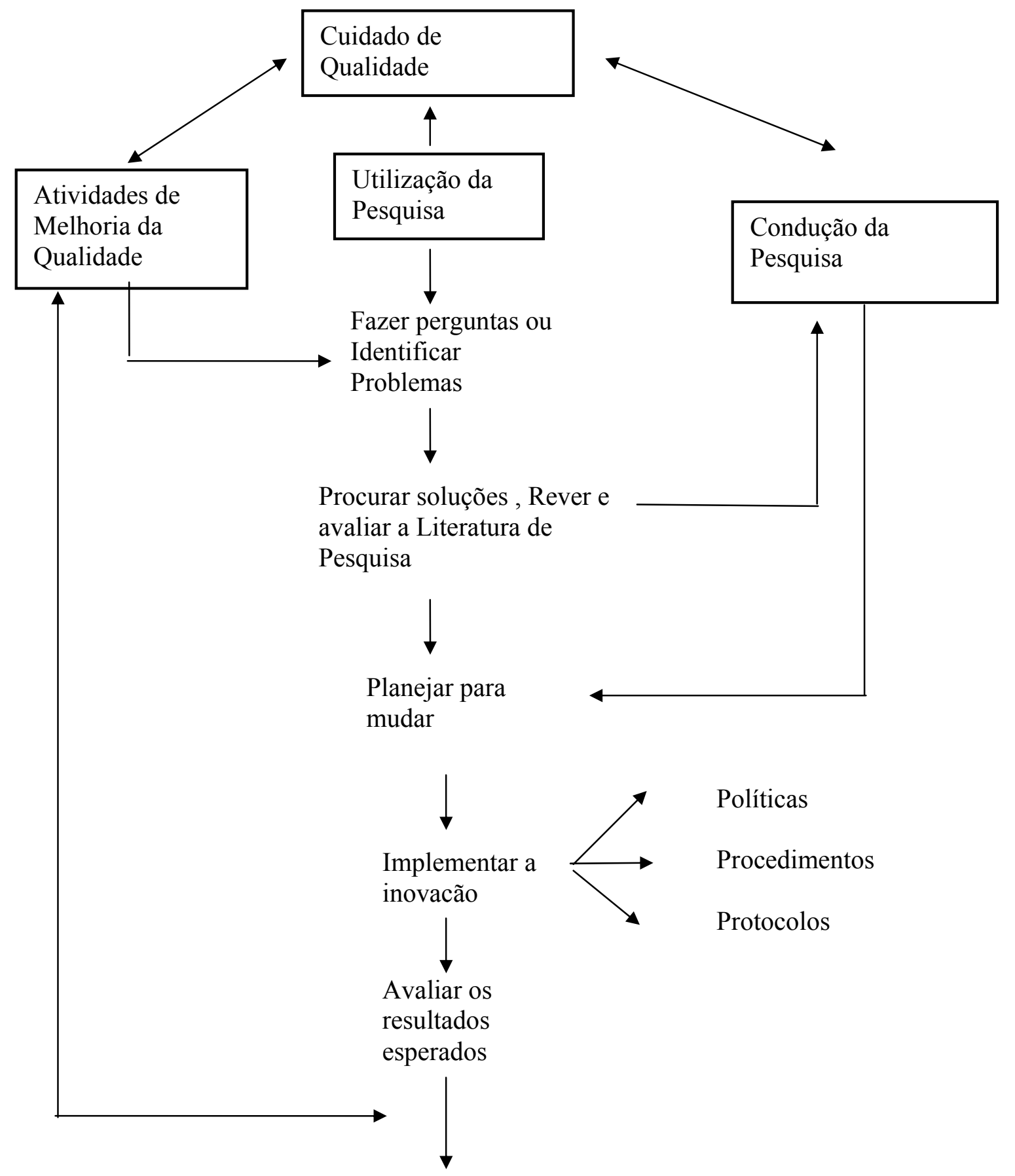

Formular os Padrões de Cuidado

Figura 2 - Modelo da prática baseada em pesquisa (Leske et al., 1994, p. 105). 
Na década de 90 este projeto evoluiu para o Modelo de Pesquisa na Prática de lowa, ressaltado como uma abordagem pragmática para melhorar a qualidade do cuidado nos Hospitais e Clínicas da Universidade de lowa e conter os custos dos cuidados com a saúde ( Titler et al, 1994; White, Leske, Pearcy, 1995).

A proposta descreveu como a visão da utilização da pesquisa como atividade esperada da enfermeira é incorporada em suas atividades e qual é o papel da instituição na criação do ambiente onde a investigação e o pensamento crítico são valorizados:

- As atividades de utilização de pesquisa são incluídas na descrição das funções dos enfermeiros, na filosofia e nos padrões do Departamento de Enfermagem.

- As enfermeiras tem liberação de tempo das atividades assistenciais para participar em pesquisa e projetos de utilização e financiamento para participar de cursos de pesquisa e eventos científicos.

- Nas unidades/ ou clínicas, o clima de investigação é demonstrado pelo encorajamento dado ao pessoal para obter consultoria para realização de novos estudos, usar protocolos de assistência baseados em pesquisa, assim como participar de grupos de estudo e comissões para atividades de desenvolvimento de projetos de utilizações. 
Identificamos que as atividades propostas pelo Modelo de lowa para implementação dos resultados de pesquisa na prática seguem os passos criados pelo Projeto CURN, porém de forma mais avançada pois na década de 90, nos EUA, já existia maior produção de pesquisa clínica em enfermagem e um maior número de enfermeiros que participaram da pós-graduação e tinham conhecimento de pesquisa.

Além disso, nos serviços já existiam outras fontes de informação sobre a situação da qualidade, como Programas de Melhoria de Qualidade, que usam técnicas de pesquisa para obter informações sobre alguns indicadores .

Como no modelo CURN, o modelo de lowa propõe que as mudanças na prática podem ser desencadeadas de duas formas: por um problema na prática ou por um novo conhecimento advindo da pesquisa. Entretanto nas duas formas, a busca de respostas para as questões será feita por uma "comissão" de enfermeiras organizada com este propósito.

Este modelo também é desenvolvido em fases ou passos, com pontos de decisão, conforme apresentado na figura 3. 
PRÁTICA BASEADA EM PESQUISA PARA PROMOVER A QUALIDADE DO CUIDADO / EVENTOS ENGATILHADORES PARA MELHORAR A PRÁTICA POR MEIO DE PESQUISA

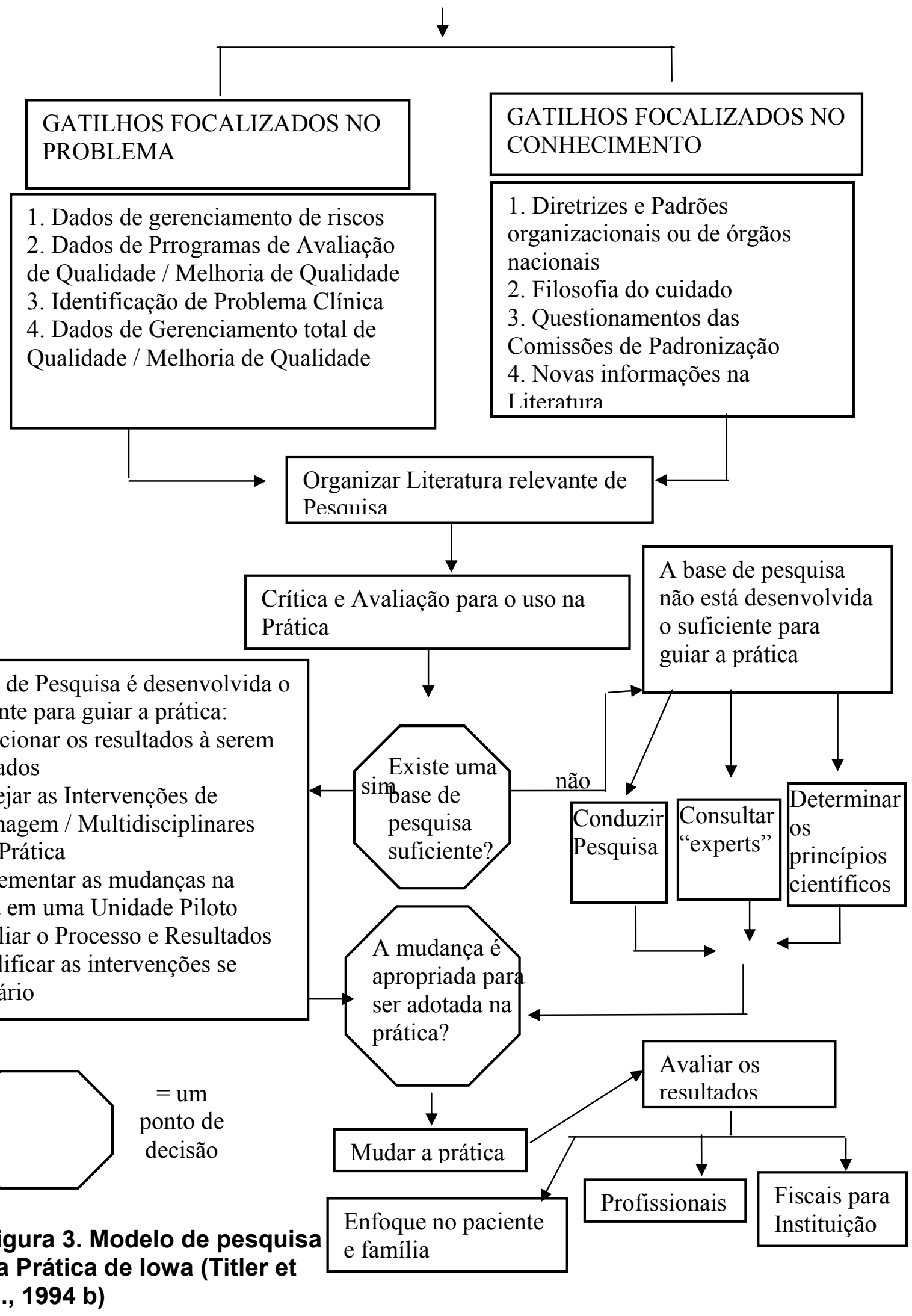


A primeira fase, quando iniciada pela identificação dos problemas da prática, pode incluir as questões clínicas encontradas com maior freqüência assim como dados de Programas de Gerenciamento de Riscos ( potencial para problemas) e Programa de Qualidade Total.

Quando a primeira fase é iniciada pelo conhecimento, este pode advir da disponibilidade de novas informações da literatura; de mudança de padrões da prática profissional, ou da filosofia do cuidado.

Um grande fator para a disponibilização de novos conhecimentos para a prática clínica, no contexto americano na década de 90 e incorporado pelo modelo de lowa, foram as Diretrizes para a prática clínica divulgadas por agências governamentais e organizações de especialistas como forma de nortear os profissionais ou fazer recomendações sobre as "melhores práticas". Além disso, novos tipos de publicações, as revisões integrativas e metaanálises, favorecem que os profissionais adquiram novos conhecimentos e comecem a questionar a sua prática ( Titler et al, 1994 b).

Os próximos passos do modelo de lowa, os quais incluem a busca da literatura relevante sobre o assunto e a sua análise para crítica e avaliação, são realizados da mesma forma e com os mesmos critérios propostos no Projeto CURN. Entretanto, as enfermeira pesquisadoras ( com doutorado) contratadas pela instituição é que auxiliam e assessoram as enfermeiras das comissões nestas atividades, servindo também nos papéis de modelo para que as mudanças aconteçam. Quando necessário, as comissões buscam assessoria 
do próprio pesquisador que produziu o resultado de pesquisa que está sendo avaliado para possível implementação.

No próximo passo, quanto não há pesquisa suficiente para apoiar a mudança na prática, o modelo de lowa recomenda a condução de pesquisa para buscar o embasamento necessário porém, que até que estes resultados sejam obtidos, os princípios científicos ou o consenso entre especialistas no assunto é que determinarão as recomendações das intervenções apropriadas. Entretanto, quando existem pesquisas suficientes cujos resultados atenderam os critérios para a utilização, inicia-se o novo processo de translação para implementar as mudanças inicialmente em uma unidade piloto.

O modelo de lowa destacou a importância do conceito de "empowerment" do profissional onde a sua participação de forma efetiva no processo de mudança, desde o estabelecimento do problema, a criação dos protocolos para utilização e seleção dos resultados esperados, irá fortalecer a sua base de conhecimento e irá capacitá-lo para responder aos desafios apresentados por colegas da área ou pela equipe multidisciplinar com informações baseadas e pesquisa.

Para Titler et al. 1994, a avaliação de mudanças na prática clínica após a implementação deve ser feita tanto sob a perspectiva do processo de assistência ou seja, pela forma com que a assistência é prestada, quanto pelos

\footnotetext{
* to empower - dar poder, capacitar, empoderecer
} 
seus resultados, antes que as mudanças sejam generalizadas para toda a instituição.

Para as autoras, o segundo ponto crítico de decisão para adoção da mudança deve considerar o seu custo e a economia que será feita, o seu impacto na qualidade do cuidado, o aumento ou diminuição do risco de lesão iatrogênica para pacientes, a competência dos profissionais para realizar a mudança após terem sido educados e o apoio dos administradores em enfermagem para a realização das mudanças.

Avaliação para a implementação envolve três aspectos:

> Capacidade de transferência dos resultados de pesquisa

$>$ Análise da razão custo/benefício: paciente, staff e instituição

> Possibilidade de implementação: recursos, clima organizacional, necessidade de assistência externa.

Ressaltam que todos estes fatores devem ser então incorporados no estabelecimento dos resultados que serão avaliados e no impacto que a mudança irá trazer para os pacientes, profissionais e nos resultados financeiros para a instituição.

No Reino Unido, as publicações sobre o desenvolvimento de modelos para utilização da pesquisa na prática na sua forma instrumental na década de 70 e 80 não são freqüentes. As experiências ocorreram na forma de projetos de “pesquisa - ação" que visavam tanto criar mudanças na assistência e ensino de enfermagem, como colher informação sobre os processos e resultados. Utilizaram o referencial de Kurt Levin, assim como os componentes de 
Programas de Garantia de Qualidade propostos por Donabedian (Hunt, 1987; Webb, 1989).

Na década de 90, o Sistema de Saúde, inglês sob o impacto da recessão econômica, teve a imposição governamental para melhorar a eficiência e efetividade dos serviços assim como garantir a excelência clínica. Foram estabelecidas então, estratégias, em nível nacional para aumentar as atividades de pesquisa e a sua disseminação num novo modelo que incluía o uso de outras evidências, além das científicas, para fundamentar a prática clínica dos profissionais (Gerrish \& Clayton, 1998).

No Brasil identificamos algumas publicações nacionais que destacaram a importância dos modelos colaborativos entre Universidade e Instituição de Saúde no intuito de possibilitar a utilização instrumental da pesquisa na prática, porém a sua operacionalização não foi apresentada (Mendes, 1989; Lopes, 1990; Stefanelli, 1992; Cassiani \& Passarelli, 1999).

\section{2 - A utilização da Pesquisa na forma conceitual}

Para Stetler (1985) o uso conceitual ou cognitivo do resultado da pesquisa implica que a utilização ocorre em qualquer momento que o conhecimento baseado em pesquisa é conscientemente usado na prática pelo enfermeiro. Assim, de posse do conhecimento, o enfermeiro pode individualmente, tentar uma inovação em uma situação clínica para ver se a 
mesma funciona, ou utilizar a abordagem com uma população de pacientes com problemas clínicos em particular. A autora enfatiza que entretanto o julgamento clínico quanto a utilização, exige uma enfermeira crítica e reflexiva. Destaca que o conhecimento da pesquisa influencia sobre como pensamos e a questionarmos as suposições que baseiam a prática.

Apresenta ainda que a aplicação cognitiva pode acontecer quando o conhecimento vindo da pesquisa influencia o pensamento ao invés da ação, levando o profissional a refletir "como pensa sobre a sua prática".

O modelo de Stetler foi proposto como forma de envolver o enfermeiro para utilização da pesquisa e a integrar esta atividade em sua prática cotidiana em qualquer área da enfermagem onde uma decisão precisa tomada. Na sua proposição inicial, Stetler destacava que a aplicação cognitiva da pesquisa poderia ser feita independentemente do envolvimento da instituição. A autora chamou a sua abordagem de modelo do "practitioner" no qual o enfermeiro especialista clínico (com mestrado para a prática clínica) é visto como sendo orientado pelo conhecimento e não pela tarefa, e que utiliza a pesquisa como um processo e como um produto para cuidar, ensinar ou gerenciar cientificamente.

A autora defendeu dentro de sua abordagem a utilização pelo enfermeiro de informações de outras fontes que não a pesquisa para embasar as suas decisões, argumentando que isto é necessário se considerarmos a dimensão mais ampla de conhecimento que forma a base da enfermagem, além da ciência. 
Este referencial foi refinado por Stetler na década de 90, com a explicação de seu embasamento teórico na nova versão construída indutivamente, a partir da sua experiência na utilização com enfermeiros especialistas clínicos ( figura abaixo)

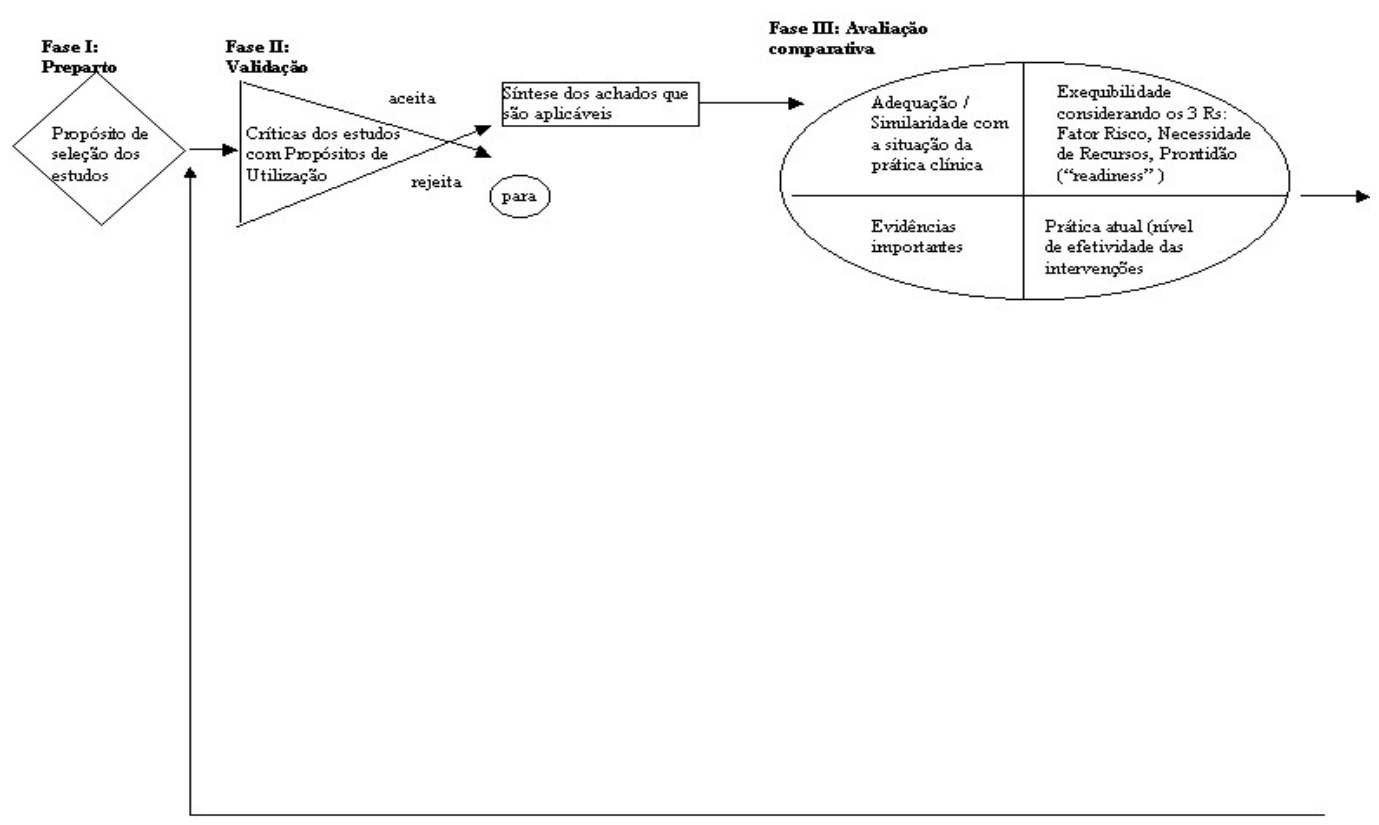




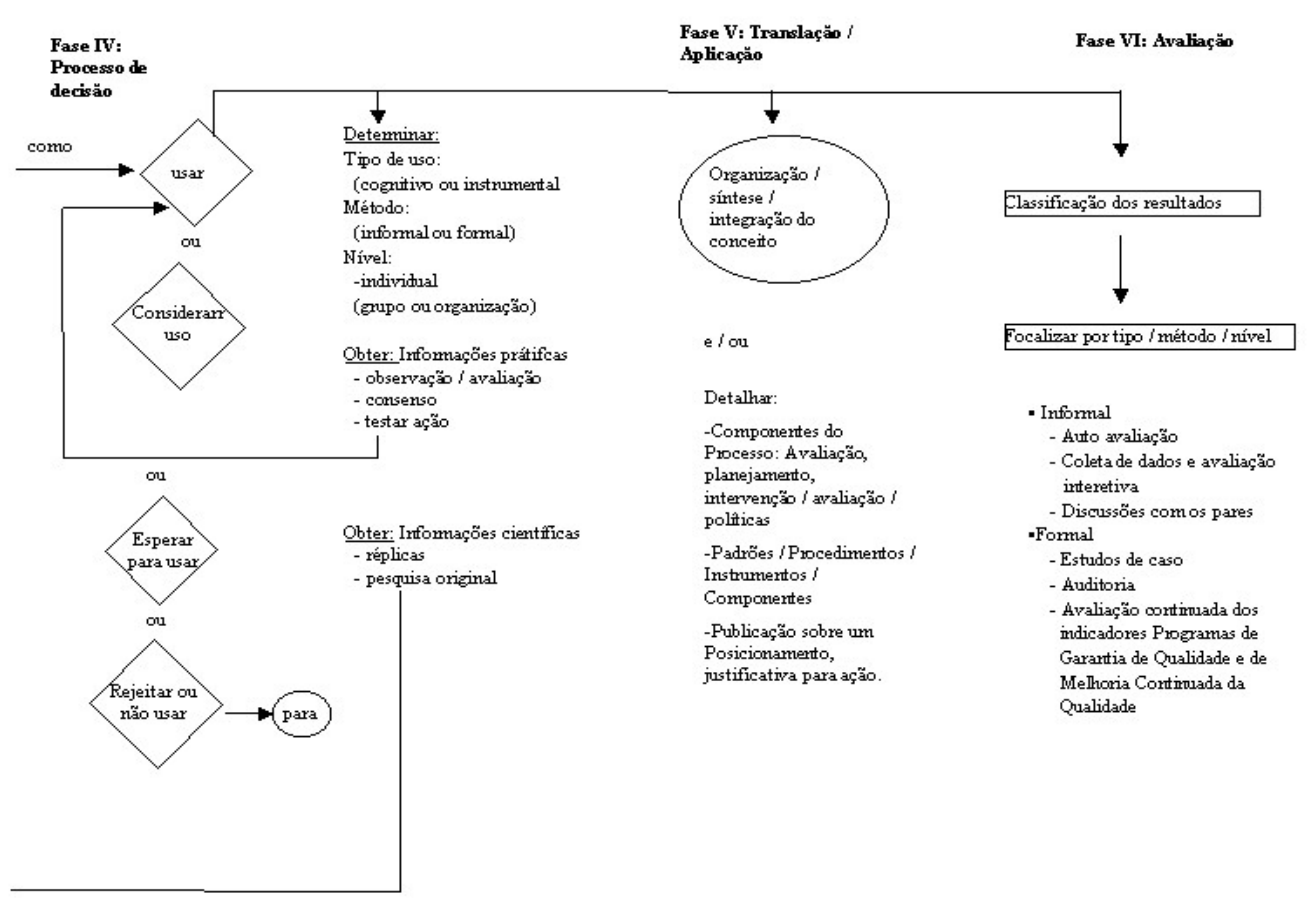

Figura 4: Modelo de Stetler para Utilização da Pesquisa (STETLER, 1994)

Na nova versão do modelo, Stetler (1994) reconheceu também a importância dos estímulos ambientais externos e internos que podem influenciar o uso dos resultados de pesquisa na instituição, questões estas já abordadas nos outros modelos de utilização que enfocam as condições organizacionais.

O modelo de Stetler, foi apresentado em seis fases, cada uma das quais destinadas a:

“1. estimular o pensamento critico sobre a aplicação pragmática dos resultados; 2. resultar em uso cuidadoso e progressivo da pesquisa no contexto da prática; e 3. diminuir 
algumas das fragilidades humanas para tomar decisões e utilizar o conhecimento ( Stetler, 1994, p. 15-25)”.

As etapas do processo de utilização de pesquisa apresentadas pela autora são muito semelhantes as do projeto CURN porém além de focalizar na atividade do profissional individual, destacou também que se este não tiver informação sobre a utilização, o uso apropriado e efetivo, provavelmente será inibido.

Assim, a autora apresentou instrumentos e informações para que o enfermeiro possa fazer decisões em diversos pontos com competência.

$\mathrm{Na}$ fase I do modelo de Stetler, os usuários devem estabelecer os propósitos para a revisão da literatura de forma que possam identificar os resultados esperados na fase $\mathrm{VI}$ - Avaliação. A revisão pode incluir estudos de pesquisa nos seus mais diferentes designs.

Na fase II a validação dos estudos é feita pela crítica da pesquisa com o objetivo de aceitá-lo ou rejeitá-lo em relação ao potencial para aplicabilidade. Se a decisão indicar pela aceitação é então necessário apresentar uma síntese dos achados que são aplicáveis e que poderão subsidiar as mudanças na prática. Esta síntese deve: “1) refletir o significado probabilístico das estatísticas do estudo relativo aos futuros clientes, 2) refletir a relação ou associação estudada ou as variáveis, em termos que poderiam ser usados pragmaticamente em atividades diárias como coleta de dados, intervenções ou outros comportamentos relevantes". 
A fase III consta da avaliação comparativa dos resultados do estudo com a prática do profissional que está avaliando as pesquisas para buscar esta resposta.

Os questionamentos, como no modelo do projeto CURN, são feitos em relação às similaridades da amostra e da situação do estudo com a situação da prática clínica onde os resultados serão usados; os fatores de risco que envolvem a sua implementação, a necessidade de recursos e a prontidão para que as mudanças ocorram. Outro aspecto da avaliação comparativa envolve o questionamento do nível de efetividade da prática que está sendo usada para enfrentar o problema, ou da situação que se pretende mudar, o que muitas vezes não é conhecido e indica a necessidade de avaliação. O último aspecto desta fase envolve o reconhecimento das outras fontes de evidência, além da pesquisa, que podem complementar o suporte das recomendações para a prática, já que muitas vezes as pesquisas são em pequeno número e a decisão sobre conduzir a prática precisa ser feita.

$\mathrm{Na}$ fase IV o processo de decisão irá ocorrer envolvendo quatro possibilidades: a) "usar", ou seja, colocar o conhecimento em uso na forma instrumental, conceitual ou simbólica sem ter que esperar por novos dados; b) “considerar o seu uso", o que pode ser feito após observações pessoais da eficácia da medida ou quando a consulta a especialistas resulta em um consenso sobre a adoção; c) "esperar para usar" posteriormente, no futuro, até que outras pesquisas sejam feitas para resolver os conflitos existentes ou para demonstrar que não há riscos; d) "rejeitar ou não usar" devido aos riscos ou 
custos envolvidos, falta de resultados consistentes ou suficientemente fortes ou a adequação da prática atual.

$\mathrm{Na}$ fase $\mathrm{V}$ o propósito é forçar o profissional a pensar usando generalização lógicas e a racionalmente formar ou reformar os resultados e outras informações relevantes em termos de ações. Posteriormente, as implicações para a prática clínica, gerencial ou educacional, devem ser detalhadas na forma de passos para um procedimento, justificativas para direcionar a seleção de intervenções, ou para fornecer argumentos persuasivos sobre um posicionamento ou um problema.

A fase VI, a avaliação, se inicia com esclarecimentos dos resultados esperados que referem-se ao propósito definido na fase de preparação, que pode ser feito formal ou informalmente. Stetler recomenda que a avaliação formal siga as abordagens propostas no projeto CURN ou do modelo pesquisaação para ter o rigor de pesquisa.

Destaca que as duas formas de avaliação podem indicar a necessidade de nova aplicação do modelo, destacando a natureza cíclica do processo de utilização da pesquisa.

No Brasil, Mendes (1989) expôs sua perspectiva sobre a utilização conceitual do conhecimento, explicando este uso no ensino pelo enfermeiro docente ao transmitir o seu saber para os alunos, na prática assistencial onde o enfermeiro pode testá-lo e mesmo refutá-lo e na prática da pesquisa onde pode gerar novos conhecimentos. 
Destacou a importância dos grupos de pesquisa com a inclusão de alunos e enfermeiros para que os resultados dos estudos se difundam de forma mais acelerada para a prática assistencial e para o próprio ensino, trazendo mudanças nas formas de pensar a enfermagem.

\section{3 - Utilização da pesquisa na forma simbólica ou política}

Esta forma de utilização envolve o uso da pesquisa como uma ferramenta ou instrumento político para legitimar uma posição ou uma prática (Stetler, 1994). Estabrooks (1999) o define como "o uso de resultados de pesquisa (da enfermagem ou não) para persuadir outras pessoas, que geralmente estão em uma posição de decisão a realizar mudanças nas condições, políticas e práticas relevantes para os enfermeiros, pacientes, ou para a saúde de indivíduos ou grupos".

Styles (1992) destacou o significado político dos resultados de pesquisa que demostraram nos EUA na década de 80, a eficácia de certas intervenções de enfermagem para a redução dos custos e a melhoria da qualidade da assistência à saúde de certos grupos da população.

No Brasil podemos observar que os enfermeiros pesquisadores tem assumido cada vez mais posições de destaque nas agências de financiamento de pesquisa e direção de Secretarias de Saúde, o que pode representar uma valorização de suas contribuições para as políticas públicas. 
Em resumo, a análise das diferentes propostas para utilização da pesquisa na prática indicam que a utilização instrumental, conceitual e simbólica, podem ocorrer de forma simultânea assim como uma pode preceder a outra em relação a ordem de ocorrência.

O uso conceitual pelo enfermeiro pode levar a questionamento sobre a situação da prática de forma que o uso simbólico estimule na instituição a organização de projetos para a disseminação da utilização instrumental.

Identificamos que todas as propostas para utilização instrumental da pesquisa abordam a questão com uma visão sistêmica, onde é considerada a multidimensionalidade dos fatores internos e externos que interferem e sofrem interferência no processo. 
3 - O MODELO DA PRÁTICA BASEADA EM EVIDÊNCIA 


\section{3 - O modelo da Prática Baseada em Evidências}

$\mathrm{Na}$ década de 90 identificamos nas publicações o surgimento de um novo conceito relacionado à utilização da pesquisa na prática " A prática baseada em evidência" (PBE). O conceito surgiu na área de Medicina Medicina Baseada em Evidências (MBE) e apresentou-se como uma "nova forma" de exercer a prática (assistencial e ensino), com base em evidências e não em tradições, mitos e preferências do profissional.

Identificamos nas publicações que embora de origens antigas, o surgimento do movimento do MBE logo seguido pela Enfermagem baseada em Evidências, deu-se no Reino Unido, impulsionado pelo avanço científico e tecnológico ocorrido com o grande aumento do número de pesquisas e da facilidade para a sua divulgação e acesso em banco de dados computadorizados. Estes avanços foram associados à utilização de conhecimentos da área de epidemiologia, os quais permitem avaliar a pesquisa e outras fontes de conhecimento existentes como forma de apoiar as decisões profissionais.

Thomas \& Hess (1998) entretanto argumentaram, que a MBE na verdade é um novo rótulo para um antigo conceito onde o objetivo continua o mesmo: estimular os profissionais a procurar um embasamento ou evidência para a prática a qual muitas vezes é inconsistente, fragmentada, baseada na autoridade e em observações não sistematizadas e não científicas. 
O movimento é visto como um novo paradigma assistencial e pedagógico e como uma ferramenta, que se bem usada, pode modificar os resultados obtidos com a assistência de qualidade e reduzir o custo dos serviços de saúde.

O referencial da MBE foi proposto e desenvolvido inicialmente por um grupo de estudos na área médica, na Universidade de Mc Master do Canadá na década de 80 (Jennings \& Loan, 2001). Posteriormente, este referencial ganhou uma maior dimensão ao se expandir para outros países incluindo os do Reino Unido, onde se solidificou ao se estabelecer como Centro Cochrane, destinado a produzir revisões sistemáticas da literatura, meta-análises e recomendações para a prática.

Este conceito foi adotado pelo Serviço Nacional de Saúde do Reino Unido como referencial, ou modelo para a prestação dos serviços de saúde, compreendendo tanto a assistência médica quanto à de enfermagem com a meta de :

“... assegurar, através dos recursos disponíveis, a maior melhoria possível da saúde física e psicológica da população do Reino Unido" (Colyer \& Kamath, 1999).

Para o alcance desta meta, as decisões devem ser orientadas pela evidência do custo das intervenções e da efetividade clínica.

A definição conceitual e a operacionalização da Prática Baseada em Evidências (compreendendo a prática dos diversos membros da equipe de saúde) é encontrada nas publicações que analisamos como provenientes da 
área médica, onde o termo MBE se transforma para $\mathrm{PBE}$, numa compreensão dos autores que seus princípios são os mesmos:

"Medicina baseada em evidência é o uso consciente, explícito e criterioso da melhor evidência atual para tomar decisões sobre o cuidado de pacientes individuais.... medicina (prática) baseada em evidências significa integrar a qualidade de perito clínico individual do profissional, com a melhor evidência clínica externa disponível proveniente da pesquisa sistemática” (Sackett et al, 1996 apud: Closs \& Cheater, 1999 p.10; Colyer \& Kamath, 1999 p. 189; French, 1999 p.73).

A abordagem da PBE inclui a realização de várias atividades de forma sistemática para resolver um problema e gerar mudanças e melhoria na prática, o que é semelhante a proposta dos modelos de utilização de pesquisa. No entanto, utiliza diferentes fontes de evidência para nortear a resolução do problema além dos resultados de pesquisa, incluindo as preferências do paciente.

A abordagem da PBE enfatiza a utilização de parâmetros para determinar as intervenções mais apropriadas para serem utilizadas, estabelecendo uma hierarquia de evidências. No topo desta hierarquia estão os resultados de estudos experimentais randomizados e controlados, representando a forma mais forte de evidências. Os estudos descritivos 
representam uma forma mais fraca de evidência e aqueles utilizando métodos qualitativos não são considerados nesta hierarquia.

A abordagem utiliza a revisão sistemática da literatura e a meta-análise como formas de agrupar estudos de replicação e pela análise estatística ou não de seus resultados, avaliar a efetividade das intervenções.

A utilização deste referencial para embasar a prática exige a disponibilidade de resultados de pesquisas com fortes evidências, que as intervenções realizadas produziram resultados positivos na área prática, o que ainda não é freqüente na área de enfermagem mesmo na realidade americana. (Ketefian, 2001)

Outro fator limitante para utilização do PBE é que os fenômenos relacionados à assistência de enfermagem, nem sempre podem ser estudados pelos métodos quantitativos valorizados neste referencial (Naish, 1997).

Nos Estados Unidos, o conceito da PBE foi introduzido pela Agência de Pesquisa e Políticas de Cuidados em Saúde ( Agency for Health Care Policy and Research - AHCPR), depois transformada em Agência para Pesquisa e Qualidade do Cuidado em Saúde - AHRQ ( Jennings \& Loan, 2001; Stetler, 1998 a).

Esta instituição, foi criada pelo governo americano, com o objetivo de produzir recomendações baseadas em estudo e experiências de peritos, especialistas clínicos, para orientar as intervenções relativas a problemas considerados prioritários naquele país. A agência produziu diretrizes que 
focalizaram as questões mais comuns e que envolviam os maiores custos para o sistema .

A hierarquia de evidências criadas pela AHCPR e disseminadas nas Diretrizes para a Prática Clínica foram incorporadas pelos enfermeiros americanos pois foram criadas com a participação de especialistas também da área enfermagem ( Bergstrom et al, 1995; Jacox et al, 1994) e foram adotadas pelos serviços de saúde em geral para nortear a assistência prestada e para a avaliação dos resultados obtidos .

Stetler et al. (1998 a) e Stetler (2001) propuseram uma adaptação do esquema de evidências do AHCPR para ser utilizado na enfermagem e incorporou-o no referencial teórico do modelo de utilização de pesquisa apresentado anteriormente (Stetler, 1994) transformando-o em modelo alternativo da PBE. O modelo de Stetler atualizado detalhou a realização do processo de síntese da literatura e a seleção das evidências adicionais aos resultados de pesquisas. A autora considera que a evidência é caracterizada por alguma coisa que fornece uma prova para se tomar uma decisão, compreendendo os achados da pesquisa formal assim como o consenso entre peritos e profissionais especializados. Argumenta entretanto, que dentro de uma organização, é realístico incluir também fatos ou dados relacionados às atividades e às operações para melhoria da assistência que sejam confiáveis, verificáveis e coletados utilizando métodos de pesquisa.

Stetler (1998 a; 2001) destacou que para integração da PBE em uma instituição, é necessário o estabelecimento de uma nova cultura, criar a 
capacidade para os seus membros se transformarem na direção proposta e manter esta mudança através de revisões da infra-estrutura.

Estes pressupostos são semelhantes àqueles indicados por Horsley (1983) e Titler et al, (1994 b) como necessários para que as mudanças sejam implementadas e persistam em uma organização. No entanto, Stetler (2001) e Stetler et al. (1998 b), reforçam o papel do enfermeiro especialista clínico como agente da mudança, com domínio da área clínica e dos métodos de pesquisa e da utilização do pensamento crítico para iniciar e manter o processo de decisão da prática baseada em evidências.

Rosswurm \& Larrabel (1999) descreveram um novo modelo para a PBE derivado da literatura à ela relacionada, assim como da literatura sobre a utilização da pesquisa e a teoria de mudanças. O objetivo do modelo, segundo as autoras, é guiar os profissionais durante todo o processo de mudança para a PBE, iniciando com a coleta de dados referente às necessidades de mudanças e terminando com a integração de um protocolo baseado em evidências.

Apresentam um instrumento para padronizar a revisão e a crítica da literatura, onde a hierarquia da força de evidência considera os parâmetros estabelecidos pela AHRQ. O modelo apresentado utiliza os passos propostos pelo projeto CURN com incorporação de conhecimento proveniente das diretrizes da AHRQ, Centro Cochrane e outras fontes das revisões sistemáticas para embasar as intervenções que serão incluídas nos protocolos.

$\mathrm{Na}$ análise destas abordagens propostas para a implementação da prática baseada em evidências, identificamos que estas apresentam os 
mesmos componentes ou etapas para conduzir à incorporação do resultado de pesquisa, ou outra forma de evidência, na prática clínica com o objetivo de transformá-la.

Entretanto, a diferença entre os dois modelos está na fase anterior, quando outros conhecimentos, além daqueles obtidos por pesquisa, podem ser utilizados como evidência para a prática.

Stetler et al (1998a e 1998b), além da adaptação para a enfermagem da hierarquia das forças de evidências propostas pela AHCPR apresentaram ainda as características da atividade da revisão integrativa da literatura, para gerar evidências para a prática. Destacaram a importância de não se utilizar o termo "prática baseada em pesquisa" quando suas bases científicas são fracas já que a linguagem pode passar ao usuário numa confiança que não deveria existir. Neste caso recomendam o uso do termo "prática baseada em evidências". 
4 - CONTEXTO E CONSEQUÊNCIAS DA UTILIZAÇÃO DA PESQUISA NA PRÁTICA DE ENFERMAGEM 


\section{4 - Contexto e conseqüências da utilização da pesquisa na prática de enfermagem}

A análise do conceito de "utilização da pesquisa na prática" e da "prática baseada em evidências", permitiu identificar que a meta final do processo é a obtenção de melhorias nos resultados e na qualidade da assistência. Esta percepção é justificada pela afirmação dos autores de que as grandes variações observadas nas práticas e nos resultados obtidos, indicavam que melhorias poderiam ser feitas.

Entretanto, a força propulsora das mudanças foram as pressões econômicas mundiais sentidas nas organizações, nas décadas de 80 e 90 as quais exigiram uma reestruturação das instituições de saúde, com ênfase nas medidas para redução dos custos.

Estes eventos foram acompanhados pela diminuição da demanda de pacientes para a hospitalização e a concentração nos hospitais de pacientes de tratamento complexos, além do aumento do poder do consumidor sobre os serviços e de suas exigências por assistências de melhor qualidade e menor custo.

Para enfrentar estes desafios as instituições de saúde começaram a incorporar as teorias de Deming, Juran e outros, que embasavam os modelos de Gestão de Qualidade Total (GQT) utilizados nas indústrias americanas. 
Estes modelos são compostos por sistemas organizados e integrados onde o processo de trabalho visa a melhoria contínua da qualidade dos seus resultados (Zonsius \& Murphy, 1995).

Um fator importante para a incorporação dos conceitos da GQT nas instituições de saúde foi a imposição externa da Comissão Conjunta de Acreditação de Hospitais (Joint Comission on Accreditation of Healthcare Organization - JCAHO), que desde a década de 50 era responsável pela avaliação e estabelecimento de padrões de qualidade técnico-administrativos para hospitais. Assim, a qualidade do cuidado ao paciente é vista como resultado ou conseqüência de todos os serviços individuais à ele prestados pela instituição.

A enfermagem, que desde o seu início tem a filosofia e o compromisso de fazer o melhor para o paciente e não causar danos (Nightingale, 1989), colaborou no processo de transposição das idéias da GQT das indústrias para os hospitais.

O trabalho de enfermeiras pesquisadoras como Dra. Sue Hegyvary, foi considerado como essencial para este desenvolvimento. Os dados de pesquisas foram utilizados para a construção dos indicadores de qualidade tanto do processo como dos resultados da assistência institucional, incluindo ainda informações sobre o ponto de vista do paciente e do pessoal de enfermagem (Zonsius \& Murphy, 1995).

Assim, as Comissões de Melhoria de Qualidade (CMQ) passam a produzir e a utilizar dados referentes aos indicadores de qualidade, usando 
técnicas de pesquisa, assim como a desenvolver projetos de mudanças nos serviços conforme os modelos de utilização da pesquisa e da prática baseada em evidências.

As intervenções consideradas nos Programas de Melhoria de Qualidade (PMQ) pelas comissões incluem as de risco, volume e custo elevado e aquelas com potencial para produzir problemas.

Os PMQ, o papel dos enfermeiros como parte das CMQ multidisciplinares, o uso das técnicas de pesquisa para coleta de dados como surveys ou auditorias, os ciclos de Qualidade que enfatizam o uso de método de solução de problemas (Planeje, Faça, Avalie, Aja) e os referenciais da GQT, são temas comuns nas publicações que justificam a utilização do conhecimento oriundo da pesquisa ou de outras evidências para a melhoria da qualidade.

Com a incorporação desta visão a avaliação das intervenções de enfermagem é feita tanto na sua dimensão técnica, relacionada a segurança e efetividade clínica na situação de cuidado institucional, como na sua dimensão econômica com análises de custo-benefício.

Nesta nova visão, o conhecimento e a competência do profissional para a prática clínica são valorizadas, pois resultados negativos podem significar a insatisfação dos clientes, aumento dos custos da hospitalização, assim como processos legais contra as instituições e seus profissionais (Weiler, 1992; Brent, 2001; Soloway, 1998).

Identificamos na literatura que desde a década de 80 , indicadores de qualidade eram usados nas instituições como variáveis de mensuração da 
efetividade dos serviços. Dados referentes à estes indicadores são coletados para relatórios institucionais ou para atender as requisições da Comissão Conjunta de Acreditação de Hospitais.

Estes enfoques foram incorporados pela liderança de enfermagem americana na década de 90, observado tanto pelas ações do Centro Nacional de Pesquisa em Enfermagem (CNPE) como da Associação Americana de Enfermagem (A.N.A.).

Burns \& Grove (1997) relatam que em 1992, o CNPE promoveu uma Conferência em Pesquisa de Resultados para o Paciente (Patient Outcomes Research) com o tema "Exame da efetividade da prática de enfermagem “. Referem também que na principal conferência do evento, a Dra. Hinshaw, então diretora do Centro, sugeriu:

"a necessidade de serem identificadas sob a perspectiva da enfermagem, condições clínicas que fossem mais específicas às intervenções de enfermagem sob o ponto de vista da prevenção de doenças, promoção de saúde, controle dos sintomas e melhoria dos efeitos de doenças agudas e crônicas". Destacou "todos nós temos familiaridade com condições clínicas que são centrais para a nossa prática como a integridade da pele, dor, incontinência urinária, náusea e vômito, déficit nutricional, confusão, restrição na mobilidade, fadiga e doenças relacionadas ao estresse. É muito importante que em nossos programas de pesquisa comecemos tanto 
definir como refinar os resultados para o paciente que são específicos das intervenções que focalizam em tais condições clínicas" (Burns \& Grove, 1997, p.577).

A A.N.A, em 1995 iniciou um projeto para identificar estes indicadores de qualidade, considerados específicos para a enfermagem com o objetivo de “demonstrar o que as enfermeiras já sabem - que um enfermeiro ao lado do leito pode significar a diferença entre um cuidado bom ou ruim, ou um cuidado pior" (Stanley \& Foer, 1996). Foram selecionadas inicialmente 21 indicadores nas categorias de "resultados" do cuidado, "processo" do cuidado e "estrutura" do cuidado, considerando os conceitos de Qualidade Total (Reed et al, 1998). Posteriormente este conjunto de indicadores foram refinados com a manutenção de 10 indicadores, cinco dos quais já eram dados que encontravam-se disponíveis nas instituições: número de enfermeiros, técnicos e pessoal não qualificado; proporção de pessoal de enfermagem / paciente; nível educacional e qualificação de enfermeiro, taxa de rotatividade de pessoal, e uso de enfermeiros de agências de terceirização. Os indicadores de resultados do cuidado selecionados precisavam ter mais investimentos para a sua qualificação por meio de pesquisa e consistiam: infecção do trato urinário (hospitalar); úlcera de pressão, erros de medicação, queda com lesão física e satisfação do paciente.

A Associação Americana de Enfermagem desenvolveu, na década de 90, uma intensa campanha para treinamento dos enfermeiros na utilização dos métodos de pesquisa para obtenção destes dados e para encorajar o 
envolvimento dos enfermeiros nas atividades de mensuração e melhoria de qualidade dos serviços (Stanley \& Foer, 1996). Neste período, outras estratégias para viabilizar a utilização dos resultados de pesquisa na prática com a visão de provocar melhorias foram realizadas pela A.N.A. (Warren \& Heermann, 1998). A primeira foi recomendar aos programas de bacharelado em enfermagem, o fornecimento do conhecimento básico sobre o processo de pesquisa aos alunos. A segunda foi estabelecer como padrão para a prática clínica, dentre outros, dois indicadores de performance profissional relacionados a questão: o enfermeiro utiliza os achados de pesquisa na sua prática e o enfermeiro avalia sistematicamente a qualidade e a efetividade da prática de enfermagem.

Esta ênfase na qualidade e necessidade de desenvolvimento de pesquisas com enfoque nos resultados, levou à criação de uma nova área de conhecimento na saúde e enfermagem a saber: "outcomes research" ou, pesquisa de avaliação dos resultados (Burns \& Grove, 1997; Reed et al, 1998).

Embora o enfoque das investigações seja o resultado da assistência nos serviços, observa-se uma ênfase para o uso de indicadores negativos como o ocorrência de eventos adversos.

No Brasil a questão da qualidade da assistência e a sua associação com a prática profissional do enfermeiro é abordada no Código de Ética dos profissionais de enfermagem, porém a questão pode ser mais profunda quando nos reportamos ao pequeno número de enfermeiros existentes no país, considerando a população nacional e à configuração do trabalho da 
enfermagem nas instituições onde a assistência é realizada na sua maior parte por auxiliares de enfermagem.

A questão do impacto da assistência de enfermagem na América Latina, com enfoque nos seus resultados é abordada por Holzemer (1994) que destacou a importância da avaliação do contexto onde esta prática está acontecendo, o que inclui as crenças, atitudes, valores, recursos materiais e humanos disponíveis e condições de saúde da população. Ressaltou ainda a necessidade de incluir na avaliação os padrões de comunicação entre os profissionais, assim como a forma de organização ou prestação da assistência. 
5 - A DIFUSÃO DO USO DOS RESULTADOS DA PESQUISA NA PRÁTICA DE ENFERMAGEM 


\section{5 - A difusão do uso dos resultados da pesquisa na prática de enfermagem}

O processo envolvido na utilização dos resultados de pesquisa na prática de enfermagem pode ser explicado pela teoria de Rogers (1983) conforme explicitado por Mendes (1989).

Os resultados de pesquisa são representados como uma inovação quando percebidos por enfermeiros que não o conheciam, mesmo que na verdade estes não sejam recentes.

Vários autores utilizam os pressupostos de Rogers do processo decisório quanto a adoção ou não de uma inovação para compreender ou explicar a difusão da pesquisa na prática de enfermagem (Brett, 1987; Mendes, 1989; Coyle \& Sokop, 1990; Landrun, 1998; Buss et al, 1999; Dooks, 2001). A teoria de Rogers preconiza que:

"A difusão de uma inovação é influenciada pela natureza da inovação e pela maneira como é comunicada aos membros de um sistema social" (Rogers, 1983).

Para o autor, as características da pessoa que está instituindo a mudança (agente de mudança), da própria inovação e o ambiente social onde as mudanças são introduzidas são antecedentes para a mudança ou a inovação ocorrer. 
O processo decisório envolve a consecução de cinco estágios, distribuídos no tempo que é variável para cada indivíduo: conhecimento, persuasão, decisão, implementação e confirmação.

O grau de adoção da inovação varia em diferentes sistemas sociais podendo ocorrer de forma mais rápida, ou mesmo não ocorrer, porém o sistema sempre sofre mudanças em decorrência do surgimento de uma inovação.

Este referencial tem sido utilizado por pesquisadores em enfermagem para identificação das barreiras que impedem ou dificultam a utilização da pesquisa pelos enfermeiros assim como dos elementos que facilitam o seu uso no sistema social.

Brett (1987) é citada como a autora da primeira publicação sobre o assunto com este enfoque, à partir do qual outros foram realizados.

Uma breve descrição de 14 resultados de pesquisa que tinham base suficiente para serem implementadas na área de enfermagem médico-cirúrgica na época e atendiam os critérios para utilização propostos no Projeto CURN, compuseram o instrumento de pesquisa desenvolvido pela autora. As respostas dos 216 sujeitos levou à identificação do estágio em que se encontravam no processo de adoção da inovação. A autora identificou que de $34 \%$ a $95 \%$ dos enfermeiros tinham conhecimento da maior parte das 14 inovações; $28 \%$ a $92 \%$ estavam no estágio de persuasão para utilizar a inovação; e que $6 \%$ a $79 \%$ estavam no estágio de implementação da inovação. Entretanto, uma análise da extensão de difusão de cada uma das inovações consideradas individualmente indicou que das 14 intervenções baseadas em pesquisa, somente duas 
estavam no estágio de conhecimento pela maioria dos sujeitos, sete no estágio de persuasão, cinco no estágio de implementação e somente uma no estágio de utilização / adoção.

Coyle \& Sokop em 1990 replicaram o estudo de Brett (1987) com 113 enfermeiros e incluíram também a investigação dos atributos dos enfermeiros e suas percepções sob as rotinas do hospital relacionadas às 14 intervenções de enfermagem. Nenhuma das práticas eram desconhecidas para toda a amostra de enfermeiras e a maioria conhecia 9 das 14 práticas. Quanto à persuasão para usá-las, 7 a $91 \%$ das enfermeiras acreditavam nas 14 práticas porém somente 8 eram reconhecidas como importantes por mais de $50 \%$ da amostra.

Duas características estavam associadas ao melhor escore de adoção da inovação: participação em conferência onde o resultado da pesquisa foi apresentado e leitura do periódico Heart \& Lung. Os enfermeiros que perceberam que havia uma rotina institucional relacionada à intervenção estudada, tiveram melhores escores na área de persuasão e uso de inovação.

Os resultados levaram as autoras a fazerem recomendações para que as instituições criassem mecanismos de incentivo para apoiar a implementação dos resultados da pesquisa na prática como programas educacionais, tempo para leitura e participação em "jounal clubs" para crítica e síntese de publicações, participação em comissões de pesquisa e de garantia de qualidade.

Destacaram também a responsabilidade pessoal dos enfermeiros com a sua formação sobre pesquisa, sua atualização constante e para a utilização na 
prática, destacando a natureza colaborativa dos esforços para provocar mudanças na prática e na profissão.

Funk, Tornquist \& Champagne (1995) também utilizaram a teoria de difusão de inovação de Rogers para embasar a construção de um instrumento de 28 itens, onde as barreiras identificadas na literatura e no Projeto CURN foram agrupadas em 4 áreas referentes às características da inovação, dos canais de comunicação e dos membros do sistema social. O fator tempo foi considerado uma dimensão que aparece em todas estas áreas.

O instrumento (Escala de Barreiras) foi utilizado em suas pesquisas nos Estados Unidos e em réplicas realizadas por autores em outros países. Os resultados obtidos pelos mesmos são apresentados no quadro 1. 
Quadro 1 - Classificação da barreiras para a utilização da pesquisa considerando o seu posto ou "ranking" (Percentagem de enfermeiros que citaram cada item como uma barreira grande ou moderada) segundo vários autores

\begin{tabular}{|c|c|c|c|c|c|c|}
\hline Barreiras & 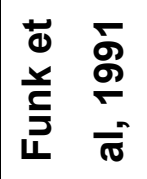 & 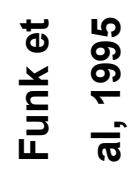 & 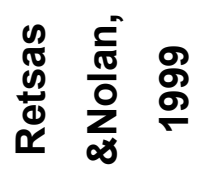 & 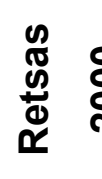 & 을 $\frac{0}{\frac{1}{\pi}}$ & O \\
\hline \multicolumn{7}{|l|}{$\begin{array}{l}\text { Características do enfermeiro: valores, habilidades e conhecimento } \\
\text { sobre pesquisa }\end{array}$} \\
\hline Falta de conhecimento sobre a pesquisa & 3 & 1 & 3 & 12 & & 11 \\
\hline Estar isolado de outros colegas com os quais poderia discutir a pesquisa & 11 & 6 & 12 & 7 & & 18 \\
\hline Não sentir-se capaz de avaliar a qualidade da pesquisa & 14 & 7 & 13 & 8 & & 6 \\
\hline Sentir que os benefícios de mudar a prática serão mínimos & 18 & 18 & 25 & 19 & & 19 \\
\hline Ver pouco benefício pessoal & 19 & 14 & 17 & 15 & & 22 \\
\hline Não estar disposto a mudar / tentar novas idéias & 21 & 19 & 22 & 16 & & 17 \\
\hline Não perceber a necessidade de mudança da prática & 24 & 22 & 28 & 28 & & 24 \\
\hline Não ver o valor da pesquisa para a prática & 25 & 16 & 27 & 25 & & 27 \\
\hline
\end{tabular}




\begin{tabular}{|c|c|c|c|c|c|}
\hline \multicolumn{6}{|l|}{ Características da organização: presença de barreiras e limitações } \\
\hline $\begin{array}{l}\text { Autoridade insuficiente para mudar os procedimentos da assistência ao } \\
\text { paciente }\end{array}$ & 1 & 4 & 7 & 2 & 1 \\
\hline Tempo insuficiente no trabalho para implementar novas idéias & 2 & 2 & 1 & 1 & 3 \\
\hline Médicos não cooperam com a implementação & 4 & 17 & 6 & 6 & 7 \\
\hline Administração não permite a implementação & 5 & 24 & 19 & 14 & 4 \\
\hline Outros funcionários não vão apoiar a implementação & 6 & 11 & 8 & 10 & 9 \\
\hline Os resultados da pesquisa não são generalizáveis para a instituição & 7 & 5 & 9 & 9 & 5 \\
\hline Condições inadequadas para implementação & 8 & 13 & 5 & 3 & 8 \\
\hline Tempo insuficiente para ler as pesquisas & 10 & 8 & 2 & 5 & 12 \\
\hline \multicolumn{6}{|l|}{ Características da inovação: qualidade da pesquisa } \\
\hline A pesquisa ainda não foi aplicada & 15 & 20 & 18 & 23 & 16 \\
\hline Incerteza sobre a credibilidade dos resultados da pesquisa & 20 & 23 & 23 & 22 & 20 \\
\hline Literatura reporta resultados conflitantes & 22 & 26 & 26 & 24 & 21 \\
\hline Inadequações metodológicas da pesquisa & 23 & 27 & 24 & 26 & 23 \\
\hline
\end{tabular}




\begin{tabular}{|c|c|c|c|c|c|}
\hline $\begin{array}{l}\text { Os artigos relatados nas pesquisas não são publicados tão rápido quanto } \\
\text { necessário }\end{array}$ & 26 & 25 & 11 & & 25 \\
\hline As conclusões retiradas da pesquisa não são justificadas & 27 & 28 & 29 & 29 & 28 \\
\hline \multicolumn{6}{|l|}{$\begin{array}{l}\text { Características da comunicação: apresentação e acessibilidade da } \\
\text { pesquisa }\end{array}$} \\
\hline As análises estatísticas não são compreensíveis & 9 & 3 & 4 & 4 & 2 \\
\hline A literatura relevante não é compilada em um só lugar & 12 & 10 & 20 & 18 & 10 \\
\hline As implicações para a prática não são apresentadas de forma clara & 13 & 9 & 10 & 11 & 13 \\
\hline Os artigos / relatos de pesquisa não estão prontamente disponíveis & - & 15 & 21 & 27 & 15 \\
\hline A pesquisa não é reportada de forma clara e compreensível & 16 & 12 & 15 & 17 & 14 \\
\hline A pesquisa não é relevante para a prática de enfermagem & 17 & 21 & 16 & 20 & 26 \\
\hline
\end{tabular}

Funk et al., 1991 - Estados Unidos da América - enfermeiros

Funk et.al., 1995 - Estados Unidos da América - enfermeiros /administradores

Retsas \& Nolan, 1999 - Austrália - enfermeiros

Retsas, 2000 - Austrália - enfermeiro

Parahoo, 2000 - Irlanda do Norte - enfermeiros 
No primeiro estudo realizado por Funk et al. (1991), com 924 enfermeiras americanas da área clínica, as principais barreiras identificadas foram referentes às características da organização ( sistema social).

Barreiras relacionadas à falta do conhecimento do enfermeiro sobre os resultados de pesquisa, assim como o senso de isolamento de colegas com conhecimento sobre o assunto com os quais poderiam discutir a pesquisa também foram identificadas como importantes. Fatores referentes a forma de apresentação e divulgação da pesquisa também foram ressaltados como barreiras.

A percepção destas barreiras para enfermeiros em cargos administrativos nas instituições foi objeto de outro estudo (Funk et al., 1995). A falta de conhecimento sobre os resultados da pesquisa ocupou o primeiro lugar na lista de barreiras, seguido da falta de tempo para implementar novas idéias no trabalho. A compreensão das análises estatísticas apresentadas nos estudos foi a terceira barreira mais importante, seguida da percepção da falta de autoridade para mudar os procedimentos com os pacientes. As autoras destacaram que outras pesquisas realizadas nos Estados Unidos indicaram o mesmo resultado, apontando para a necessidade de adoção de medidas em todos os aspectos do sistema social e da comunicação da inovação enfocados por Rogers (1983).

No estudo de Retsas \& Nolan (1999), na Austrália, o tempo insuficiente no trabalho para implementar novas idéias e para ler pesquisas foram as principais barreiras identificadas por 149 enfermeiros de um hospital, seguido 
da falta de conhecimento sobre a pesquisa. As outras barreiras prioritárias foram referentes a análise estatística e outras características da organização.

Retsas (2000) em outro estudo de réplica com 400 enfermeiros na Austrália identificou que das seis barreiras principais, cinco estavam relacionadas a fatores institucionais, sendo que, como nos estudos anteriores, a compreensão das análises estatísticas também foi vista como uma barreira importante para a utilização dos resultados. O autor destaca a importância desta compreensão para que estratégias sejam dirigidas para ação dentro da organização institucional e na profissão como um todo.

O estudo de Parahoo (2000), desenvolvido na Irlanda do Norte com 1368 enfermeiras identificou que das dez principais barreiras identificadas, sete eram relacionadas à instituição, uma relacionada à capacidade do enfermeiro em avaliar os resultados da pesquisa e duas quanto à forma de apresentação dos resultados que tornavam difícil a sua compreensão e o acesso.

Estas barreiras identificadas na atualidade são muito semelhantes àquelas identificadas na década de 80 no Brasil e no Reino Unido e talvez muito mais importantes agora quando o número de periódicos e publicações cresceram de forma exponencial, exigindo do profissional a utilização de novos conhecimentos de informática e da língua inglesa, se quiser manter-se atualizado sobre o conhecimento disponível para ser avaliado para utilização na prática.

Estas mudanças na complexidade das inovações das últimas décadas, não passaram despercebidas pelos enfermeiros pesquisadoras e da prática 
assistencial e são evidenciadas nas estratégias utilizadas ou propostas como maneiras para sobrepor as barreiras para utilização do conhecimento na prática, nas publicações analisadas.

As estratégias que identificamos, relatadas na literatura internacional como facilitadores da utilização da pesquisa foram agrupadas considerando as características da organização, da profissão, dos enfermeiros, da inovação (qualidade da pesquisa) e da comunicação, conforme apresentação anterior de Titler (1997).

\section{Estratégias para diminuir as barreiras relacionadas a qualidade da pesquisa $^{1}$}

- Enfatizar a importância e valor de estudos de réplica.

- Realizar revisão integrativa, sistemática e meta-análise para sintetizar os resultados de pesquisa.

- Estabelecimento de Centros Colaboradores de Pesquisa com alunos de Pós-Graduação, Graduação e Enfermeiras da prática, liderados por pesquisadores experientes para produzir dados válidos e confiáveis que poderão ser aplicados na prática.

\footnotetext{
${ }^{1}$ Hunt 2001, Stetler et al.; 1998 b; Droogan \& Cullum, 1998; Holmes, 1995; Cronin, 1998; Titler \& Mendes, 1999; Renshaw et al.; 1999.
} 
- Criar condições para que os Centros de Pesquisa tenham suporte administrativo e para escrever projetos para solicitar financiamento (garantir tempo, pessoas e recursos financeiros).

\section{Estratégias para diminuir barreiras relacionadas a comunicação dos resultados de pesquisa ${ }^{2}$}

- Criação e manutenção de periódicos que enfatizam a utilização da pesquisa e outras fontes de evidências.

- Financiamento de conferências sobre a utilização da Pesquisa e Prática Baseadas em evidência.

- Publicação de Resumos de Pesquisa em Informativos / Boletins.

- Divulgação de sites na internet para levantamento bibliográfico, diretrizes para a prática clínica, meta-análise e revisões integrativas.

- Uso da internet para divulgação de protocolos baseados em pesquisa / evidências.

- Desenvolvimento de Centros de Produção e Disseminação de Protocolos para a prática baseados em pesquisa / evidências.

- Uso de discussões online com fórum de especialistas.

\footnotetext{
2 Bueno, 1998; Beyea, 2000; Humphris, 1994; Junkin, 2000; Soukoup, 2000; Titler \& Mendes, 1999; Youngblut \& Brooten, 2000; Hinrichs \& Huseboe, 2001; Young, 1999; Charles, 2000; Hunt, 2001; Beel et.al., 1994; Maljanian et. al, 2002; Conn et al.; 2002
} 
- Uso de vídeo tape para demonstrar Protocolos Baseados em Pesquisa / Evidências.

- Desenvolvimento de séries de Mesas Redondas nas instituições sobre utilização da Pesquisa em colaboração com a Universidade.

\section{Estratégias para diminuir barreiras relacionadas ao conhecimento e habilidades das enfermeiras ${ }^{3}$}

- Integrar os conhecimentos e habilidades necessárias para o processo de utilização da pesquisa e Prática Baseada em Evidências (PBE) na graduação, pós-graduação e educação continuada.

- Requerer realização ou participação em Projetos de Utilização da Pesquisa e PBE como parte do programa educacional de graduação e pós-graduação.

- Desenvolvimento e uso de recursos auxiliares baseados em resultados de pesquisa ou PBE como periódicos, livros, material na Internet, journal club.

- Desenvolvimento de habilidade para uso de tecnologia eletrônica (sistemas de busca, e-mail).

- Ensino e uso de critérios de avaliação de sites da Internet.

- Cursos de residência e mestrado com enfoque na utilização da pesquisa.

\footnotetext{
${ }^{3}$ Cannon; Boswell, 2001; Klassen, Karshmer \& Lile, 2002; Rambur, 1999; Barnsteiner, 1996; Pearcy, 1995; Holland, 2001; Warren \& Herrmann, 1998; Mac Guire, 1990; Dufault \& Sullivan, 1999; Crane, 1995; Hunt, 2001; Moch \& Goldsmith, 2000; Cavanagh \& Tross, 1996; Lekander et al., 1994; Schmitt, 1999; Prevost, 1996.
} 
- Cursos à distância pela Internet sobre desenvolvimento e utilização da pesquisa.

- Desenvolvimento de manual para ensino de procedimentos de enfermagem, baseados em pesquisa.

- Implementar currículo educacional com enfoque no questionamento das bases disponíveis para a prática.

- Uso de revistas eletrônicas especializadas em revisões integrativas.

\section{Estratégias para diminuir as barreiras relacionadas a atitudes das enfermeiras $^{4}$}

- Demonstrar por meio de Programas de Controle de Qualidade como a utilização da pesquisa ou PBE pode mudar os resultados da prática clínica.

- Criar / utilizar livros-textos para ensinar intervenções / procedimentos com as evidências que a embasam.

- Favorecer a aproximação de enfermeiras clínicas dos pesquisadores para que ambos valorizem um ao outro.

- Realizar pesquisas relevantes para a prática de enfermagem.

\footnotetext{
${ }^{4}$ Akinsanya, 1994; Hunt, 2001; Klassen et al.; 2002.
} 


\section{Estratégias para diminuir barreiras dentro da profissão ( competência das} associações de classe e associações especialistas) ${ }^{5}$

- Incentivo para desenvolvimento e implementação de Modelos Colaborativos de Utilização de Pesquisa.

- Financiamento de Projetos de Utilização de Pesquisa.

- Realização de Conferências, Reuniões Científicas.

- Desenvolvimento de Padrões de Excelência para Prática Profissional.

- Publicação de Periódicos específicos para divulgação de resultados de Projetos de Utilização.

- Identificar áreas prioritárias para projetos de utilização.

- Planejamento e desenvolvimento de Programas Colaborativos ao invés de Projetos Individuais.

- Criação de Centro de Investigação Clínica dentro de Associações de Especialistas.

- Promoção da Integração da Academia e Prática Clínica pela valorização da atividade clínica do Docente.

- Criação e manutenção de Banco de Dados sobre Pesquisadores e Especialistas Clínicos.

\footnotetext{
${ }^{5}$ Floyd, Falahee, Fhobir, 2000; Gray, 1999; Caramanica, 2000; Crane, 1995; Hunt, 2001; Tranmer et al.; 1995.
} 
- Criar e manter Fórum de discussão online sobre questões da prática clínica.

\section{Estratégias para diminuir as barreiras institucionais para utilização da}

$$
\text { pesquisa }^{6}
$$

- Valorização da Pesquisa como atividade esperada do enfermeiro refletida no plano de ascensão na carreira / promoção.

- Alocar recursos humanos e financeiros para projetos de investigação da pesquisa.

- Investir na qualificação dos enfermeiros.

- Desenvolver equipes / comissões para projetos de Utilização da Pesquisa.

- Ter enfermeira com domínio dos métodos de pesquisa e utilização para coordenar atividades e servir como modelo.

- Ter comitê de Controle de Qualidade integrado com comitê de Utilização de Pesquisa.

- Fazer parcerias com Universidades para atividades colaborativas.

- Utilizar recursos tecnológicos para difusão de conhecimento dentro da instituição.

- Ter biblioteca com periódicos ou livros ou convênio com bibliotecas universitárias.

\footnotetext{
${ }^{6}$ Stonestreet \& Lamb-Harvard, 1994; Crane, 1995, Horsley, 1983, Van Mullen et al, 1999 e 2001;Hunt, 2001; Omery \& Willians, 1999; Titler et al, 1997; Moch \& Goldsmith, 2000; Camiah 1997; Prevost, 1996; Junkin, 2000; Lekader et al 1994; Barnsteiner, 1996; Charles, 2000; Funk et al, 1995; Cronenwett, 1995; Van Mullen et al.; 2001.
} 
- Ter espaço físico para exposição / divulgação de projetos de Utilização de Pesquisa e Prática Baseada em Evidências.

- Contratar especialistas como consultores para educação continuada e síntese da pesquisa.

Com base na análise das publicações, visualiza-se que para a utilização dos resultados da pesquisa na prática há necessidade do estabelecimento de um ambiente onde os enfermeiros sintam que podem questionar e avaliar a prática atual e sejam estimulados e apoiados na busca de soluções baseadas em pesquisa e a testá-las de forma apropriada.

Percebemos também a necessidade do estabelecimento de uma "comunidade de enfermeiros" que inclui tanto pesquisadores experientes como alunos de pós-graduação, graduação e enfermeiros com título de doutor, mestre, especialistas e assistenciais além de gerentes, unidos com propósito comum de se desenvolverem, conduzir, utilizar e disseminar as pesquisas visando a melhoria da qualidade da assistência.

A análise da literatura nacional permitiu identificarmos que aqui no Brasil, as publicações abordam a questão das barreiras presentes para a produção de conhecimento pelo enfermeiro assistencial, e nas estratégias que podem facilitar a condução de pesquisas na prática clínica. 
A utilização da pesquisa na forma instrumental é vista como essencial e importante porém segundo os autores ainda não ocorre em consequência de inúmeras barreiras provenientes tanto das características sociais do sistema institucional, como do sistema educacional, além das características do próprio enfermeiro e da pesquisa disponível.

As barreiras e estratégias para sobrepô-las são apresentados à seguir na forma de recortes das citações dos autores que foram agrupadas por áreas .

\section{A) Produção de Pesquisa:}

\section{Barreiras profissionais para produção da pesquisa ${ }^{7}$}

- As prioridade da Universidade e dos Serviços são diferentes assim as pesquisas não atendem as necessidades dos serviços nem da população.

- Os financiamentos para pesquisa são alocados para pesquisadores e Programas de Pós-Graduação das Universidades.

- Expectativa histórica da produção da pesquisa estar centrada na Universidade (Modelo Acadêmico de Produção), não existe ainda uma cultura de pesquisa fora da Pós-Graduação.

- Distanciamento de docentes e enfermeiros assistenciais.

- Enfermagem é uma Ciência jovem no Brasil.

\footnotetext{
${ }^{7}$ Angerami, 1993 b; Koizumi, 1997; Leite et al, 2001; Haddad \& Guariente, 2000, Cassiani \& Passarelli, 1999; Castilho, 2000; Lopes, 1989, Almeida, 1985; Lopes, 1990.
} 
- A produção de pesquisa se iniciou na Pós-Graduação na década de 70. É preciso ter maior número de pesquisadores para aumentar o número de Pesquisa que ainda se concentram em maior número na região sudeste.

- Existem poucos resultados de pesquisa clínica no Brasil, a maior parte dos estudos utilizados na prática clínica são da literatura internacional.

- Enfermeiros têm relutância em ler, analisar, criticar artigos e aplicar os resultados da pesquisa.

- Não ver a pesquisa como um instrumento que pode auxiliar na validação de práticas já consagradas, qualificando o seu uso como de transformação crítica do presente, pela possibilidade de apontar as mudanças necessárias

- Pesquisa é vista como necessidade acadêmica apenas para o avanço na carreira.

- Profissional é formado para cumprimento de normas e rotinas institucionais.

\section{Estratégias propostas para melhorar a produção 8}

- Desenvolvimento de réplica de pesquisas para poder construir evidências

- Curso de metodologia científica para enfermeiros e docentes

- Criação de Núcleos / Grupos de Pesquisa com participação de docentes, alunos e enfermeiros assistenciais.

\footnotetext{
${ }^{8}$ Rocha \& Boemer, 1992; Castilho, 1994; Garcia et al.; 1995; Arruda \& Silva, 1998, Trevisan \& Mendes, 1991; Mendes \& Trevisan, 2000.
} 
- Promover melhor articulação Universidades - Hospitais.

- Orientação de enfermeiros por docentes para desenvolver pesquisas e redigir trabalhos.

- Ver a pesquisa como ferramenta de desenvolvimento do profissional na "era do conhecimento".

- Trazer professores visitantes com bons currículos e boa produção em pesquisa para implementar linhas de investigação.

- Promover a demanda de enfermeiros pesquisadores para pós-graduação no exterior.

- Organização das lideranças da enfermagem em torno de uma diretriz política que permita confluências da pesquisa, engajando-as aos grandes projetos para produzir um conhecimento contextualizado.

- Desenvolver estudos sobre condições e estratégias que favoreçam o envolvimento do enfermeiro em pesquisa.

- Desenvolvimento de Projetos Integrados de Pesquisa.

- Implantar e desenvolver Programas de Iniciação Científica para graduandos.

B) Divulgação da Pesquisa

Barreiras para divulgação dos resultados das pesquisas ${ }^{9}$

\footnotetext{
${ }^{9}$ Koizumi, 1997; Rocha \& Boemer, 1992.
} 
- Artigos publicados em inglês, e os enfermeiros não os compreendem.

- A maior parte das teses / dissertações não se transformaram em artigos científicos.

- A área de enfermagem possui alguns periódicos nacionais que publicam trabalhos muito bons, ao lado de outros, de menor qualidade.

C) Características do Sistema Social

\section{Estratégias propostas para melhorar a divulgação ${ }^{10}$}

- Divulgar pesquisas nas instituições onde foram realizadas - apresentação oral e pôster.

- Docentes devem utilizar palavras mais simples ao falarem sobre pesquisa e orientarem os alunos e enfermeiros.

- Ter periódicos de ampla divulgação com conselho editorial rigoroso.

- Publicar resultados em Boletins Informativos, Revistas da Instituição e Semanas de Enfermagem.

\footnotetext{
${ }^{10}$ Cassiani\& Passarelli,1999; Fernandes \& Silva, 1995.
} 


\section{Barreiras relacionadas ao conhecimento, atitudes e habilidades do enfermeiro $^{11}$}

- Falta de conhecimento sobre metodologia científica / falta de preparo para a pesquisa.

- Dificuldade de acesso à biblioteca.

- Falta de tempo para atividades de pesquisa.

- Falta de interesse pela pesquisa.

- Falta de enfermeiros motivados.

- O aluno de graduação não tem formação em metodologia de pesquisa.

- Os enfermeiros acreditam que redigir um trabalho científico é um processo complexo.

- Os enfermeiros não compreendem os livros de metodologia de pesquisa.

- Os enfermeiros desconhecem as condições ideais para a realização da pesquisa em seu cotidiano.

- Os enfermeiros não estão capacitados para avaliar a aplicabilidade da pesquisa.

- A maioria das pesquisas são publicadas em inglês ou outra língua estrangeira.

- A maioria das pesquisas foram feitas em outros países e é difícil implementá-las em nosso meio.

\footnotetext{
${ }^{11}$ Lopes, 1990; Cassiani \& Passarelli, 1999; Cassiani et al, 1998; Castilho, 2000; Koizumi, 1997,
} 
- Docentes preferem usar livros ao invés de publicações científicas mais atuais.

- Carência de estudos nacionais sobre cuidado e conforto essenciais para a prática clínica.

- O enfermeiro de instituição hospitalar não incorporou a visão de si mesmo como pesquisador.

- A pesquisa não é introjetada como parte constante, específica e inserida no rol das atividades profissionais do enfermeiro.

- Os enfermeiros são formados para reproduzir o modelo funcionalista.

\section{Estratégias para melhorar o conhecimento / habilidades dos enfermeiros $^{12}$}

- Solicitar colaboração da Universidade para cursos de metodologia científica para enfermeiros.

- Desenvolvimento de projetos de pesquisa com temáticas relacionadas as necessidades dos enfermeiros assistenciais.

- Ter acervo de livros e periódicos nas instituições para serem utilizados pelos enfermeiros.

- Estimular enfermeiros a participarem de Núcleos de Pesquisas Universidade - Hospitais. 
- Desenvolver no enfermeiro o compromisso com o desenvolvimento, aplicação e divulgação da pesquisa.

- Alocar recursos para que os profissionais dominem as situações, a tecnologia e os saberes do seu tempo e seu ambiente que possibilite o pensar e a busca de soluções criativas para os problemas.

- Envolver o aluno como consumidor da pesquisa desde a graduação.

- Educar o aluno para desenvolver pesquisa.

- Estimular enfermeiros para fazerem Pós-Graduação e investigar questões da prática clínica.

\section{Barreiras institucionais (serviços de saúde) ${ }^{13}$}

- Falta de incentivo da instituição empregadora.

- Falta de apoio para digitação de trabalhos.

- Inexistência de acompanhamento científico para a realização de pesquisa

- O hospital não sente necessidade ou tem interesse que o enfermeiro faça trabalhos científicos.

- As organizações são espaços altamente burocratizados onde há pouco espaço para profissionais inquiridores e críticos.

\footnotetext{
${ }^{12}$ Cassiani et al, 1998; Castilho, 2000; Koizumi, 1997; Lopes, 1989; Trevisan, Mendes, Angerami, 1991; Echer et al 1998.

${ }^{13}$ Castilho, 2000; Lopes, 1989, Lopes, 1990; Garcia et al.; 1995; Fernandes \& Silva, 1995;
} 
- Não há nas organizações uma política definida que proporcione a realização da pesquisa.

- Os administradores não valorizam o desenvolvimento da pesquisa porque não percebem esta atividade como essencial para a instituição.

- O conservadorismo e autoritarismo característico da profissão agem como barreiras para utilização do "novo" . O direcionamento é para o cumprimento de normas e rotinas.

\section{Estratégias para diminuir as barreiras institucionais (universidade e serviços de saúde) ${ }^{14}$}

- Realização de parcerias e convênios com instituições internacionais como ação de Centro Colaborador da OMS para desenvolvimento da Pesquisa.

- Criar Núcleos e linhas de pesquisa relacionadas à prática clínica nos Programas de Pós-Graduação e nos Departamentos de Enfermagem das Universidades.

- Criação de Núcleos de Pesquisas em Enfermagem dentro da Divisão de Enfermagem em Hospitais Universitários com colaboração de docentes da Universidades.

- Convidar enfermeiro docente da Universidade para organizar e iniciar atividades de Núcleo de Pesquisa dentro do Hospital Universitário. 
- Inserir no processo de trabalho do enfermeiro o exercício da ação / reflexão / ação por meio da utilização da metodologia científica.

- Oferecer apoio científico, financeiro administrativo e publicação de trabalhos científicos.

- Os trabalhos científicos realizados por enfermeiras do Núcleo de Pesquisa da Instituição de Saúde devem partir da realidade prática para promover a reflexão sobre a prática por meio das etapas do método científico e retornar a ela transformando-a.

- Promoção de Encontros Científicos, Palestras e Cursos sobre Metodologia da Pesquisa na Instituição de Saúde, com convites a Especialistas externos

- Auxílio aos enfermeiros pesquisadores para obtenção de recursos externos para financiamento da pesquisa.

- Facilitar as condições para os enfermeiros cursarem a pós-graduação (estímulos verbais, folgas nas escalas, escolha de horário).

- Os Programas / Serviços de Educação continuada devem incorporar os programas de desenvolvimento do enfermeiro na pesquisa / assumir responsabilidade de instrumentalizá-lo para isto.

- Liberar enfermeiros para cursarem pós-graduação e re-incorporar o profissional posteriormente, valorizando o conhecimento e promovendo-o a "agente de mudança".

\footnotetext{
${ }^{14}$ Porto, 2001; Trentini \& Paim, 2001, Haddad \& Guariente, 2000; Cassiani \& Passarelli, 1999; Boemer et al, 1990; Castilho, 2000; Lopes, 1989; Echer et al,1998; Fernandes \& Silva, 1995.
} 
- Demonstrar que o conhecimento vindo da pesquisa pode gerar melhores resultados em termos de produtividade, qualidade e soluções inovadoras.

- A adoção da pesquisa como ferramenta de desenvolvimento de pessoal necessita ter primeiro a anuência da administração, definição de políticas para captar recursos, proposição de programas de capacitação para enfermeiros, criação de clima propício para a sua realização.

- Dar afastamento para os enfermeiros para participar de cursos e encontros.

- Solicitar das Universidades oferecimento de Cursos de Extensão Universitária para formação de enfermeiros para desenvolvimento e difusão da pesquisa.

- Criação de Comitê de Pesquisa Operacional em Enfermagem para orientar e oferecer apoio técnico e logístico aos enfermeiros de Hospitais Universitários para desenvolvimento de trabalhos científicos.

- Ter enfermeiro - doutor com dedicação integral e exclusiva para o Comitê de Pesquisa na Divisão de Enfermagem.

- Reorganização das atividades do enfermeiro com exclusão daquelas de caráter rotineiro e burocrático e passíveis de realização por outros elementos da equipe sem comprometimento da qualidade assistencial.

- Formação de grupos de discussão e reflexão para sensibilizar os profissionais para a mudança de paradigma do papel do enfermeiro assistencial e incorporar a investigação como componente indispensável e fundamental da prática. 
- Ter biblioteca e tempo programado para levantamento bibliográfico e formação de acervo com assunto de interesse da Unidade de trabalho.

A identificação das barreiras para o desenvolvimento da pesquisa e a identificação das estratégias para sobrepô-las na literatura nacional, demonstra que há uma preocupação profissional com a questão, e que a Universidade e os docentes/pesquisadores tem ainda um longo caminho para percorrer na formação de massa critica para realizar as mudanças na prática.

Entretanto, a análise da literatura internacional indica também que este caminho deve ser compartilhado com os enfermeiros assistenciais e gerentes institucionais e que a parceria trará contribuições e crescimento para ambas as partes, e para a profissão como um todo, na diminuição do vácuo existente.

A análise da literatura permitiu identificar também que tanto as barreiras como as condições facilitadoras propostas pelos autores nacionais e internacionais para a produção e utilização da pesquisa são muito semelhantes, independente do país onde o estudo foi conduzido.

Estas semelhanças são decorrentes históricas da natureza do trabalho do enfermeiro na prática clínica e das características das instituições de ensino e assistência onde as práticas eram e são muitas vezes baseadas em rituais, tradições e na submissão à autoridade onde o questionamento ao poder instituído não era comum e nem bem vindo.

Entretanto, este saber institucionalizado tem cada vez mais sido substituído pelo saber do conhecimento advindo da pesquisa. Isto muitas vezes 
provoca a desestabilização nas relações tanto entre os próprios pares, como entre os outros profissionais da equipe de saúde.

$\mathrm{Na}$ era do conhecimento e de restrições econômicas que vivemos, tanto as instituições como os profissionais enfrentam desafios especiais decorrentes dos riscos em potencial que são associados com o uso de práticas inadequadamente testadas ou obsoletas.

Para enfrentar estes desafios precisamos estar abertos para as mudanças e inovações e encontrar maneiras para acelerar a identificação, divulgação e adoção das melhores práticas existentes.

À título de contribuição para diminuição das barreiras referentes ao conhecimento dos resultados de pesquisa, destacamos das publicações analisadas, fontes de evidências para a prática do enfermeiro, produzidas pelos autores revisados, na forma de Protocolos de intervenção (quadro 2) e fontes com acesso online (quadro 3).

Observamos, pela análise da literatura que certos problemas clínicos são considerados de enfoque prioritário nas instituições hospitalares para que as intervenções utilizem os resultados de pesquisa visando a eficácia das medidas preventivas e terapêuticas.

Um destes problemas é a úlcera de pressão. Fernandes (2000) identificou que a úlcera é considerada um problema sério pela sua elevada prevalência, sua associação com elevada morbilidade e mortalidade ou pelos elevados custos e sofrimento físico e emocional que representam. 
Assim, torna-se necessário a produção de pesquisas e o desenvolvimento e utilização de novas estratégias para que este conhecimento seja utilizado em forma de intervenções de enfermagem e produzam impacto na vida dos pacientes e nos serviços, assunto que abordamos à seguir.

\section{QUADRO 2 - PROTOCOLOS DE INTERVENÇÃO}

\begin{tabular}{|l|l|}
\hline \multicolumn{1}{|c|}{ Protocolos de Intervenção baseado em } & \multicolumn{1}{|c|}{ Referência } \\
\hline Controle de dor em pacientes de CTI & Titler et al, 1994 \\
\hline Contínua & Leske et al, 1994 \\
\hline Aspiração endo-traqueal & \\
\hline Passagem de Sonda NG e Sonda NE para & Rakel et al, 1994 \\
alimentação do pacientes & \\
\hline Administração de injeção intramuscular & Beecroft \& Kongelbeck, 1994 \\
\hline Administração de insulina sub-cutânea & Nicoll \& Beyea, 1996 \\
\hline Precauções de alergias por latex & Steelman, 1995 \\
\hline Curativo de cateter venoso periférico & Pettit ; Kraus, 1995 \\
\hline Identificação de Pacientes em Risco para & Mc Collam, 1995 \\
Quedas & \\
\hline Implementação das Diretrizes para controle & Bach, 1995 \\
\hline
\end{tabular}




\begin{tabular}{|l|l|}
\hline da dor no pós-operatório & \\
\hline Terapia Assistida por Animais em UTI & Cole \& Gawlinski, 1995 \\
\hline Avaliação do Risco de Úlcera de pressão & Bergstrom et al, 1995 \\
\hline Tratamento de úlcera de pressão em idosos & Specht et al, 1995 \\
\hline Redução de contenções em pacientes de & Cruz et al, 1997 \\
\hline Cuidados com cateter venoso central & Larsen \& Thurston, 1997 \\
\hline Controle de dor aguda & Young, 1999 \\
\hline Tratamento de constipação intestinal & Hinrichs \& Husenboe, 2001 \\
\hline Prevenção e tratamento de úlcera de & Logan et al, 1999 \\
pressão & \\
\hline
\end{tabular}




\section{QUADRO 3 - FONTES DE EVIDÊNCIA ONLINE (Diretrizes, revisões integrativas, revisões sistemáticas, protocolos)*}

\begin{tabular}{|c|c|}
\hline $\begin{array}{l}\text { - Agency for Health Care Research and } \\
\text { Quality }\end{array}$ & http://www.ahrq.gov \\
\hline - National Guideline Clearing house - EUA & http://www.guidelines.gov \\
\hline $\begin{array}{l}\text { - GNIRC Research Dissemination Core - } \\
\text { University of lowa College of Nursing - } \\
\text { EUA }\end{array}$ & $\begin{array}{l}\text { http://www.nursing.uiowa.edu/centers/g } \\
\text { nirc/protocols.htm }\end{array}$ \\
\hline $\begin{array}{l}\text { - Centre for Evidence based Nursing - } \\
\text { Reino Unido }\end{array}$ & $\begin{array}{l}\text { http://www1.york.ac.uk/healthsciences/c } \\
\text { entres/evidence/updindex.htm }\end{array}$ \\
\hline $\begin{array}{l}\text { - Joanna Briggs Intitute for Evidence } \\
\text { Based Nursing - Austrália }\end{array}$ & http://www.joannabriggs.edu.au \\
\hline - Cochrane Collaboration & http://www.cochrane.org \\
\hline $\begin{array}{l}\text { - NHS Centre for Reviews and } \\
\text { Dissemination - Reino Unido }\end{array}$ & http://www1.york.ac.uk/inst/crd.htm \\
\hline - Brazilian Cochrane Center ${ }^{* *}$ & http://www.unifesp.br/suplem/cochrane \\
\hline
\end{tabular}

\footnotetext{
* Os endereços (URL) foram confirmados em 08/10/2002

** Faz parte do Cochrane Collaboration
} 
6 - A DIVULGAÇÃO DO CONHECIMENTO SOBRE ÚLCERA DE PRESSÃO UTILIZANDO A INTERNET 


\section{6 - A divulgação do conhecimento sobre úlcera de pressão utilizando a internet}

\section{1 - O conhecimento sobre úlcera de pressão}

O conhecimento sobre a prevenção e tratamento da úlcera de pressão é considerado básico para o profissional de enfermagem sendo o seu ensino fundamental logo no início da formação do enfermeiro. É uma área que conta com grande número de publicações que recomendam as mais diferentes intervenções. Entretanto, muitas destas não tem qualquer fundamentação de pesquisa sendo baseadas em mitos, tradições e rituais (Polet \& Caliri, 2001; Rabeh, 2001).

O assunto tornou-se uma preocupação social e política nos Estados Unidos no final da década de 80 pelo ônus que isto causava aos cofres públicos e consumidores em geral. Os profissionais de saúde envolvidos com a questão, entre eles enfermeiros da área clínica e pesquisadores, formaram uma comissão nacional para investigar as bases científicas existentes na época para estabelecer recomendações para a prática, ensino e pesquisa, e pressionar o governo para fazer mudanças nos serviços e formas de pagamento, visando à redução da incidência da úlcera em 50\% até o ano de 2000 (NPUAP, 2001). 
Na avaliação após 10 anos, o grupo observou que avanços positivos foram obtidos no período como a publicação das duas Diretrizes para a Prática Clínica para a Prevenção e Tratamento da Úlcera de Pressão pela AHRQ, a padronização da avaliação de risco e melhorias nas tecnologias para prevenção e tratamento (NPUAP, 2001).

O desafio estabelecido para a década atual é a incorporação de novas pesquisas nas diretrizes já existentes e a sua utilização na prática para melhorar a qualidade do cuidado e a segurança do paciente (NPUAP, 2001).

No Brasil, Rabeh (2001) identificou que nas décadas de 70 e 80 as publicações sobre o assunto foram escassas, com enfoque para relatos de experiência. Já na década de 90 foi observado um aumento das publicações, sendo a sua maioria pesquisa descritiva, conduzida como dissertação de mestrado.

Esta escassez de publicações nacionais sobre o assunto reflete a situação já discutida anteriormente, onde a maior parte da pesquisa em enfermagem no Brasil ainda é conduzida nas universidades como requisito acadêmico e muitas vezes desvinculadas das necessidades dos serviços e da população.

Entretanto, esta situação não é muito diferente em outros países e em diversas situações as Diretrizes da AHRQ tem sido adaptadas com inclusão dos estudos próprios de cada região.

Um painel de profissionais europeus, o "European Pressure Ulcer Advisory Panel (EPUAP)" desenvolveu as diretrizes para prevenção e 
tratamento da úlcera de pressão para nortear a ação das equipes multiprofissionais naqueles países disponíveis em inglês a francês (Teot et al, 2001).

Também na Austrália, as diretrizes desenvolvidas pela Associação Australiana de Tratamento de Feridas tem orientado as instituições sobre as evidências disponíveis para a prática clínica, oriundas de publicações internacionais e de autores daquele país (Carville \& Stacey, 2001).

No Brasil desde 1996, utilizamos as diretrizes norte-americanas sobre úlcera de pressão no ensino da graduação na Escola de Enfermagem de Ribeirão Preto e cursos de extensão para enfermeiros e profissionais de saúde.

Observamos entretanto, uma grande procura por parte de enfermeiros e outros profissionais de saúde, de maiores informações sobre assunto, e percebemos que havia uma falta de informações básicas, necessárias para a prática profissional.

Esta observação, aliada à nossa percepção do papel do docente e pesquisador na translação dos resultados da pesquisa e outras evidências para a prática, nos levaram a planejar a construção de um site na Internet para facilitar este processo de disseminação do conhecimento e diminuir as barreiras de acesso ao conhecimento.

Nossa percepção é corroborada por Hinshaw (2000) que afirmou que o maior desafio da enfermagem para o século 21 é o desenvolvimento de modelos e estratégias para translação da base de conhecimento existente para a prática de enfermagem e utilizar isto para o desenvolvimento das políticas de 
saúde. Para a autora, este desafio implica em construir e implementar estratégias para que estas informações cheguem até os enfermeiros para que, criticamente, possam incorporá-las e utilizá-las no processo de decisão quanto às intervenções mais adequadas para a obtenção de melhores resultados para os clientes.

A decisão pela construção do site de Internet baseou-se na análise das diferentes formas que este recurso pode ser utilizado e nos pressupostos das teorias de Rogers e Havelock utilizadas pelos enfermeiros pesquisadores como embasamento dos modelos de utilização de pesquisa ou de outras evidências na prática clínica (Loomis, 1985; Horsley, 1983; Coyle \& Sokop, 1990; Buss et al. 1997; Dooks, 2001).

\section{2 - A Internet como meio para divulgação de informação}

As mudanças sociais ocasionadas pelo surgimento da Internet foram comparada com o processo de difusão da imprensa por Rogers (2000). O autor destacou que a invenção da imprensa liberou os livros de suas correntes, tornando o conhecimento mais disponível para o público. Enfatizou entretanto que embora esta inovação tenha sido um fator chave para o renascimento da civilização ocidental e o começo da ciência, o grande impacto da imprensa só ocorreu 400 anos mais tarde, com o início da comunicação em massa pela publicação do primeiro jornal. 
Rogers (2000) argumentou que esta demora no tempo para a difusão da inovação foi decorrente, pelo menos em parte, da necessidade de uma infraestrutura, no caso, a alfabetização em massa da audiência pública.

Já a difusão do uso da comunicação por computador pela Internet, ocorreu em menos de 50 anos após a sua invenção em 1945, tornando-se a inovação com maior rapidez de difusão do que qualquer outra na história da humanidade (Rogers, 2000).

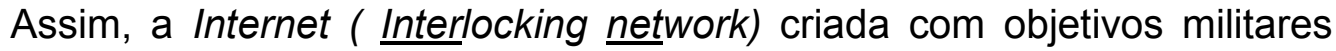
teve o seu uso difundido, inicialmente, como meio de comunicação entre instituições governamentais e universidades americanas e posteriormente, para o público em geral. Isto trouxe profundas modificações no conceito de tempo e espaço e através da rede podemos hoje estar ligados aos grandes centros de pesquisa, às grandes bibliotecas e interagir com as pessoas em todas as partes do mundo de maneira eficiente (Caliri, 1997).

Esta remoção da barreira física da distância trouxe importantes conseqüências para a sobreposição da distância social, criando nova forma de interação humana, encorajando a globalização (Rogers, 2000).

Évora (1998) analisando a literatura relacionada ao uso do computador na educação em enfermagem identificou que um aspecto fundamental destacado pelos autores, é o preparo dos enfermeiros para utilização de novas técnicas de ensino que utilizaram os recursos computacionais entre eles a Internet. 
O uso desta ferramenta para divulgar o conhecimento sobre úlcera de pressão, pode auxiliar os enfermeiros a superarem algumas das barreiras que dificultam o acesso a informações advindas de pesquisas, conforme já apresentado (Funk et al, 1991; Funk et al, 1995; Retsas \& Nolan, 1999; Parahoo, 2000).

Rogers (1983) destacou em sua teoria que a percepção apresentada pelos indivíduos sobre os atributos da inovação é que influenciarão a sua adoção. Estes atributos ou características são avaliados quanto a:
a) Vantagem relativa que apresentam.
b) Compatibilidade com os valores, crenças e necessidades.
c) Complexidade.
d) Ser passível de experimentação.
e) Ser passível de observação.

\section{3 - O site "Úlcera de Pressão"}

A Internet pode ser vista como um agrupamento de inovações tecnológicas dinâmicas, que pode ser compatível com um contexto de ensino onde os alunos tenham acesso a computadores em rede.

No campus da Universidade de São Paulo em Ribeirão Preto, este acesso é possível nas salas Pró-aluno da Escola de Enfermagem e na Biblioteca Central. 
$\mathrm{Na}$ atualidade, o uso do correio eletrônico, "o bate papo" e os sistemas de busca fazem parte do cotidiano dos alunos, o que caracteriza o uso do site de úlcera de pressão como uma ação de baixa complexidade.

A vantagem relativa do seu uso pode estar associada à obtenção de conhecimentos para a prática clínica, o que nem sempre é percebido como importante pelo aluno no início dos cursos. Entretanto, o profissional que percebe que não tem as informações que precisa ao encontrar um problema na prática, pode valorizar o recurso se este atender as suas necessidades.

As informações oferecidas, no site são passíveis de experimentação na prática clínica e os resultados das intervenções de enfermagem propostas podem ser observados nas experiências clínicas.

As vantagens do uso da Internet tem sido destacadas sob o enfoque de permitir que o aluno aprenda na sua própria velocidade e de acordo com as suas necessidades individuais.

Baseada nestes pressupostos, na construção do site "úlcera de pressão" incorporamos textos e imagens que permitissem ao usuário compreender conceitos referentes à prevenção e tratamento que são complexos e interrelacionados e que no entanto podem ser utilizados na prática.

O conteúdo do site (Apêndice) foi desenvolvido em tópicos conforme apresentado abaixo:

\section{Úlceras de Pressão}

- Apresentação 
- Prevenção

- Importância do problema

- Objetivo

- Definições

- Estágios da úlcera de pressão

- Avaliação do risco - Escala de Braden

- Cuidados com a pele e tratamento inicial para prevenção

- O uso de superfícies de suporte e alívio de carga mecânica

- Educação para prevenção

- Tratamento

- Resumo - Força da Evidência das Recomendações

- Objetivo

- Gerenciamento do cuidado ao paciente com úlcera - trabalho da equipe

\section{I - Avaliação do paciente e da úlcera}

- Re-avaliação

- Monitoração do progresso

- Saúde física e complicações

- Avaliação nutricional e cuidados

- Avaliação da dor e tratamento 
- Avaliação psicossocial e tratamento

- Avaliação dos Recursos disponíveis

\section{II - Controle de Sobrecarga nos tecidos}

- Técnicas de posicionamento do paciente na cama

- Escolha de superfícies de suporte

- Técnicas de posicionamento para o paciente sentado

\section{III - Cuidados com a úlcera}
a) Desbridamento
b) Limpeza da ferida
c) Curativos
d) Uso de terapias coadjuvantes

\section{IV - Controle da colonização bacteriana e infecção}

\section{V - Reparo operatório}
a) Seleção do paciente
b) Controle dos fatores que dificultam a cicatrização
c) Seleção de procedimentos operatórios
d) Cuidado pós-operatório 


\section{Educação e melhoria da qualidade}

- Protocolos de ensino para prevenção e tratamento

- Casos

- Produção científica

- Dissertações de Mestrado

- Trabalhos publicados na forma de resumos

- Recomendações para a prevenção

- Referências bibliográficas - em construção

- Links

- Tutorial para ensino do uso da internet

- Bancos de dados para levantamento bibliográfico

- Publicações online internacionais

- Páginas nacionais sobre tratamento de feridas

- Fabricantes de produtos (internacionais)

- Órgãos governamentais

- Agências de financiamento de pesquisa

- Links em saúde

Nos tópicos "Prevenção", "Tratamento" e "Recomendações" utilizamos uma síntese das evidências fornecidas pela AHCPR (Bergstrom et al., 1992; Bergstrom et al., 1994). 
O "protocolo de ensino" para prevenção e tratamento foi desenvolvido partindo da proposta de Maklebust \& Sieggrcen, 1996; Warner \& Konnerth, 1993.

No tópico "casos" foram incluídas cinco situações reais de tratamento de paciente com lesão de medula espinhal, obtidas em pesquisas descritivas que conduzimos anteriormente (Rangel \& Caliri, 1998; Prado \& Caliri, 1998; Caliri et al., 1999).

A "produção científica" dos alunos de graduação e pós-graduação sob a nossa orientação, as quais tem contribuído para a construção do conhecimento sobre este assunto também foi divulgados no site no tópico com este título.

A seção links foi construída com o objetivo de permitir que o usuário acesse outras fontes de informação relacionadas ao assunto na busca de novas evidências. A seleção destas fontes, considerou os critérios propostos na literatura para avaliação de um site, quais sejam: quem é o autor ou instituição responsável pelo site, quais as suas qualificações ou credenciais; quais os objetivos do site, a atualização de informações, a qualidade da apresentação e acesso (Hacker, 2000).

$\mathrm{Na}$ "Apresentação" do site destacamos o seu objetivo na educação de alunos, profissionais e do público em geral e disponibilizamos o nosso endereço eletrônico como recurso para comunicação com os usuários.

A avaliação da utilização do site na divulgação do conhecimento é apresentada a seguir. 


\section{4 - A divulgação do conhecimento sobre úlcera de pressão pela Internet}

As Diretrizes para a Prática são vistas atualmente como as formas mais freqüentemente empregadas para auxiliar os profissionais e pacientes a tomarem decisões sobre a assistência apropriada em situações clínicas específicas. O enfoque do desenvolvimento e utilização das Diretrizes tem sido dirigido tanto para o estabelecimento de padrões para o cuidado, quanto para a obtenção de melhores resultados e maior segurança para o paciente (Trowbridge \& Weingarten, 2001).

A disseminação das informações contidas nas Diretrizes pode ser feita de forma passiva por meio de aulas expositivas, conferências e material impresso e são considerado mecanismos não coercivos para promover mudanças.

As leis, regulamentos e padrões institucionalizados que usam as diretrizes para estabelecer a forma de prestação de serviços têm sido consideradas como mecanismos coercivos (Trowbridge \& Weingarten, 2001).

Trowbridge \& Weingarten (2001) destacam que as ações interativas estabelecidas entre o profissional que divulga as "melhores práticas" e os usuários deste conhecimento tem sido consideradas como novas formas para favorecer mudanças efetivas de comportamento para adesão às Diretrizes. Afirmaram entretanto que ainda não está claro se a integração da Internet nas tecnologias educativas irá resultar em mudanças substanciais na eficácia e nos custos do ensino. 
O site "úlcera de pressão" tem sido utilizado tanto para a disseminação passiva das informações para os usuários, quanto no estabelecimento de interações dos mesmos com o docente-pesquisador, desencadeando o processo conhecimento - ação - reflexão, destacado como necessário para que as mudanças aconteçam (Havelock apud Loomis, 1985).

Assim, à visão de Havelock da ligação entre o sistema fonte e o sistema do usuário incluiríamos a Internet para permitir a conexão e formação da rede de comunicação, conforme a figura 5.

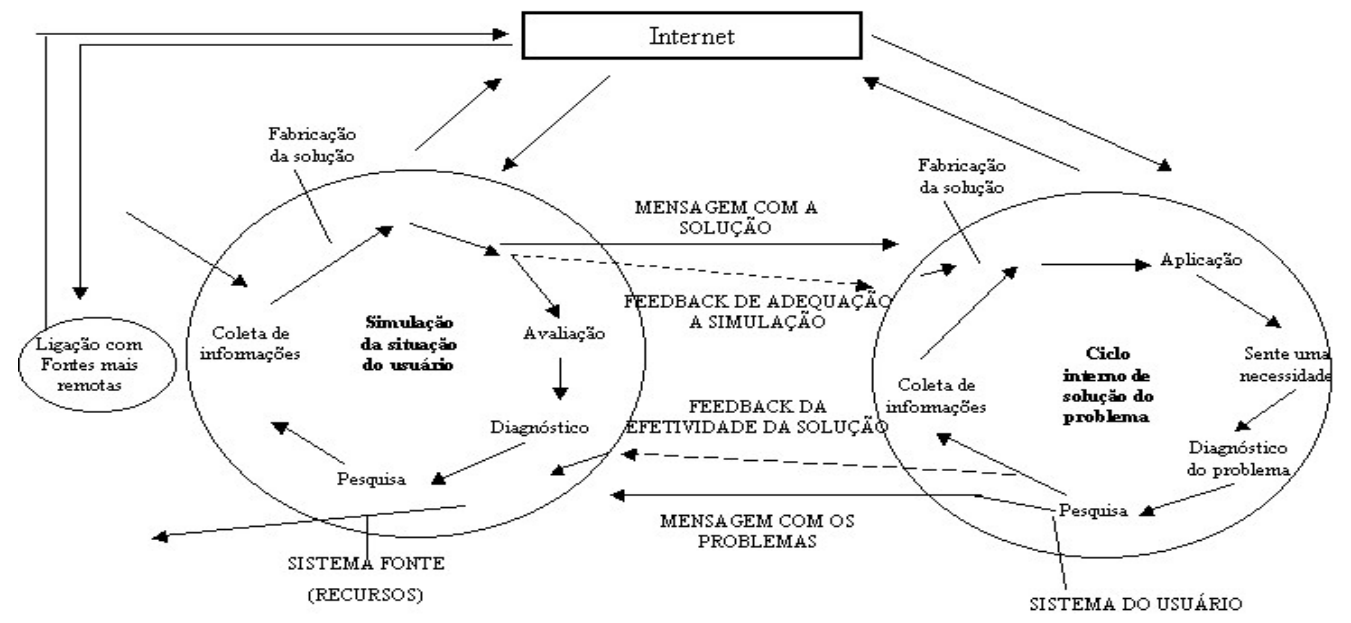

Figura 5 - Adaptação do modelo de Havelock, de ligação entre dois sistemas para resolução do problema. 
A nossa avaliação da utilidade desta forma de divulgação do conhecimento sobre úlcera de pressão é baseada em evidências que podemos considerar ainda como fracas, mas que poderão ser reforçadas com a realização de pesquisas futuras sobre o assunto.

A primeira evidência foi obtida por um estudo descritivo (Caliri, Miyazaki \& Pieper, 2002) que investigou o conhecimento de alunos de enfermagem sobre úlcera de pressão e a sua associação com atividades extracurriculares, como participação em grupos de discussão e palestras sobre o assunto, leitura de artigos e o uso do site da Internet.

O nível de conhecimento foi obtido utilizando um teste cujos itens foram derivados das Diretrizes da AHCPR para a prevenção e tratamento de úlcera de pressão que foi traduzido e validado para o português.

Os resultados indicaram que os alunos acertaram $67,7 \%$ do teste e que os alunos que participaram de atividades extracurriculares como grupos de discussão e palestras tiveram resultados melhores. O site da Internet foi utilizado por poucos alunos $(25,3 \%)$, no entanto utilizando testes estatísticos, identificamos a presença de associação entre esta atividade e o número de acerto no teste.

Os resultados desta pesquisa permitem observar que embora as informações estivessem disponíveis no site da Internet, poucos alunos utilizaram o recurso, mas quando o fizeram esta ação trouxe-lhes benefícios, evidenciados pelos resultados obtidos no teste. A pesquisa apontou haver a necessidade de outras investigações sobre o assunto para identificar as 
barreiras e estímulos relacionadas ao sistema social e a inovação que interferem na utilização do recurso pelos alunos.

A segunda evidência da utilidade da Internet para responder as necessidades dos usuários quanto ao conhecimento sobre úlcera de pressão foi obtida pela análise quantitativa e qualitativa da troca de mensagens eletrônicas ocorridas entre estes e o sistema fonte da informação e posteriormente, com a inclusão de novos membros na "rede".

Desde o seu início, o site teve mais de 20.000 acessos porém não temos condições de avaliar o tipo de uso ocorrido com o conhecimento obtido em decorrência desta ação. As mensagens eletrônicas, entretanto, podem ser analisadas de forma mais abrangente pela identificação de seus conteúdos.

Porém, como destaca Duffy (2002), os mesmos princípios éticos utilizados para a realização de surveys ou levantamentos na forma presencial devem reger qualquer investigação usando a Internet, assim nos limitaremos aqui a descrever algumas características dos usuários do site, o tipo de informação procurada e a finalidade.

A maior freqüência de mensagens é procedente de familiares de pacientes que apresentam úlcera e estão no domicílio (idosos com doenças crônico-degenerativas, paraplégicos, politraumatizados).

As questões abordadas são referentes ao tratamento de ferida e ao uso do colchão especial. As mensagens destacam a importância das informações oferecidas pelo site e da falta de consenso existente entre os profissionais quanto às intervenções mais adequadas. Os usuários são na sua maior parte 
da região sudeste e sul do Brasil. Grande parte dos usuários solicitam informações / indicações de profissionais ou serviços qualificados, o que não podemos atender. Nos limitamos a informar para a procura dos Serviços de Saúde e com as informações obtidas, discutir as opções de tratamento.

A segunda categoria de usuários é de profissionais da saúde: enfermeiros, nutricionistas, fisioterapeutas e médicos. As informações mais solicitadas são quanto à construção de protocolos para organização da assistência curativa e preventiva na área hospitalar, asilo / casa de repouso e assistência domiciliar. As questões mais freqüentes são concentradas na área de tratamento da ferida: uso de papaína, ácidos graxos, açúcar,laser.

Os alunos de graduação na área de enfermagem são os usuários com menor freqüência de mensagens eletrônicas e as solicitações são referentes a informações bibliográficas para a realização de trabalhos acadêmicos.

A análise destes resultados permitiu evidenciar que a Internet tem potencial para ser adotado como fonte de informação pelos enfermeiros e outros profissionais assim como pelos cuidadores informais.

Esta tendência já havia sido observada nos EUA por Leaffer \& Gonda (2000) no entanto as autoras identificaram que a enfermagem ainda não utiliza este recurso de forma rotineira nem para a educação do futuros enfermeiros ou dos pacientes.

Entretanto observamos que a utilização deste recurso vem sendo estimulado pelo seu potencial de desvelar novos caminhos para a 
aprendizagem independente de profissionais e consumidores dos serviços de saúde.

O aumento do número de bancos de dados com acesso online, as revistas eletrônicas, sites de instituições de pesquisa e serviços e páginas pessoais de pesquisadores e profissionais podem facilitar o acesso a informação no entanto a seleção criteriosa torna-se cada vez mais importante.

As informações encontradas/oferecidas precisam ser avaliadas utilizando os critérios de validade, importância e aplicabilidade propostos desde a década de 70 pelos idealizadores do Projeto CURN e depois reforçados na proposta da prática baseada em evidências.

Também as evidências não oriundas da pesquisa precisam ser investigadas com o intuito de avaliar/melhorar a sua força ou poder para produzir melhores resultados na prática clínica. 
7 - CONSIDERAÇÕES FINAIS 


\section{7 - Considerações Finais}

As transformações que se evidenciaram no mundo contemporâneo se refletem na forma como vemos e exercemos a Enfermagem como profissão.

O atendimento das necessidades da sociedade, requerendo um enfermeiro crítico, reflexivo, que intervenha na prevenção e resolução dos problemas de saúde de forma eficiente, exige grandes transformações no sistema onde o profissional é formado e onde atua.

Estas transformações e os seus resultados, dependem da integração, colaboração e compromisso de todas as partes que compõem estes sistemas. Para que as intervenções na prática clínica de enfermagem produzam resultados positivos e causem impacto nos serviços e na saúde da população elas precisam ser baseadas em pesquisas ou nas melhores evidências disponíveis.

Para chegarmos a esta condição torna-se necessário à transposição de diversas barreiras como apresentadas anteriormente, utilizando-se de estratégias também identificadas para a formação de uma comunidade de enfermagem.

A visão de comunidade implica:

"na evidência de um sistema social complexo, formado estrategicamente para responder a necessidades e problemas 
e atingir metas e resultados que nenhum de seus constituintes poderia obter agindo sozinho" (Sullivan, 1998).

A adoção desta visão sinergística irá permitir o desenvolvimento em todos os seus membros, da capacidade de aprender e a identificar as necessidades do grupo para que as mudanças planejadas aconteçam.

A integração dos enfermeiros/docentes e enfermeiros da prática clínica, alunos de graduação e pós-graduação com esta visão de comunidade empenhada em trabalhar em torno de um problema comum, pode produzir o sinergismo necessário para produzir mudanças em todo o sistema social da Enfermagem.

As interações estabelecidas entre as pessoas podem levar a identificação que a solução para um problema, depende de ações individuais que no seu conjunto podem causar grandes mudanças vistas talvez anteriormente como impossíveis.

Trazendo esta reflexão para o campo da utilização do conhecimento na prática de enfermagem, ao examinarmos os papéis dos diferentes membros do sistema social identificamos que quando não fazemos parte das soluções para resolver a questão, provavelmente estamos contribuindo para a persistência do problema.

Embora esta resolução dependa das ações de todos os envolvidos, o enfermeiro/docente tem provavelmente um maior domínio dos instrumentos 
para implementar as mudanças que devem ser utilizados e compartilhados com os outros membros do sistema social.

O conhecimento necessário para a condução da pesquisa e as diferentes formas de utilização não podem ser resumidos em disciplinas de metodologia científica para alunos e enfermeiros. As evidências advindas da pesquisa ou de outras fontes precisam ser a base do ensino desde o início na graduação.

A esta ação, torna-se necessário também à adoção e ensino da noção que em ciência, nada é definitivo e imutável sendo necessário, para o desenvolvimento do profissional, o domínio dos métodos de pesquisa que são necessários como ferramentas de busca, análise crítica e síntese dos novos conhecimentos.

Também os enfermeiros atuando na prática clínica precisam ter o domínio deste conhecimento, oferecimento que não pode ser limitado somente àqueles que fazem pós-graduação.

Projetos colaborativos de utilização da pesquisa na prática, entre a Universidade e Instituições de Saúde utilizando os métodos da pesquisa-ação podem promover não somente o desenvolvimento do pensamento crítico necessário para o processo de decisão clínica e gerencial fundamentados no conhecimento mas também a avaliação e o reconhecimento da realidade desta prática e quão eficiente esta tem sido para causar impactos na vida dos receptores do cuidado. O questionamento e reflexão sobre o processo e estrutura institucional onde a prática clínica acontece e os resultados são obtidos, podem levar à mudanças na forma de pensar e agir tanto dos 
enfermeiros/docentes como dos enfermeiros assistenciais e a transformar a realidade hoje apresentada.

Para que as mudanças aconteçam e que os projetos colaborativos sejam viabilizados, são necessários investimentos e transformações nas concepções que norteiam as ações tanto por parte dos enfermeiros/docentes e enfermeiros clínicos como das instituições que são partes integrantes do sistema social de Enfermagem.

O processo de adoção de uma inovação, no caso da utilização dos resultados de pesquisa ou outras evidências, compreende diversas atividades além daquelas que permitem a produção do conhecimento divulgado em publicações nacionais e internacionais.

A política internacional da avaliação do docente e das universidades com o referencial " publish or perish" contribue em grande parte para a persistência do vácuo existente entre a academia e a situação da prática clínica de enfermagem. Entretanto, em nível internacional tem sido observado um movimento para requerer que as outras categorias de atividades relacionadas à docência, importantes para a evolução do conhecimento e da enfermagem, assim como a qualidade de seus serviços sejam encorajadas e valorizadas no meio acadêmico e científico (GASSICK, 1999).

Este movimento, baseia-se no reconhecimento que a produção do conhecimento pelo docente deve ser valorizada assim como a sua divulgação

\footnotetext{
* Publique ou pereça
} 
em periódicos de qualidade mas que "sem a integração o conhecimento tornase pedantismo, sem aplicação torna-se irrelevante e sem compartilhamento pelo ensino a sua continuidade é perdida" (GASSICK, 1999).

Acreditamos que a divulgação dos resultados da pesquisa em enfermagem, pela publicação em periódicos fornece um mecanismo para avaliar as contribuições feitas pelos indivíduos e instituições acadêmicas na área do conhecimento. Entretanto, para que a difusão do conhecimento se dê dentro do sistema social de enfermagem, outras estratégias precisam ser utilizadas para influenciar o processo decisório dos enfermeiros, o que depende do emparelhamento das pessoas e de seus interesses.

Comungamos do pensamento apresentado por Mendes et al. (2000) que as parcerias e o envolvimento compartilhado do enfermeiro-docente e o enfermeiro-clínico representam estratégias para o desenvolvimento e valorização tanto do profissional como da profissão, o que pode respresentar a possibilidade de realização de pesquisas com a subsequente utilização de seus resultados e a obtenção do objetivo mútuo - a qualidade do cuidado prestado ao ser humano. 
8 - REFERÊNCIAS BIBLIOGRÁFICAS 


\section{8 - Referências Bibliográficas}

ALMEIDA, M.C.P.; ROCHA, J.S.Y. O saber de enfermagem e a sua dimensão prática. São Paulo, Cortes, 1986, 127p.

ALMEIDA, M.H. O conhecimento das (os) enfermeiras (os) sobre os resultados de pesquisa em enfermagem. $4^{\circ}$ Seminário Nacional de Pesquisa em Enfermagem. São Paulo, 1985, p.243-257.

ANGERAMI, E.L.S Rotina de verificação de temperatura. Estudo de alguns fatores interferentes e suas implicações. Tese (Doutorado). Escola de Enfermagem de Ribeirão Preto, USP, 1972.

ANGERAMI, E.L.S. Estudo epidemiológico da temperatura corporal em pacientes internados em um hospital - escola.Tese (Livre-docência). Escola de Enfermagem de Ribeirão Preto, USP, 1977.

ANGERAMI, E.L.S. O desenvolvimento da pesquisa no Brasil. Revista Latino Americana de Enfermagem, v. 1 (n.espe), p.43-52, dez 1993 (a). 
ANGERAMI, E.L.S. O mister da investigação do enfermeiro. Revista Latino Americana de Enfermagem, v. 1, n.1, p.11-22, jan 1993 (b).

ARRUDA, E.N.; SILVA, A.L. Programa integrado de pesquisa cuidando e confortando: retrospectiva histórica. Texto \& Contexto enfermagem, v.7, n.2, p.13-35, maio-ago 1998.

AKINSANYA, J, Making research useful to the practising nurse. Journal of Advanced Nursing, v.19, n.174-179, 1994.

$\mathrm{BACH}, \mathrm{D} . \mathrm{M}$. Implementation of the Agency for Health Care Policy and Research Postoperative Pain Management Guideline. Nursing Clinics of North America, v. 30, n. $3,518-528,1995$.

BARNSTEINER, J.H. Research - based practice. Nursing Administration Quarterly, v.20, n.4, p.52-58, 1996.

BEECROFT, P.C.; KONGELBECK, S.R. How safe are intramuscular injections? Clinical issues in critical care nursing, v.5, n.2, p.207-215, 1994.

BELL, S. et al. Implementing a research based protocol: an interactive approach AACN - Clin Issues Crit Care Nurs., v.5, n.2, p.147-151, 1994. 
BERGSTROM, N; ALLMAN, R.M.; CARLSON, C.E.; EAGLESETEIN, W.; FRANTZ, R.A.; GARBER, S.L.; GOSNELL, D.; JACKSON, B.S.; KEMP, M.G.; KROUSKOP, T.A.; MARVEL, E.M.; RODCHEAVER, G.T \& XAKELLIS, G.C. Pressure ulcers in adults: Prediction and Prevention. Clinical Practice Guideline. Quick Reference Guide for Clinicians. n³ Rokville, MD: US Departament of Health and Human Services, Public Health Service Agency for Health Care Policy and Research. Publication n 92-0050. May, 1992

BERGSTROM, N; ALLMAN, R.M.; ALVAREZ, O.M.; CARLSON, C.E.; FRANTZ, R.A.; GARBER, S.L.; GOSNELL, D.; JACKSON, B.S.; KAMINSKI, M.V.; KEMP, M.G.; KROUSKOP, T.A.; LEWIS, V.L.; MAKLEBUST, J.; MARGOLIS, D.J.; MARVEL, E.M.; REGER, S.I.; RODEHEAVER, G.T; SALCIDO, R.; XAKELLIS, G.C.; YARKONY, G.M. Pressure ulcer treatment. Clinical Practice Guideline. Quick Reference Guide for Clinicians. US Department of Health and Human Services, Public Health Service, Agency for Health Care Policy and Research. Publication 95-0652, December, 1994.

BERGSTROM, N.; BRADEN, B.; BOYNTON, P.; BRUCH,S. Using a researchbased assessment scale in clinical practice. Nursing Clinics of North America, v.30, n.3, p.539-552, 1995.

BEYA, S. Finding internet resources to support evidence - based practice. AORN Journal, v.72, n.3, p.514-515, 2000. 
BOEMER, M.R.; SANTOS, B.M.O.; AGUILLAR, O.M.; STOPA, M.J.R. Proposta alternativa para a produção científica de enfermeiros assistenciais. Revista Escola de Enfermagem USP, v. 24, n.2,, p.211-23, ago 1990.

BRENT, N.J. Are ignoring best practices changes putting your agency at legal and financial risk? Home Health care Nurse, v.19, n. 11, p.721-724, 2001.

BRETT, J.L. Use of nursing practice research findings. Nursing Research, v. 36, n.6, p.344-349, 1987.

BROOME, M.E. Integrative literature reviews for the development of concepts. In: Rodgers, B.L. \& Knaff, K.A. Concept development in nursing. Foundations, techniques and applications, chapter 13, p.231-250. Philadelphia, $2^{\text {nd }}$ WB Sanders, 2000.

BUENO, M.M. Promoting nursing research through newsletters. Applied Nursing Research, v.11, n.1, p.41-44, 1998.

BURNS, N.; GROVE, S.K. The practice of nursing research: conduct, critique \& utilization, W,B Sanders. Phipadelphia, $3^{\text {rd }}$ ed, 1997. 
BUSS, I,C;; HALFENS, R.H.G.; ABY-SAAD, H.H.; KOK,G. Evidence-based nursing practice: both state of the art in general and specific to pressure sores. Journal of Professional Nursing, v.15, n.2, p.73-83, 1999.

CALIRI, M.H.L. O programa "sandwich" de Doutorado no exterior - Uma experiência em Enfermagem. Revista Latino Americana de Enfermagem, v.2, n.1, p.155-156, 1993.

CALIRI, M.H.L. Tentando resolver as incertezas. Trajetória das mulheres ao enfrentarem o processo da histerectomia. Tese (Doutorado). Escola de Enfermagem de Ribeirão Preto, USP, 1994.

CALIRI, M.H.L. Usando os recursos da Internet na enfermagem. Revista Latino Americana de Enfermagem, v.5, n.1, p.97-102, 1997.

CALIRI, M.H.L.; ALMEIDA, A.M.; SILVA, C.A. Câncer de mama: a experiência de um grupo de mulheres. Revista Brasileira de Cancerologia, v.44, n.3, p.239-47, 1998.

CALIRI, M.H.L.; MIYAZAKI, M.Y.; PIEPER, B. Knowledge about pressure ulcers by undergraduate nursing students in Brazil. Journal of Ostomy I Wound management (Prelo) 
CALIRI, M.H.L.; PRADO, K.G.; ANGELO, D.A.D.; DEFINO, H.L. O perfil demográfico do lesado medular atendido no ambulatório de ortopedia de um hospital escola. Congresso do Instituto de Ortopedia e Traumatologia “ Combined Meeting” Mayo Clinic. Anais, São Paulo, maio de 1999.

$\mathrm{CAMIAH}, \mathrm{S}$. Utilization of nursing research in practice and application strategies to raise research awareness amongst nurse practitioners: a model for success. Journal of Advance Nursing, v.26, n., p.1193-1202, 1997.

CANNON, S.B.; BOSWELL,C. Adressing the community research needs of Baccalaureate Students. Nursing and Health Care Perspectives, v. 22, n.4, p.194-196, 2001.

CARAMANICA, L.; MALJANIAN, R.; MCDONALD D.; TAYLOR, S.K.; MACRAE, J.B.; BELAND, D.K. Evidence based nursing practice, part 1: A hospital and university collaborative. Journal of Nursing Administration, v. 32, n.1, p.2730, 2002.

CARVILLE, K.; STACEY, M.C. Chronic wound management in Australia. In: Krasner, D.L.; Rodeheaver, G.T.; Sibbald, R.G. (Eds) Chronic wound care: a clinical source book for healthcare professionals. $3^{\text {rd }}$ ed. HMP Communications, Wayne, 2001, chapter 18, p.163-174. 
CAVANAGH, S.; TROSS,G. Utilizing research findings in nursing: policy an practice considerations. Journal of Advanced Nursing, v. 24, n. , p.1083-1088, 1996.

CASSIANI, S.H.B.; PASSARELLI,L.R. Pesquisar em enfermagem: um processo de ação da enfermeira. Revista Gaúcha de Enfermagem, v.20, n.1, p.91-110, jan 1999.

CASSIANI, S.H.B.; PELÁ, N.T.R.; STOPA, M.J.R.; AGUIAR, E.; COLOGNA, M.H.Y.T. O processo de desnvolvimento de pesquisas clínicas em hospitais: relato da experiência de um programa. Revista de enfermagem da UERJ, v, 6, n.1, p.285-92, jun 1998.

CASTILHO, V. Educação continuada em enfermagem: a pesquisa como possibilidade de desenvolvimento de pessoal. Mundo saúde (1995), v. 24, n.5, p.357-60, set-out 2000 .

CASTILHO, V. Necessidade de programa de pesquisa no serviço de enfermagem. Revista Paulista de Enfermagem, v. 13, n.1/3, p. 13-5, jan-dez 1994. 
CHARLES, R. The challenge of dissemination innovations to direct care providers in health care organizations. Nursing Clinics of North America, v.35, n.2, p.461-469, 2000.

CLOSS,S. J.; CHEATER, F.M. Evidence for nursing practice: a clarification of the issues. Journal of Advanced Nursing, v.30, n.1, p.10-17, 1999.

COLE, K.M. GAWLINSKI . Animal assisted therapy in the intensive care unit: a staff nurse's dream comes true. Nursing Clinics of North America, v. 30, n.3, p.529-538, 1995.

COLYER, H,; KAMATH,P. Evidence based practice. A philosophical and political analysis: some matters for consideration by professional practitioners. Journal of Advanced Nursing, v, 29, n.1, p.188-193, 1999.

CONN,V.S.; BURKS, K.; RANTZ, M. KNUDSEN,K.S. Evidence-based Practice for Gerontological nursing. Journal of Gerontological Nursing, v. n. p. 4552, 2002.

COYLE,L.A.; SOKOP,A.G. Innovation adoption behavior among nurses. Nursing Research, v.39, n.3, p.176-180, 1990.

CRANE, J. The future of research utilization. Nursing clinics of North America, v. 30, n.3, p. 565-577, 1995. 
CRONIN, S.N. Research interest groups: An approach to integrating research into the practice setting. Applied Nursing Research, v.11, n.3, p.153-156, 1998.

CRONONWETT, L. R. Effective methods for disseminating research findings to nurses in practice. Nursing Clinics of North America, v. 30, n,3, p. 429-438, 1995.

CRUZ, V.; ABDUL-HAMID, M.; HEATERM B. Research based practice: reducing restrains in a acute care setting - phase 1. Journal of Gerontological Nursing, v. 23, n.2, p.31-40, 1997.

DOOKS, P. Diffusion of pain management research into nursing practice. Cancer nursing, v. 24, n.2, p. $99-103,2001$.

DONALDSON, S.K. Breakthroughs in scientific research: the discipline of nursing, 1960-1999. In: Fitzpatrick, J.J. \& Goeppinger, J. (Eds) Annual Review of Nursing Research, v.18, p.247-311, 2001.

DROOGAN, J,; CULLUM,N. Systematic reviews in nursing. International Journal of Nursing Studies, v.35, n., p.13-22, 1998. 
DUFAULT, M.A.; SULLIVAN,M.C. Generating and testing pain management standards through collaborative research utilization. IMAGE: Journal of Nursing Scholarship, v. 31, n.4, p.355-356, 1999.

DUFFY, M. Methodological issues in web-based research. Journal of Nursing Scholarship, v.34, n.1, p.83-88, 2002.

DUPAS, G.; CALIRI, M.H.L.; FRANCIOSI, M.C. Percepções de enfermeiras de uma instituição hospitalar sobre a assistência prestada à familia e à criança portadora de câncer. Revista Brasileira de Cancerologia, v.44, n.4, p.327334, 1998.

ECHER, I.C.; CROSSETTI, M.G.O.; PASKULIN, L.M.G.; COGO, A.L.P.; SANTOS, V.B.D.; SOTTOMAIOR, V.S.; TAFFE, R.E.; VICENTI, M.C. Crianção da comissão de pesquisa do grupo de enfermagem do Hospital das Clínicas de Porto Alegre. Revista Gaúcha de Enfermagem, v.19, n.1, p.56-9, jan 1998.

ESTABROOKS, C.A. The conceptual structure of Research utilization. Research in Nursing and Health, v.22, n., p.203-216, 1999. 
ÉVORA, Y.D.M. O paradigma da informática em enfermagem. Tese (Livre Docência). Escola de Enfermagem de Ribeirão Preto - USP. Ribeirão Preto, 1998.

FERNANDES, R.A.Q.; SILVA,S.H. Modalidade de fomento à pesquisa na área assistencial. Revista Brasileira de Enfermagem, v. 48, n.1, p.78-84, jan-mar 1995.

FERNANDES, L.M. Úlcera de pressão em pacientes críticos hospitalizados. Uma revisão integrativa da literatura. Dissertação (Mestrado) Escola de Enfermagem de Ribeirão Preto, Universidade de São Paulo, 2000.

FLOYD, J.A.; FALAHEE, M.L.; FHOBIR, R.H. Creation and analysis of a computerized database of (interventions to facilitate adult sleep) Nursing Research, v. 49, n.4, p.236-241, 2000.

FRENCH,P. The development of evidence - based nursing. Journal of Advanced Nursing, v,29, n,1, p.72-78, 1999.

FUNK, S.G.; TORNQUIST, E.M.; CHAMPAGNE, M.T. Barriers and facilitators of Research utilization: an integrative review. Nursing Clinics of North America, v.30, n.3, p.395-408, 1995. 
FUNK, S.G.; CHAMPAGNE, M.T.; WEISE, R.A. Barriers to using research findings in practice: The clinician's perspective. App. Nurs. Research, v.4, p. 90-95, 1991.

GARCIA, T.R.; MARTINS, E.A.; PAVELQUEIRES, S. Barreiras para a utilização do conhecimento em enfermagem: uma análise sistêmica. Ciência enfermagem, v. 1, n.1, p.61-9, 1995.

GERRISH, K.; CLAYTON,J. Improving clinical effectiveness through an evidence-based approach:metting the challenge for nursing in the United Kingdon. Nursing Administration Quarterly, v.22, n.4, p55-56, 1998.

GLASSICK, C.K.; Scholarship assessed: a special report on faculty evaluation. Hallmarks of scholarly Nursing Practice. Proceedings of the American Association of Colleges of Nursing's 1999. Faculty Practice Conference. American Association of Colleges of Nursing, p.1-8, 1999.

GOODE, C.J. BUTCHER, L.; CIPPERLEY, J.A.; EKSTROM, J.; GOSH, B.A.; HAYES, J.E.; LOVETT, M.K.; WELLENDORF, S.A. Research utilization. A study guide. Horn video productions, 1991, 60p. 
GOODE, C.J.; LOVETT, M.K.; HAYES,J.E.; BUTCHER,L.A. Use of Research based knowledge in clinical practice. Journal of Nursing Administration, v.17, n.12, p.11-18, 1987.

GRAY, M. From clinical expert to clinical investigator: our challenge for the $21^{\text {st }}$ century. WOCN Journal, v. 26, n.2, p.55, 1999.

HACKER, D. A writer's reference. Bedford / St Martin's. $4^{\text {th }}$ ed., 2000.

HADDAD, M.C.L.; GUARIENTE, M.H.D.M. A inserção do método científico na prática e na reflexão dos enfermeiros de campo. Nursing, v. 27, ano 3, p.16-18, 2000.

HALLER, K.B.; REYNOLDS, M.A \& HORSLEY, J.A. Developing research based innovation protocols: Process criteria and issues. Research in Nursing and Health,v.22, n.2, p.45-51, 1979.

HINRICHS, M; HUSEBOE, J. Research based protocol, Management of constipation. Journal of Gerontological Nursing, v. 27, n.2, p.17-28, 2001.

HINSHAW, A.S. Nursing Knowledge foi the $21^{\text {st }}$ century: opportunities and challenges. Journal of Nursing Scholarship, v.32, n.2, p.117-123, 2000. 
HOLLAND,D.E. Modeling nursing scientific inquiry. Journal of Gerontological Nursing,v, 27, n.3, p.29-33, 2001.

HOLMES,S. Systematic search offers a sound evidence base. Nursing Times, v. 92, n.4, p.37-39, 1996.

HOLZEMER, W.L. The impact of nursing care in Latin America and the Caribbean: a focus on outcomes. Journal of Advanced Nursing, v. 20, p. 5-12, 1994.

HORSLEY, J.A. Using research to improve nursing practice: a guide. CURN Project. New York, Grune \& Stratton, 1983.

HORSLEY, J.A.; CRANE J.; BINGLE , J.D. Research utilization as an organizational process. Journal of Nursing Administration, v.8, n. , p.4-6, 1978

HUMPHRIS, D. Clinical guidelines: an industry for growth. Nursing times, v.90, n.40, p.46-47, 1994.

HUNT, J. Indicators for nursing practice: the use of research findings. Journal Adv. Nursing, v.6, n.3, p.189-194, 1981. 
HUNT, M. The process of translating research findings into nursing practice. Jounal of Advanced Nursing, v.12, n.1, p.101-110, 1987.

HUNT, J. Research into practice: the foundations for evidence-based care, Cancer Nursing, v.24, n.2, p.78-87, 2001.

JACOX, A. et al. Management of cancer pain. Clinical Practice Guideline,n.9. Publication n. 94-0592. Rockville, MA, 1994.

JENNINGS, B.M.; LOAN, L.A. Misconceptions among nurses about evidencebased practices. Journal of Nursing Scholarship, v. 33, n. 2, p.121-127, 2001.

JUNKIN,J. Promoting healthy skin in various settings. Nursing Clinics of North America, v.35, n. 2, p.339-347, 2002.

KETEFIAN, S. Issues in the application of research to practice. Revista Latino Americana de Enfermagem, v.9, n.5, p.7-12, 2001.

KLASSEN,P; KARSHMER, J.; LILE, J.L. Research - based practice: applying the standard in nursing education. Journal of Nursing Education, v.41, n.3, p.121-124, 2002. 
KOIZUMI, M.S. Perfil da pesquisa de enfermagem em terapia intensiva no Brasil. Revista Escola de Enfermagem USP, v.31, n.3, p.468-85, dez 1997.

LANDRUM, B. Marketing innovations to nurses. Part 1: how people adopt innovations. Journal of Wound, Ostomy and Continence Nursing, v.25, n. 4, p. 194-199, 1998.

LARSEN,L.L.; THURSTON, N.E. Research utilization: development of a central venous catheter procedure, Applied Nursing Research, v.10, n.1, p.44-51, 1997.

LEAFFER, T.; GONDA, B. The Internet: an underutilized tool in patient education. Computers in Nursing, v.18, n.1, p.47-52, 2000.

LEKANDER, B.J.; TRACY, M.F.; LINDQUIST,R. Overcoming the obstacle to research-based clinical practice. AACN - Clin. Issues Crit. Care Nurs, v.5, n.2, p.115-123, 1994.

LEITE, J.L.; TREZZA, M.C.S.F.; SANTOS, R.M.; MENDES, I.A.C.; FELLI, V.E.A. Os projetos de pesquisa de enfermagem no CNPq: seu percurso, suas temáticas, suas aderências: 1998/2000. Revista Brasileira de Enfermagem, v.54, n.1, p.81-97, jan-mai 2001. 
LESKE,J.S.; WHITEMAN, K,; FREICHELS, T.A.; PEARCY,J.M. Using clinical innovations for Research-based practice. AACN - Clinical Issues Critical Care Nursing , v.5, n.2, p.103-114, 1994.

LOGAN, J.; HARRISON, M.B.; GRAHAM, I.D.; DUNN, K.; BISSONNETTE, J. Evidence based pressure ulcer practice: the Ottawa Model of Research use. Canadian Journal of Nursing Research, v.31, n.1, p.37-52, 1999.

LOOMIS, M.E. Knowledge utilization and Research utilization in nursing. IMAGE: The Journal of Nursing Scholarshio, v.17, n.2, p.35-39, 1985.

LOOMIS, M.E.; KRONE, K,P, Collaborative Research Development. Journal of Nursing Administration, v.10, n., p.32-35, 1980.

LOPES, C.M. Subsídios para uma reflexão acerca da aplicação de resultados de pesquisa pelo enfermeiro assistencial. Revista Brasileira de Enfermagem, v.42, n.1/4, p.128-33, jan-dez, 1989.

LOPES, C.M.Produção do conhecimento por enfermeiros assistenciais: sua utilização na prática., 1990, 186p. Tese de Doutorado - Escola de Enfermagem de Ribeirão Preto da Universidade de São Paulo, Ribeirão Preto. 
MAC GUIRE, J,M, Putting nursing research findings into practice: research utilization as an aspect of the management of change. Journal of Advanced Nursing, v. 15, p.614-620, 1990.

MALJANIAN, R. et al. Evidence-based nursing practice, part 2. Journal of Nursing Administration, v, 32, n.2, p.85-90, 2002.

MAKLEBUST, J. \& SIGGREEN, M. Pressure ulcer - Guidelines for prevention and Nursing Management $-2^{\text {nd }}$ ed, Spring House, Pennsylvania, 1996.

MASSAROLO, M.C.K.B.; CUNHA, K.C.; CIAMPONE, M.H.T.; BRAZ, E.; GAGLIARDI, E.M.D.B.; BEVILACQUA, D.F.; MAEDA, S. T.; SILVA, M.A.C.; MARKIEVICZ, V. Utilização da pesquisa de enfermagem na prática. Rev. Paulista de Hospitais v.6, n. 4, p.146-156, 1986.

MENDES,I.A. - Pesquisa em enfermagem: impacto na prática. Tese (Livre Docência) Escola de Enfermagem de Ribeirão Preto - USP, 1989.

MENDES, I.A.C. ; TREVISAN, M.A.; FERRAZ, C.A.; HIGA, E.F.R. Contribuição das disciplinas da organização da aprendizagem ao processo de parceria docente-assistencial na enfermagem. Revista Latino Americana de Enfermagem, v.8, n.2, p.47-52, 2000 
MENDES, I.A.C.; TREVISAN, M.A. Ações do centro colaborador OMS para o desenvolvimento da pesquisa em enfermagem: o caso brasileiro. Acta Paulista de Enfermagem, v.13, n.2, p. 9-15, mai-ago 2000.

MC COLLAM, M.E. Evaluation and implementation of a research - based falls assessment innovation. Nursing Clinics of North America, v. 30, n.3, p. 507$514,1995$.

MOCH,S.D.; GOLDSMITH, J. Clinicians use group-wise effort for innovation, Reflection on nursing leadership, p.32-34, $2^{\text {nd }}$ quarter, 2000.

NAISH,J. So where's the evidence? Nursing times, v.93, n.12, p.64-66, 1997.

NICOLL, L.H.; BEYA, S. Subcutaneous administration of insulin in adults: an integrative review of the research. The Online Journal of Knowledge Syntheses for Nursing, v.3, document n.4, 1996.

NIGHTINGALE, F. Notas sobre enfermagem. O que é e o que não é. Tradução de Amália Correia de Carvalho. São Paulo, Cortez; ABEn, 1989.

NUAP - National Pressure Ulcer Advisory Panel. Cuddigan, J. Ayello, E.A. \& Sussman, C. (Eds) Pressure Ulcer in America: prevalence, incidence and implications for the future. Reston, VA: NPUAP, 2001. 
OMERY, A.; WILLIANS, R.P, Appraisal of research utilization across the United States. Journal of Nursing Administration, v. 29, n.12, p.50-59, 1999.

PARAHOO, K. Barriers to, and facilitators of research utilization among nurses in Northern Ireland. Journal of Advanced Nursing, v.31, n.1, p.89-98, 2000.

PEARCEY, P. Achieving research - based nursing practice. Journal of Advanced Nursing, v. 22, p.33-39, 1995.

PETTIT, D.M.; KRAUS, V. The use of gauze versus transparent dressings for peripheral intravenous catheter sites. Nursing Clinics of North America, v.30, n.3, p.495-506, 1995.

POLETTI, N.A.A.; CALIRI.M.H.L. O cuidado de enfermagem à pacientes com feridas crônicas. A busca de evidências para a prática. VI Congresso Brasileiro de Estomaterapia / I Congresso Brasileiro em Dermatologia. São Paulo, outubro 2001, CD Rom.

POLIT, D.F.; HUNGLER, B.P. Nursing research Principles and methods. Lippincott, $4^{\text {th }}$ ed, Philadelphia, 1991. 
POLIT, D.F.; HUNGLER, B.P. Nursing research: principles and methods. J.B. Lippincott, 6ª ed, 1999.

PORTO, I.S. O Núcleo de Pesquisa em Enfermagem Hospitalar, o cuidado intensivo de enfermagem e o cuidado crítico da enfermeira. Escola Anna Nery Revista de Enfermagem, v.5, n.1, p.119-123, abr 2001.

PRADO, K.G.; CALIRI, M.H.L. Conhecimentos e práticas usadas para prevenção de úlceras de pressão em pacientes com lesão traumática de medula espinhal. VII Simpósio de Iniciação Científica da Universidade de São Paulo, Ribeirão Preto, outubro/novembro de 1998.

PREVOST,S.S. Research broadens at hospital. Reflections, First Quarter, p.20-21, 1996.

RAKEL, B.A; TILTLER, M.; GOODE, C.; BARRY-WALKER, J.; BUDREAU; G.; BUCKWALTER; K. C. nasogastric and nasointestinal feeding tube placement: an integrative review of research. AACN Clin. Issues Crit Care Nur, v.5, n.2, p.194-206, 1994.

RAMBUR, B, Fostering evidence-based practice in nursing education. Journal of Professional Nursing, v,15, n.5, p.270-274, 1999. 
RANGEL, E.M.L.; CALIRI, M.H.L. Complicações secundárias após o trauma raquimedular. VI Simpósio de Iniciação Científica da Universidade de São Paulo, Ribeirão Preto, outubro/novembro de 1998.

RABEH, S.A.N. Úlcera de Pressão: clarificação do conceito e estratégias para divulgação do conhecimento na literatura de enfermagem. Dissertação (Mestrado), Escola de Enfermagem de Ribeirão Preto - USP, 2001.

REED L.; BLEGEN, M.A; GOODE, C.S. Adverse patient ocurrences as a measure of nursing care quality. Journal of Nursing Administration v.28, n. 5 , p. 62-69, 1998.

RENSHAW, M.; STRACHAN, H.; TOMLINSON,D. Sifting evidence. Nursing times, v,95, n.38, p.26-27, 1999.

RETSAS, A.; NOLAN, M. Barriers to nurses use of research: an australian hospital study. International Journal of Nursing Studies, v.36, p 335-343, 1999.

RETSAS, A. Barriers to using research evidence in nursing practice. Journal of Advanced Nursing, v. 31, n.3, p.599-606, 2000. 
RIBEIRO, C. M. A pesquisa e a prática da enfermagem. Seminário Nacional de Pesquisa em Enfermagem. Florianópolis, 1984. Anais, p. 10-26.

ROCHA, S.M.M.; BOEMER, M.R. Impacto social da pesquisa em enfermagem. Revista Escola de Enfermagem USP, v.26 (n.esp), p.49-60, out 1992.

RODGERS, B.L. Concept analysis: an evolutionary view. In: Rodgers, B.L. \& Knaff, K.A. Concept development in nursing. Foundations, techniques and applications, chapter 6, p.73-91. Philadelphia, $2^{\text {nd }}$ WB Sanders, 1993.

ROGERS, E.M. Diffusion of innovations. $3^{\text {rd }}$ ed. New York. Free Press, 1983.

ROGERS, E.M. Diffusion of printing and the Internet. Paper presented at the Conference on the Printing Press and Internetted Computers, Rand Corporation, Sta Monica, California, outubro 2000. (Captado pela Internet no site www.rand.org/multi/parallels/sm/Rogers.pdf)

ROSSWURM, M.A.; LARRABEE, J.H. A model for change to evidence-based practice. IMAGEM Journal of Scholarship, v.31, n.4, p.314-322, 1999.

SCHMITT, M.H. Closing the gap between research and practice:strategies to enhance research utilization. Research in Nursing and Health, v.22, p.433434, 1999. 
SOLOWAY,D.N. Civil claims relating to pressures ulcers: a claimants lawyer's perspective. Ostomy / wound management, v.44, n.2, p.20+26, 1998.

SOUKOUP, M.S. The center for advanced nursing practice evidence - based practice model. Nursing Clinics of North America, v. 35, n.2, p.301-309, 2000.

SPECHT, J.P.; BERGQUIST, S.; FRANTZ, R.A. Adoption of a research -based practice for treatment of pressures ulcers. Nursing Clinics of North America, v. 30, n.3, p. 553-563, 1995.

STANLEY,S.; FOER,S. Preserving patient safety and quality nursing care. Nursing Policy Forum, v.2, n.3, p.18-20, 1996.

STEELMAN, V. Latex allergy precautions: a research based protocol. Nursing Clinics of North America, v.30, n.3, p.475-494, 1995.

STEFANELLI, M.C. Tendência na pesquisa em enfermagem. Revista da Escola de Enfermagem da USP, v.26, n. especial, p.61-66, 1992.

STETLER, C.B. Refinement of the Stetler / Marram Model for Application of Research Findings to practice. Nurs. Outlook, v.42, n.1, p.15-25, 1994. 
STETLER, C.B. Updating the Stetler Model of Research utilization to facilitate Evidence-Based. Nurs. Outlook, v.49, n.6, p.272-279, 2001.

STETLER, C.B.; BRUNELL, M.; GIULIANO, K,K. et al. Evidence based practice an the role of nursing leadership. Journal Nursing Administration, v.28, n.7/8, p.45-53, $1998(a)$.

STETLER,C.; MORSI, D.; RUCKI, S.; BROUGHTON, S.; CORRIGAN, B. FITZGERALD, J.; GIULIANO, K.; HAVENER, P.; SHERIDAN, E.A. Utilization Focused Integrative Reviews in a nursing service. Applied Nursing Research, v. 11, n.4, p.195-206, 1998 (b).

STETLER,C.B. Research utilization: defining the concept. IMAGE: Journal of Nursing Scholarship, v.17, n.2, p.40-44, 1985.

STONESTRECT, J.S.; LAMB-HAVARD, J. Organizational strategies to promote Research-based practice. AACN Clin. Issues Crit Care Nur, v.5, n.2, p.133146, 1994.

STYLES, M.M Empowering nursing research and nursing researchers. Revista da Escola de Enfermagem da USP, v.26, n.especial, p.23-32, 1992. 
SULLIVAN, T.J. Collaboration: a health care imperative. Mc Graw - Hill. New York, 1998.

TÉOT, L; MEAUME, S.; DESMOULIERE, A. Putting theory into practice: wound healing in France. In: Krasner, D.L.; Rodeheaver, G.T.; Sibbald, R.G. (Eds) Chronic wound care: a clinical source book for healthcare professionals. $3^{\text {rd }}$ ed. HMP Communications, Wayne, 2001, chapter 17, p.155-162.

TITLER, M.; MENDES,J.C. Research utilization in gerontological nursing practice. Journal of Gerontological Nursing, v.25, n.6, p.6-9, 1999.

TITLER, M.G. Research utilization: necessity or luscury? In: Mc Closkey, J.C.; Grace, H.K. (Ed) Current issues in nursing. Mosby, St Louis, 1997. Chapter 15, p.104-117.

TITLER, M.; MOSS,L.; GREINER, J.; ALPEN, M.; JONES, G.; OLSON,K.; HAUER, M.; PHILIPS, C.; MEGIVERN, K. Research utilization in critical care: an exemplar. AACN Clinical. Issues Critical Care Nursing, v.5, n.2, p.124-132, 1994.

TITLER, M.G.; KEIBER, C.; STEELMAN, V. et al. Infusing Research into Practice to promote quality care. Nursing Research, v. 43, n.5, p.307-313, 1994. 
THOMAS, D.R.; HESS, C.T. Evidence - based medicine. Resources in wound care directory, 1998. Captado pela Internet no site www.woundcarenet.com/industry/edmsg.htm em 07/04/1999.

TRANMER, J.E.; KISILEVSKY,B.S.; MUIR.DW. Nursing Research utilization strategy for staff nurses in the acute care setting. Journal of Nursing Administration, v.25, n.4, p.21-29, 1995.

TRENTINI,M.; PAIM,L. Assistência e pequisa em enfermagem: uma abordagem convergente - assistencial. Texto \& Contexto enfermagem, v. 10, n.1, p.1131, jan-abr 2001.

TREVISAN, M.A.; MENDES, I,A,C,. ANGERAMI, E.L.S. A investigação em enfermagem no Brasil. Revista Paulista de Enfermagem, v. 10, n.3, 91-5, setdez 1991.

TROWBRIDGE, R.; WEINGARTEN, S. Practice guidelines. In: AHRQ - Making HealthCare Safer: a critical analysis of patient safety practices. Evidence Report / Tecnology assessment, n.43. AHRQ Pub. nº1-E058, july 2001.

VAN MULLEM, C.V.; BURKE, L.J.; DOHMEYER, K.; FARREL, M.; HARVEY, S. JOHN, L.; KRALY, C.; ROWLEY, F.;SEBERN, F. ; TWITE, K.; ZAPP, R. 
Strategic planning for research use nursing practice. Journal of Nursing Administration, v. 29, n.12, p.38-45, 1999.

Integrating Research into practice. American Journal of Nursing, v.101, n.4, p.24A - 24H, 2001.

WARNER, D.; KONNERTH, K. A patient teaching protocol for pressure ulcer preventions and management. Ostomy / Wound management, v. 39, n.2, p.34-44, 1993.

WARREN, J.J.; HEERMANN, J.A. The research nurse intern program. Journal of Nursing Administration, v. 28, n.11, p.39-45, 1998.

WEBB,C. Action research: philosophy, methods and personal experience. Journal of Advanced Nursing, v. 14, p.403-410, 1989.

WEILER, K. Pain management as a legal responsibility Journal of Gerontological Nursing, v. 18, n.10, p.46, 1992.

WHITE, J.M.; LESKE, J.S.; PEARCY, J.M. Models and Process of research utilization. Nursing Clinics of North America, v.30, n.3, p.409-420, 1995. 
YOUNG, D.M. Acute pain management protocol. Journal of Gerontological Nursing, v,25, n.6, p.10-21, 1999.

YOUNGBLUT, J.M.; BROOTEN,D. Moving research into practice: a new partner. Nursing Outlook, v.48, n.2, p.55-56, 2000.

ZONSIUS, M.K.; MURPHY, M. Use of total quality management sparks staff nurse participation in continuous quality improvement. Nursing Clinics of North America, v.30, n1, p.1-12, 1995. 
9 - APÊNDICE

http://www.eerp.usp.br/projetos/ulcera 